University of Redlands

\title{
Evaluating Multimodal Accessibility to the Tualatin River National Wildlife Refuge
}

A Major Individual Project submitted in partial satisfaction of the requirements

for the degree of Master of Science in Geographic Information Systems

by

Karen Klinger

Mark Kumler, Ph.D., Committee Chair

Fang Ren, Ph.D.

August 2010 
Evaluating Multimodal Accessibility to the Tualatin River National Wildlife Refuge

Copyright (C) 2010

by

Karen Klinger 
The report of Karen Klinger is approved.

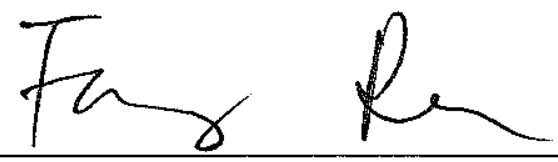

Fang Ren, Ph.D.

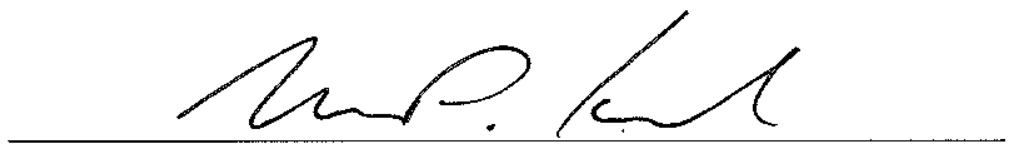

Mark Kumler, Ph.D., Committee Chair

August 2010 



\section{Acknowledgements}

I would like to thank David Drescher, my client, for providing me with my project topic and project data. Thanks to my advisor, Mark Kumler, for his advice and support throughout this project. I would like to acknowledge Debbie Riley and the other members of the MS GIS faculty for their support throughout this program. I would also like to recognize Ray Carnes for his guidance in project management, Colin Childs for teaching me the basics of ArcGIS Network Analyst, and Jay Sandhu for his help with developing my network dataset. Last, but certainly not least, many thanks to my family for all of their support and encouragement. 



\begin{abstract}
Evaluating Multimodal Accessibility to the Tualatin River National Wildlife Refuge

by

Karen Klinger
\end{abstract}

The Tualatin River National Wildlife Refuge is located fifteen miles south of Portland, Oregon, a city known for its abundance of outdoor recreational opportunities and an expansive transportation network of light rail, busses, commuter rail, streetcars, and bike routes. National wildlife refuges provide opportunities for visitors to learn about and interact with the environment, which help to increase public appreciation of fish and wildlife. In order to develop strategies for increasing visitation and improving visitor experiences on the refuge, staff members are interested in examining likely sources and demographic characteristics of potential visitors. An analysis of transportation accessibility to the refuge was conducted using a multimodal transportation network dataset and custom service area and demographics tools. Access was measured in terms of travel distance and in terms of the amount of time taken to reach the Refuge by driving, riding a bus, biking, and/or walking. 



\section{Table of Contents}

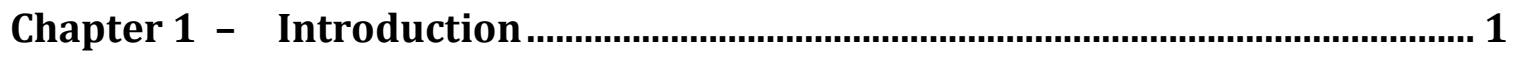

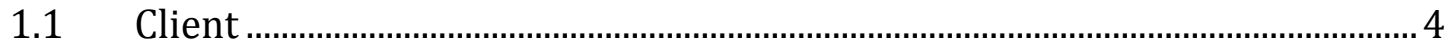

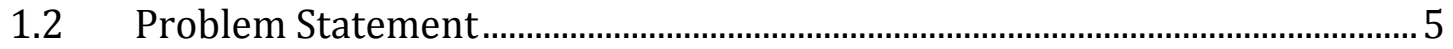

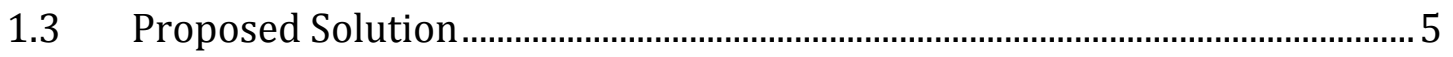

1.3.1 Goals and Objectives ……………………………………………………….

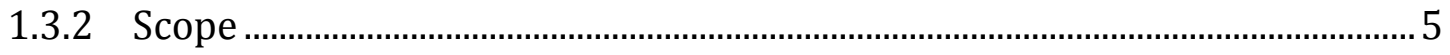

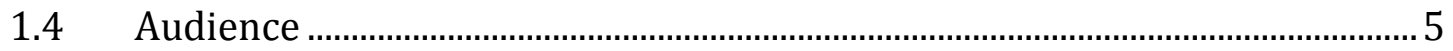

1.5 Overview of the Rest of this Report .................................................................. 6

Chapter 2 - Background and Literature Review.................................................... 7

2.1 Comparing the Radius and Network Approaches ............................................

2.2 Managing Networks with ArcGIS Network Analyst...........................................

2.2.1 Using Networks to Characterize the Accessible Population..............................

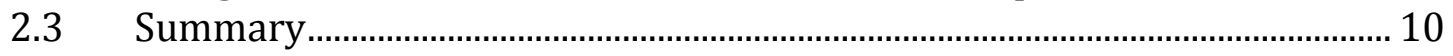

Chapter 3 - Systems Analysis and Design ………….........................................11

$3.1 \quad$ Problem Statement......................................................................................... 11

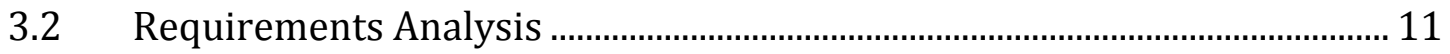

3.2.1 Functional Requirements............................................................................... 11

3.2.2 Nonfunctional Requirements .......................................................................... 12

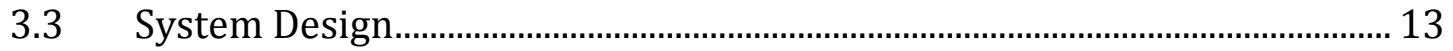

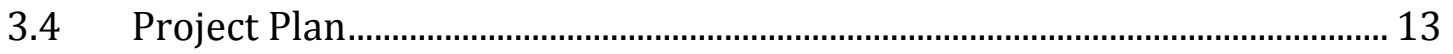

3.4.1 Requirements Analysis ................................................................................... 14

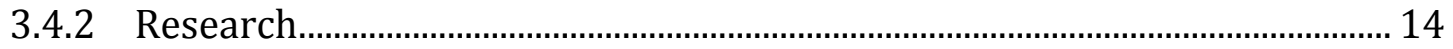

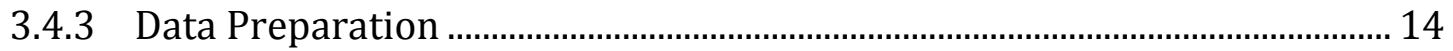

3.4.4 Transportation Network Dataset.................................................................. 14

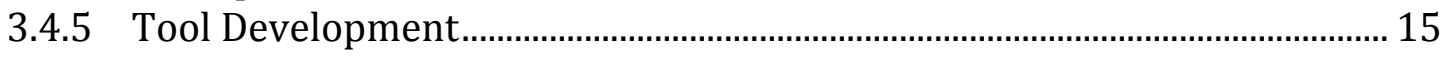

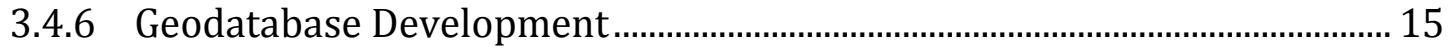

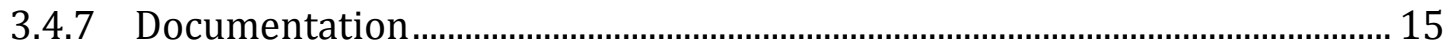

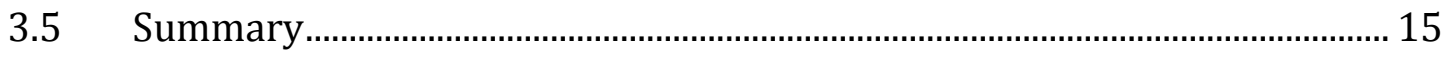

Chapter 4 - Database Design .........................................................................17

4.1 Conceptual Data Model ............................................................................... 17

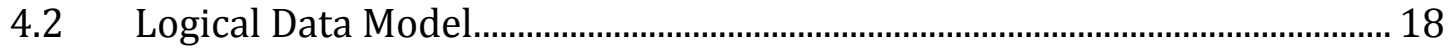

4.3 Data Sources................................................................................................. 20

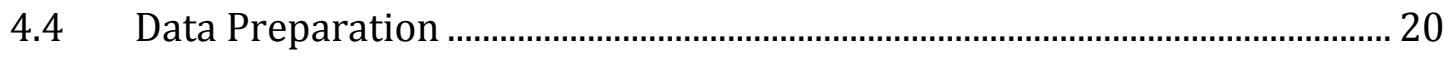

4.4.1 Bus Routes Feature Class ............................................................................ 20

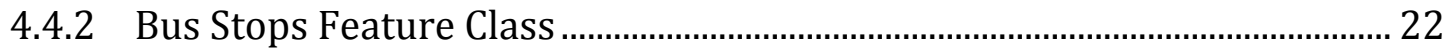

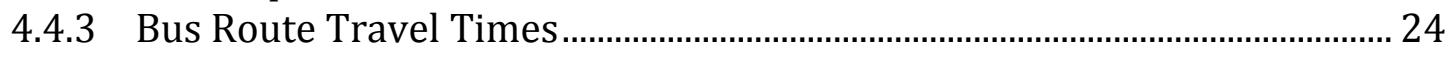

4.4.4 Bus Stop Connectivity................................................................................... 25

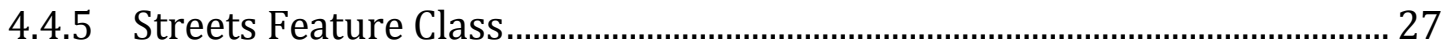

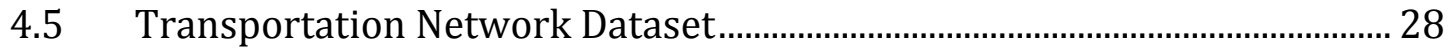

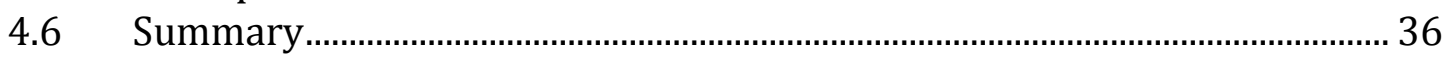

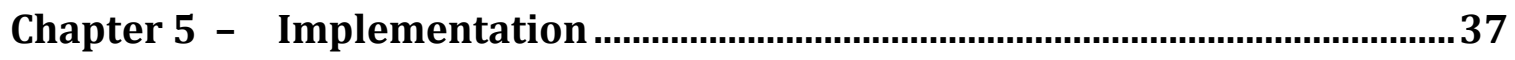




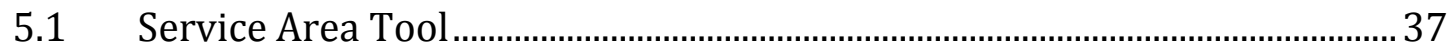

5.1.1 Service Area Model ........................................................................................... 38

5.2 Demographics Tool...……………………………………………………... 39

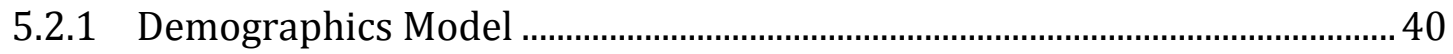

5.3 Service Area Demographics Tool ...................................................................... 41

$5.4 \quad$ Geodatabase Development ........................................................................... 43

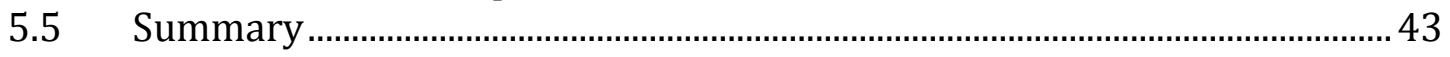

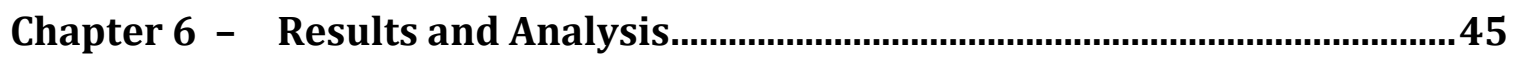

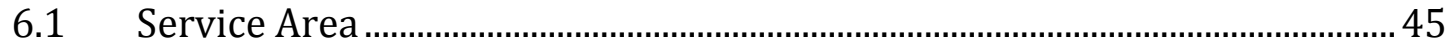

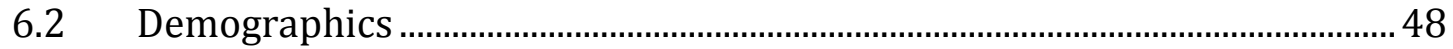

6.3 Additional Network Analyses ……………………......................................... 50

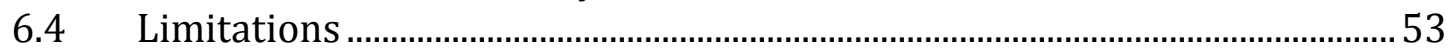

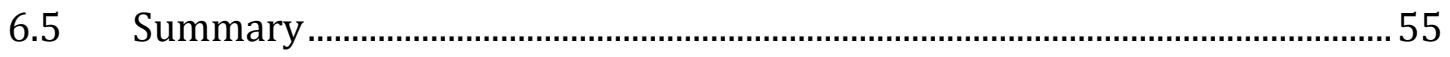

Chapter 7 - Conclusions and Future Work …….............................................57

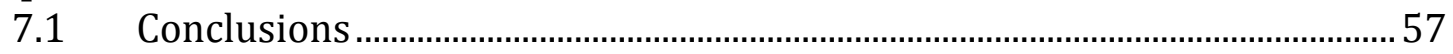

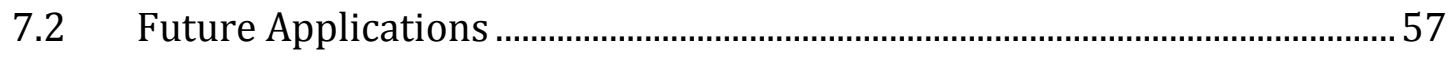

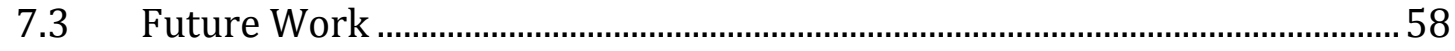

Works Cited 


\section{Table of Figures}

Figure 1-1 National Wildlife Refuges within the Contiguous United States...............1

Figure 1-2 Washington County, Oregon.....................................................................

Figure 1-3 Tualatin River National Wildlife Refuge ............................................... 3

Figure 1-4 Tualatin River National Wildlife Refuge Facilities and Trail Map ...........4

Figure 3-1 System Architecture ......................................................................... 13

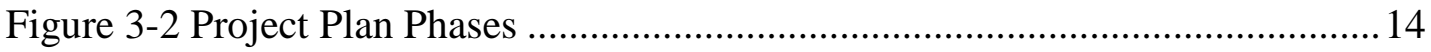

Figure 4-1 Conceptual Data Model.................................................................... 18

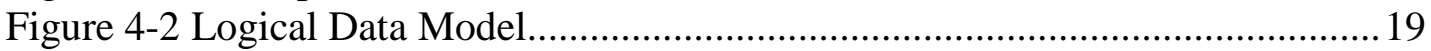

Figure 4-3 Eight Included Bus Lines .......................................................................21

Figure 4-4 Bus Stops Before and After Snapped to Bus Lines.................................22

Figure 4-5 Sample Downloaded Stop Times Table ................................................23

Figure 4-6 Sample Calculated Travel Times Table .................................................23

Figure 4-7 Sample Bus Stops Attribute Table .......................................................24

Figure 4-8 Relationship between bus routes and bus stops ......................................25

Figure 4-9 Original Stop, Stop Snapped to Bus Lines, and Stop Snapped to Streets 25

Figure 4-10 Attributes for Paired Bus Stops on Streets and Bus Lines .....................26

Figure 4-11 Boarding/Exiting Paths between Bus Stops .......................................26

Figure 4-12 Transportation Network Dataset Connectivity Properties ...................... 28

Figure 4-13 Transportation Network Dataset Elevation Properties..........................29

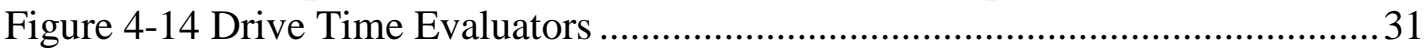

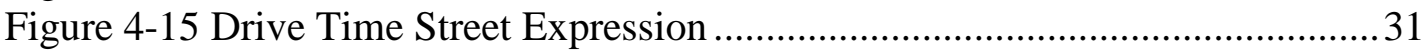

Figure 4-16 Bus, Bike, and Walk Weekday Morning Evaluators ............................32

Figure 4-17 Transportation Network Dataset Restriction Attributes........................33

Figure 4-18 One Way Restriction Evaluators ........................................................ 34

Figure 4-19 Expression Used to Handle One-Way Restrictions in From-To Direction

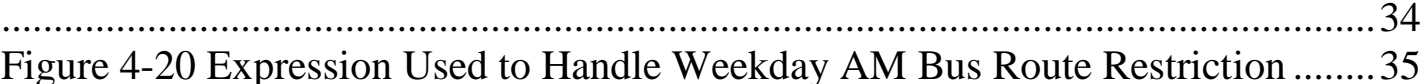

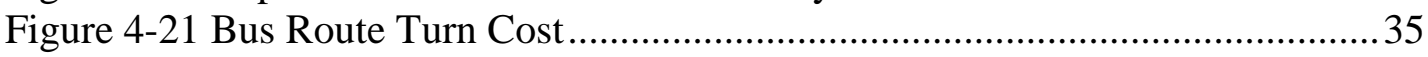

Figure 4-22 Bike Route Direction Properties ......................................................... 36

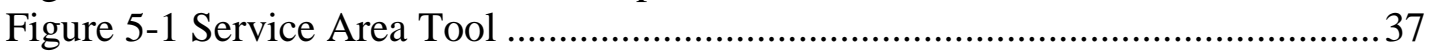

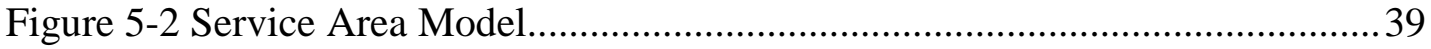

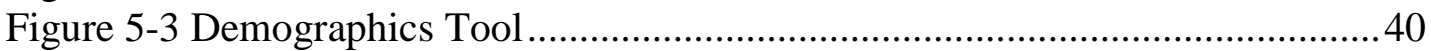

Figure 5-4 Demographics Model ......................................................................... 41

Figure 5-5 Service Area Demographics Tool ..................................................... 42

Figure 5-6 Service Area Demographics Model .................................................... 43

Figure 6-1 Service Area Tool Example Inputs .....................................................46

Figure 6-2 45 Minute Bus Ride Service Area to the Tualatin River NWR ...............47

Figure 6-3 Service Area Attributes Table .............................................................. 48

Figure 6-4 Demographics Tool Example Inputs..................................................48

Figure 6-5 Service Area Demographics Attribute Table ........................................49

Figure 6-6 45-Minute Service Areas to the Tualatin River NWR ............................49

Figure 6-7 TriMet Website Suggested Bus Route ..................................................51 
Figure 6-8 Network Analyst Suggested Bus Route............................................. 51

Figure 6-9 Google Maps Suggested Driving Route ............................................... 52

Figure 6-10 Network Analyst Suggested Driving Route ....................................... 53

Figure 6-11 30-Minute Walk Service Area to the Tualatin River NWR .................. 54

Figure 6-12 Census Features Within a 30-minute Walk to the Tualatin River NWR55

Figure 6-13 Imagery of the Included/Excluded Census Blocks.............................. 55 


\section{List of Tables}

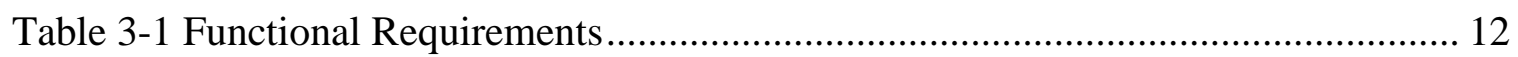

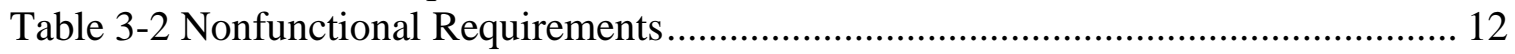

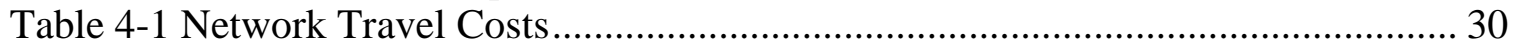

Table 6-1 Demographics for 45-Minute Service Areas to the Tualatin River NWR ....... 50 



\section{List of Acronyms and Definitions}

$\begin{array}{ll}\text { CCP } & \text { Comprehensive Conservation Plan } \\ \text { CFCC } & \text { Census Feature Class Code } \\ \text { ESRI } & \text { Environmental Systems Research Institute } \\ \text { GIS } & \text { Geographic Information Systems } \\ \text { NWR } & \text { National Wildlife Refuge } \\ \text { NWRS } & \text { National Wildlife Refuge System }\end{array}$





\section{Chapter 1 - Introduction}

With the creation of the first bird sanctuary at Pelican Island in 1903, United States President Theodore Roosevelt established the beginnings of what became the National Wildlife Refuge System (NWRS). Managed by the U.S. Fish and Wildlife Service, the NWRS is the "largest system of lands in the world dedicated to placing wildlife first" (Clark, 2003, p. 6). The National Wildlife Refuge System incorporates over 150 million acres of land on 550 national wildlife refuges in all fifty states and several U.S. territories (Clark, 2003; U.S. Fish and Wildlife Service, 2009a) (see Figure 1-1). These protected lands and waters encompass a diversity of habitats, including wetlands, coastal waters, plains, deserts, and arctic tundra.

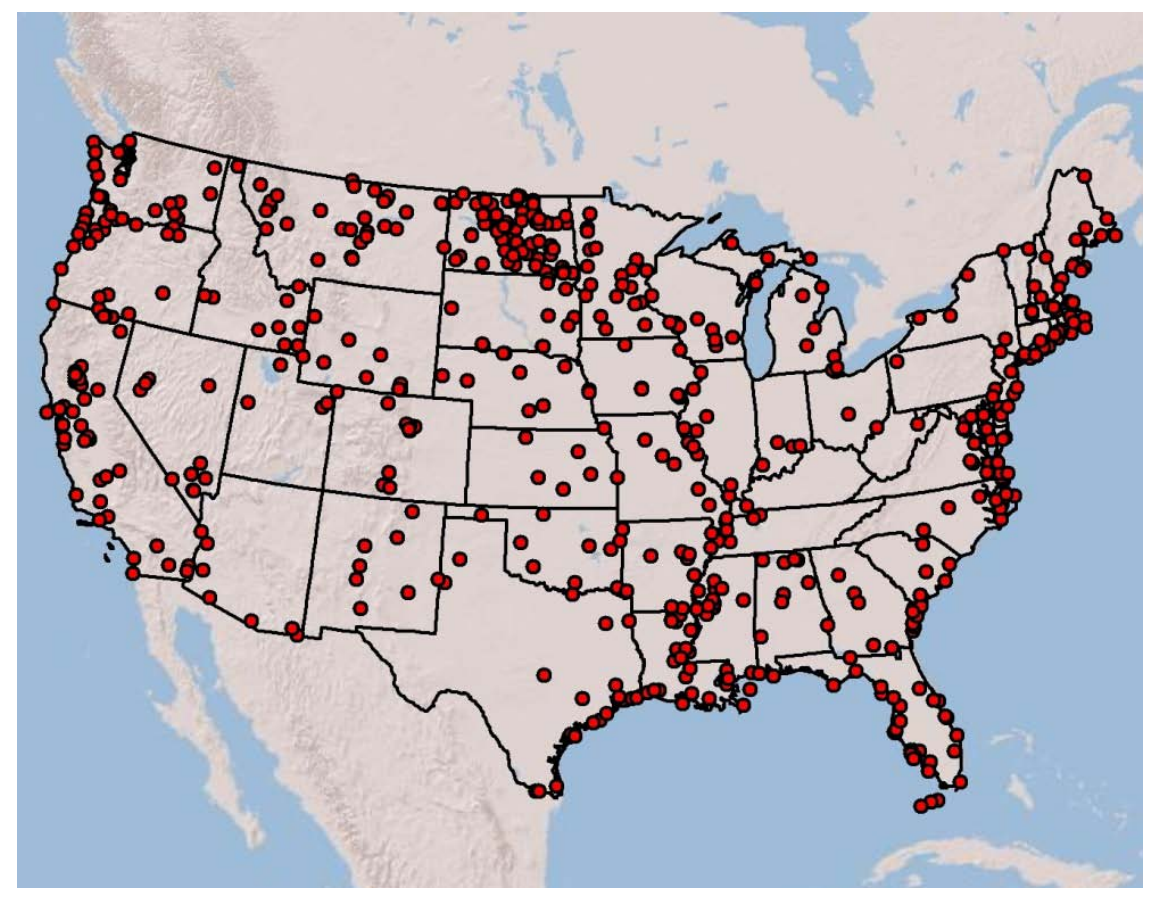

Figure 1-1 National Wildlife Refuges within the Contiguous United States

The mission of the NWRS is to "administer a national network of lands and waters for the conservation, management and where appropriate, restoration of the fish, wildlife and plant resources and their habitats within the United States for the benefit of present and future generations of Americans" (National Wildlife Refuge System Improvement Act of 1997 [NWRSIA]; Public Law 105-57). In support of this mission, the National Wildlife Refuge Improvement Act of 1997 mandated the creation of a comprehensive conservation plan (CCP) to be completed for each wildlife refuge by 2012. The purpose of the CCP is to provide guidance for management of individual refuges to achieve established goals.

Visitor services planning is an integral component of the CCP. National wildlife refuges provide opportunities for visitors to learn about and interact with the 
environment, which helps to increase public appreciation of fish and wildlife. In refuge visitor planning, managers seek to facilitate high-quality visitor experiences as visitors participate in compatible recreational uses. The six wildlife-dependent recreational uses that may occur on wildlife refuges are hunting, fishing, wildlife observation, photography, environmental education, and interpretation (NWRSIA, 1997). Understanding visitor preferences and motivations in outdoor recreation is essential to ensuring quality experiences (U.S. Fish and Wildlife Service, 2008).

The 2003-2007 Oregon Statewide Comprehensive Outdoor Recreation Plan conducted by the Oregon Parks and Recreation Department (2003) examined recreational interests and opportunities throughout the state, as well as demographic changes that may influence recreational use. Between 1990 and 2000, Oregon's population increased from 2.84 million to 3.42 million, making it the eleventh fastest growing state in the country (Oregon Parks and Recreation Department, 2003). Within Oregon, Washington County (Figure 1-2) is the second largest and second fastest growing county and home to Sherwood, the fastest growing city between 1990 and 2000. Washington County has the state's second-largest African American and Asian American populations, as well as the largest Hispanic population. Within Washington County, there are few state parks and one national wildlife refuge, the Tualatin River National Wildlife Refuge (NWR), which was chosen as the study area for this project.

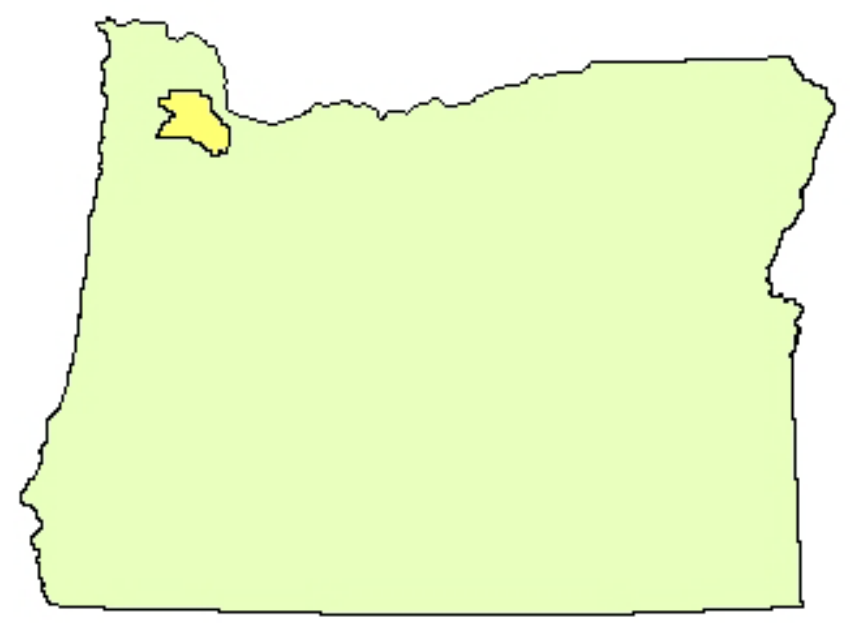

\section{Figure 1-2 Washington County, Oregon}

The Tualatin River NWR (Figure 1-3) is located within the Tualatin River floodplain near Sherwood, Oregon, and includes 1,850 acres of acquired land and 5,510 acres approved for potential future acquisitions (U.S. Fish and Wildlife Service, 2009b). One of the goals of the Tualatin River NWR is to "provide high quality opportunities for wildlands and wildlife-dependent recreation and environmental education to enhance public appreciation, understanding, and enjoyment of refuge fish, wildlife, habitats, and cultural resources with an emphasis toward urban residents" (U.S. Fish and Wildlife Service, 2009b, p. 2). In June 2006, the refuge opened to the public with new visitor 
service facilities to achieve this goal (Figure 1-4). In 2008, a wildlife center with additional facilities was completed (U.S. Fish and Wildlife Service, 2009b).

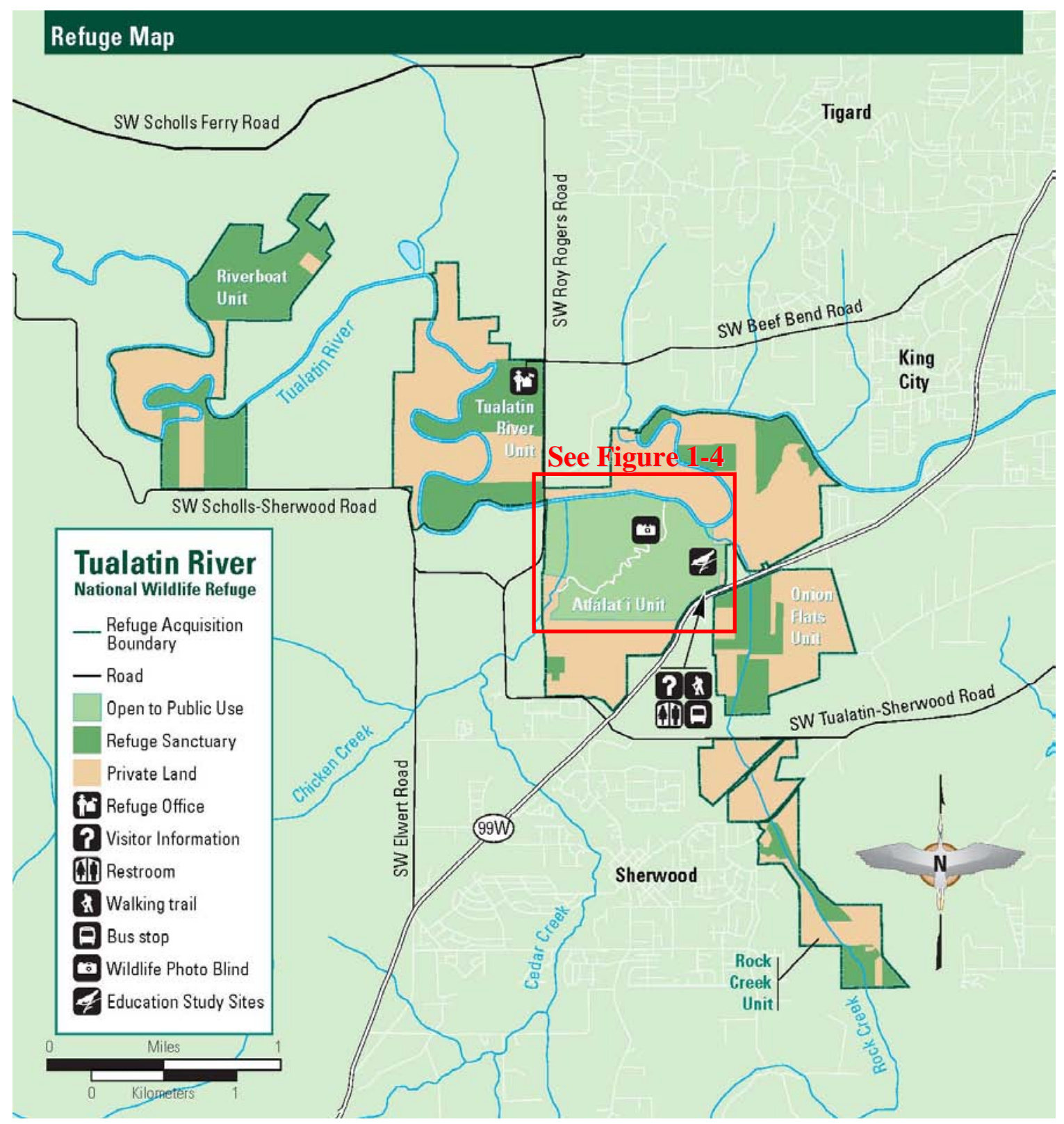

Figure 1-3 Tualatin River National Wildlife Refuge (Adapted from http://www.fws.gov/tualatinriver/visit.html) 


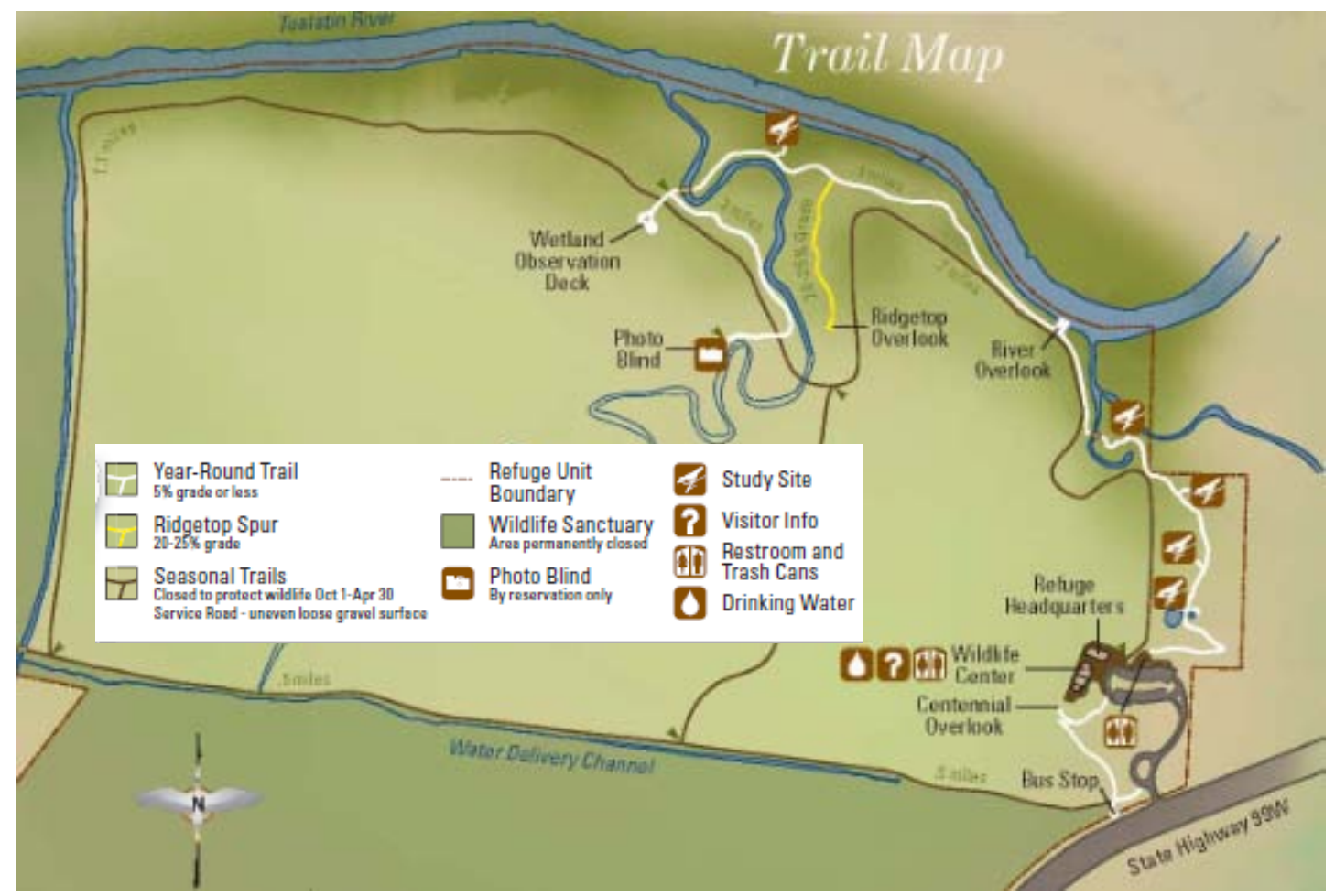

\section{Figure 1-4 Tualatin River National Wildlife Refuge Facilities and Trail Map (Adapted from Tualatin River National Wildlife Refuge, 2008)}

A study examining Oregon's population in the 1990s found that the Portland metropolitan area, which includes Multnomah and Washington counties, received the majority of migrants to Oregon, compared to central Oregon and the south coast (Judson, Reynolds-Scanlon, \& Popoff, 1999). A large portion of these Portland area migrants were between the ages of 20 and 39, which was attributed to the strong job growth in the region. A 2003-2004 edition of "Facts about Portland" (City of Portland Office of Transportation, 2004), found a $43 \%$ increase in jobs in the Portland area and a $26 \%$ increase in population between 1990 and 2003. The Portland region received the largest portion of lower income migrants (with an income of less than \$25,000), though migrants from the early 90's typically had a small income gain (Judson, Reynolds-Scanlon, \& Popoff, 1999).

\subsection{Client}

There were two clients for this project. The primary client was Mr. David Drescher, Refuge Information Branch Chief for Region 1 of the U.S. Fish and Wildlife Service. This branch coordinates and supports geographic information systems (GIS) activities for refuges in Washington, Oregon, Idaho, Hawaii, and the Pacific Islands. Mr. Drescher provides GIS support to the secondary client, the staff of the Tualatin River National Wildlife Refuge, in the completion of their CCP. For this project, Mr. Drescher provided assistance in tool determination, data acquisition, and general project guidance. 


\subsection{Problem Statement}

With the growing size and diversity of Washington County's population, it is becoming more important than ever to understand who is visiting the Tualatin River National Wildlife Refuge, and whether there are any constraints preventing more people from visiting the refuge. The Oregon Statewide Comprehensive Outdoor Recreation Plan reported that the five main barriers for recreational participation were a lack of time, lack of money, personal health, inadequate information, and inadequate transportation (Oregon Parks and Recreation, 2003). The focus of this project was to examine the accessibility of the refuge by different modes of transportation and analyze the demographic profile of the accessible area. This will allow the refuge to develop strategies for increasing visitation and improving visitor experiences.

\subsection{Proposed Solution}

The solution was to use a geographic information system (GIS) to develop a transportation network and tools that allow U.S. Fish and Wildlife staff members to examine refuge accessibility by different modes of transportation. This area of accessibility was combined with census data to derive a demographic profile according to user-specified variables, such as age, race, and family size. This profile was provided as both a table and a map layer.

\subsubsection{Goals and Objectives}

The goal of this project was to assist refuge staff in the development of visitor services planning within the comprehensive conservation plan. The CCP would enable managers to increase visitor numbers and improve visitor experiences. Specifically, this project designed user-guided tools to examine Tualatin Refuge visitor demographics and multimodal accessibility.

\subsubsection{Scope}

This project provided the Tualatin River National Wildlife Refuge staff with tools for analyzing visitor accessibility and demographics. As a result, this project did not focus on other areas of refuge management or CCP development such as biological or eco-regional planning. In addition, while this project provided useful tools for visitor services planning, this project was not able to meet all staff needs. It is the intention of this project that the Refuge Information Branch will be able to adapt these tools to aid in CCP development for other refuges across the region. The scope of this project, however, focused only on using data specific to the Tualatin River NWR and Portland metropolitan region.

\subsection{Audience}

The audience for this project was the staff of the Tualatin River National Wildlife Refuge and the Region 1 Refuge Information Branch. The Tualatin River NWR staff members are the primary managers and planners for the refuge and refuge CCP. The Refuge 
Information Branch assists refuges within Region 1 by providing GIS support for management and CCP development.

\subsection{Overview of the Rest of this Report}

The structure of this paper is as follows. Chapter 2 provides a literature review of relevant topics that influenced the development of this project. Chapter 3 discusses systems analysis and design. Chapter 4 provides a description of the database design. Chapter 5 gives a detailed description of the project's implementation. Chapter 6 discusses the results and analysis of using the developed tools. Finally, chapter 7 concludes with a summary and discussion of future work. 


\section{Chapter 2 - Background and Literature Review}

This chapter compares two approaches to determining the area that is accessible to the refuge. Through this examination, it was determined that a network approach was appropriate for conducting this project. Reviewed studies provided an in-depth examination of how transportation networks have been previously built and utilized. This literature review revealed methods that were used in applying the network approach to determine the accessibility of the Tualatin River National Wildlife Refuge.

\subsection{Comparing the Radius and Network Approaches}

There are two primary methods of measuring distance in determining accessibility: the radius method and the network method. The radius method uses an "as-the-crow-flies" or straight-line approach, in which a circular buffer of a specified distance is applied to either the center or boundary of the area of interest to delineate the accessible area. This simple approach provides a decent estimate of accessibility (Landex \& Hansen 2006).

However, there are a number of problems with the radius method. First, this approach does not account for travel barriers such as fences and bodies of water (Kreisa, 2007; Nicholls, 2001). Consequently, it does not accurately reflect the accessible area, since the actual travel distance is typically greater than the direct distance. Another disadvantage in using this method is that if the buffer is applied to the area's boundary, it assumes access around the entire boundary (Nicholls, 2001). Thus, if access is limited to specified entry points, the calculated accessible area is inaccurate. Further, if the center location of the boundary is used as the buffer center, then the irregular shape of the boundary is not accurately taken into consideration (Nicholls, 2001).

The network method uses an established transportation infrastructure for determining distance. This approach accounts for established transportation routes, such as roads and bike lanes, that visitors are likely to use. Further, this method can utilize specified entry points rather than the boundary's central location, countering the disadvantages found in the radius approach (Nicholls, 2001).

\subsection{Managing Networks with ArcGIS Network Analyst}

ESRI's ArcGIS software with the Network Analyst extension is a useful tool for building transportation networks. When building a transportation network dataset, a number of issues must be considered. The network builder needs to decide which transportation modes will be included and, if the network is multimodal, determine how the networks will be linked to each other (Hansen \& Munoz, 2008). Decisions must also be made in defining network attributes such as measuring travel time and travel restrictions.

Transportation networks can be composed of one or more travel modes and are used for a variety of analyses including examining accessibility and evaluating transportation systems. Street networks are a common type of single mode transportation and can represent roads and/or sidewalks. This can be used for neighborhood planning such as examining pedestrian access to neighborhood parks (Nicholls, 2001; Oh \& Jeong, 2007) and improving pedestrian travel (Aloisio, Cruz, Marcus, \& Whitlow, 2002). Streets can also be used to measure accessibility by driving. For example, Starcher (2007) 
examined 30-minute driving times to West Virginia hospitals. This analysis produced hospital service areas used to evaluate statewide hospital coverage. As a result, a street network can be used to determine access by car and/or foot at a local and statewide level.

Multimodal networks combine different transportation types to allow for a more comprehensive representation of available transportation means and can be used to perform more complex accessibility analyses. Integrating walking and bus routes allow planners to examine accessibility of available public transportation services and determine the impacts of planned modifications (Aloisio et al., 2002; Tribby 2009). By combining driving routes with this pedestrian network, planners can also examine whether travel by transit is likely compared to travel by automobile (Racca 2004). In addition, including driving as a viable transportation mode also takes into account a possible trip involving driving to a Park \& Ride prior to using the public transit system. Hansen and Munoz (2008) created a multimodal network with roads (for walking and driving), bus routes, and train routes to provide Minneapolis, Minnesota with a trip planning service for car and pedestrian travel. As a result, a user could produce a route that included walking to a bus stop, getting on a bus, transferring to a train, getting off a train, and walking to the final destination with a reasonable travel time and distance.

Hansen and Munoz (2008) and Tribby (2009) used similar approaches in determining the shared access points used to link a transit network and a road/sidewalk network. Hansen and Munoz (2008) used bus stops located off of the road and bus networks as the connecting point layer with two new line segments created to represent pedestrian travel between the road and bus stop and between the bus route and bus stop. Tribby (2009) used boarding points located on the walking network as the access points, which were connected to bus stop points on the transit network through a boarding line and exit line.

Travel time calculations are dependent on transportation mode and data sources. Travel time for road networks can be calculated using the road's speed limit to estimate the amount of time to travel along each road segment (Hansen \& Munoz, 2008). For TIGER/Census road files, speed limits can be determined by joining the road shapefile to a Census Feature Class Code (CFCC) table file, which provide a speed limit for each CFCC classification (Starcher, 2007). Aloisio et al. (2002) calculated travel time for both streets (line segments) and intersections (nodes), which were obtained through field observations, interpolations from sample intersections, and from modeling software.

One method used to calculate travel time for the transit network was to take the average speed of the transit route (Hansen \& Munoz, 2008). Tribby (2009) calculated transit time using a published time schedule for scheduled stops. Morning peak times (between 7 A.M and 9 A.M.), afternoon peak times (between 4 P.M. and 6 P.M.), and off-peak travel times (other times) were calculated by averaging the time between two scheduled stops and assigning it to the segment between the two stops. A proportion field was used to estimate the travel time for stops between scheduled stops by determining the lengths between all stops and dividing it by the length between the two scheduled stops on either side. To determine the travel time to an unscheduled stop, the proportion value for that line segment was multiplied by the time field for the scheduled stops on either side of the unscheduled stop. Similarly, Aloisio et al. (2002) used a transit network with bus route line segments split by scheduled time points. Line segments were assigned the difference in time of the connected time points. 
Pedestrian travel times were calculated with a range of average walking speeds, which included $3 \mathrm{~km} /$ hour (1.9 miles/hour) (Tribby, 2009), $1 \mathrm{~m} / \mathrm{second}$ (2.2 miles/hour) (Oh \& Jeong, 2007), 3 miles/hour (Racca, 2004), and 5 km/hour (3.1 miles/hour) (Hansen \& Munoz, 2008). Aloisio et al. (2002) differentiated travel time by the facility type. For example, a pedestrian travelling along roads with missing sidewalks, street crossings, or driveway crossings would likely travel slower than on uninterrupted sidewalks.

Restriction attributes can be applied to both pedestrian and vehicular modes of travel. Hansen and Munoz (2008) restricted pedestrian travel to local roads since, for example, walking along a highway is not permitted. These restrictions were determined from the CFCC classification (Hansen \& Munoz, 2008). Car travel was restricted through a one-way attribute, which defined line segments as allowing either two-way travel, oneway travel in the direction of flow, or one-way travel in the opposite direction of flow (Hansen \& Munoz, 2008). This would prevent routes from including streets where travel was prohibited in a given direction. Transit travel was restricted according to the orientation of the route. Thus, a pedestrian travelling along a bus route in one direction can only travel on routes in that direction and stop at the associated bus stops.

In order to validate the accuracy of the transportation network, Hansen and Munoz (2008) examined drive time, shortest-path, and pedestrian-time query results. Drive time query results were compared with Google Maps and Microsoft's Live Search Maps using the same origin and destination locations. The shortest-path results were compared to Live Search Maps, which provides a similar analysis. Pedestrian-time queries were examined to ensure that results were logical.

\subsubsection{Using Networks to Characterize the Accessible Population}

In addition to creating a transportation network, ArcGIS Network Analyst is also used to calculate a service area, which outlines the region that is accessible to a designated location using available transportation means. For example, Starcher (2007) used the service area function in Network Analyst to calculate the area accessible to West Virginia hospitals within a 30-minute drive.

The service area function uses network impedance values (i.e. travel distances or travel times) to calculate buffers around selected facilities. Because the transportation network is used, areas that are inaccessible due to barriers (such as fences and rivers) are not included in the results. In addition, the impacts of changes to the transportation network on the service area can be examined (Landex \& Hansen, 2006).

Demographic information can be combined with the service area to characterize the population that resides within the accessible area. Kreisa (2007) and Nicholls (2001) used census block data to analyze the demographics of the service area. Kreisa (2007) explained that while census tracts are commonly used for analyses, their sizes vary depending on settlement density and they often assume an even population distribution and thus an equally affected population. Thus, census blocks were used, because "it allowed the lowest amount of aggregation, as blocks are usually small in area and more homogenous in population” (Kreisa, 2007, p. 8). Census block data includes information on a number of demographic variables including population, population density, race, gender, age, household size, family size, and renter/owner status. In both studies, only census blocks with their geographic center in the service area were considered to have access. Nicholls (2001) noted that this technique provided an estimate of population 
characteristics, which was determined sufficient for the level of detailed information needed.

\subsection{Summary}

The Tualatin River National Wildlife Refuge staff desire an effective means for analyzing the area that is easily accessible to the refuge and where potential visitors might come from. The accessible area (also known as the service area) is best determined by the network approach, which uses transportation networks to account for actual travel means that visitors would use to get to the refuge. This method requires the user to determine the transportation modes that will be included (single or multiple) and set network attributes such as travel time and restrictions. Once calculated, the service area can be combined with census information to obtain demographic characteristics of the accessible area. 


\section{Chapter 3 - Systems Analysis and Design}

Chapter 3 discusses the system that was designed during this project. This includes a description of the problem that was addressed, details of the system requirements, a summary of the system architecture, and an outline of the project plan for system development.

\subsection{Problem Statement}

The U.S. Fish and Wildlife Service desired an easy-to-use system that would allow staff members to analyze the area that is accessible to the Tualatin River National Wildlife Refuge. This system would incorporate a number of transportation modes including bus routes, bike routes, and streets (used for both walking and driving). Using this system, staff members would be able to identify the area that is accessible to the refuge (also known as the service area) and characterize it in terms of selected demographic variables. Knowing the area that is accessible to the Refuge and knowing the demographic characteristics of the people that live there could help improve visitor services planning.

\subsection{Requirements Analysis}

The functional and nonfunctional system requirements were determined in order to ensure successful development and implementation. The functional requirements describe what actions the system will perform, while the nonfunctional requirements describe how the system will perform these actions.

\subsubsection{Functional Requirements}

Discussions with the client led to the determination of the system's functional requirements (Table 3-1). The first functional requirement was that the system would use transportation data provided by the client. These data were created by the Metro Data Resource Center in Portland, Oregon. The second requirement was that the system would allow users to determine the area that is accessible to the Tualatin River National Wildlife Refuge by car, bus, bike, and/or foot travel. The final functional requirement was to enable the user to derive a population breakdown of the accessible area using available census data. 
Table 3-1 Functional Requirements

\begin{tabular}{|l|l|}
\hline Function & Description \\
\hline $\begin{array}{l}\text { The system will use provided } \\
\text { transportation data }\end{array}$ & $\begin{array}{l}\text { The client has provided transportation data } \\
\text { that will be used for accessibility } \\
\text { determination }\end{array}$ \\
\hline $\begin{array}{l}\text { The system will provide an application } \\
\text { to determine the area of accessibility }\end{array}$ & $\begin{array}{l}\text { The client desires an application to examine } \\
\text { accessibility to the Refuge by car, bus, bike, } \\
\text { and/or foot }\end{array}$ \\
\hline $\begin{array}{l}\text { The system will provide an application } \\
\text { to summarize the demographics of the } \\
\text { accessible area }\end{array}$ & $\begin{array}{l}\text { The client desires an application that will } \\
\text { summarize the accessible area by user- } \\
\text { specified demographic variables }\end{array}$ \\
\hline
\end{tabular}

\subsubsection{Nonfunctional Requirements}

The system's nonfunctional requirements were determined to ensure usability by U.S. Fish and Wildlife Service staff members with their available resources and expertise (Table 3-2). For effective integration into the client's technical infrastructure, it was necessary that all hardware, software, and data in the system were compatible. This meant that the system needed to run on ArcGIS Desktop, use computers with Windows operating system, and required all data be in ESRI format. In addition to technical compatibility, the system had to be usable by staff with limited GIS expertise. As a result, the system needed to provide easy-to-use application interfaces with sufficient help documentation. In addition, documentation and training aides were requested to enable staff members to use the system with few problems.

Table 3-2 Nonfunctional Requirements

\begin{tabular}{|l|l|l|}
\hline \multirow{2}{*}{$\begin{array}{l}\text { Category } \\
\text { Rechnical }\end{array}$} & Function & Description \\
\hline \multirow{3}{*}{$\begin{array}{l}\text { Usability } \\
\text { Requirements }\end{array}$} & Hardware & $\begin{array}{l}\text { PC-Intel with Windows operating } \\
\text { system }\end{array}$ \\
\cline { 2 - 3 } & Software & ArcGIS Desktop \\
\cline { 2 - 3 } & Data & In ESRI format \\
\cline { 2 - 3 } & Application Interfaces & Easy to use with help documentation \\
\cline { 2 - 3 } & Training & $\begin{array}{l}\text { Instructional aides for using the } \\
\text { network dataset }\end{array}$ \\
\hline
\end{tabular}




\subsection{System Design}

Based on the client's goals and system requirements, it was determined that the system would incorporate the client's data into a transportation network dataset, which could then be used for calculating and characterizing the accessible area (Figure 3-1). The client provided transportation data, including bus routes, bus stops, bike routes, and streets data in ESRI shapefile format. After sufficient data preparation, the transportation data layers were integrated into a transportation network dataset. This allowed for effective modeling of transportation elements, including distance and travel time.

In order to analyze accessibility, a tool was developed in ESRI's ModelBuilder, which incorporated service area tools from the ArcGIS Network Analyst Extension. The service area tool used the transportation network dataset as an input to calculate a service area for the Tualatin River National Wildlife Refuge entrance. A second tool was also created in ModelBuilder to characterize the service area by demographic variables selected from a census file. The service area tool and the demographics tool produced service area layers for documentation in visitor services planning.

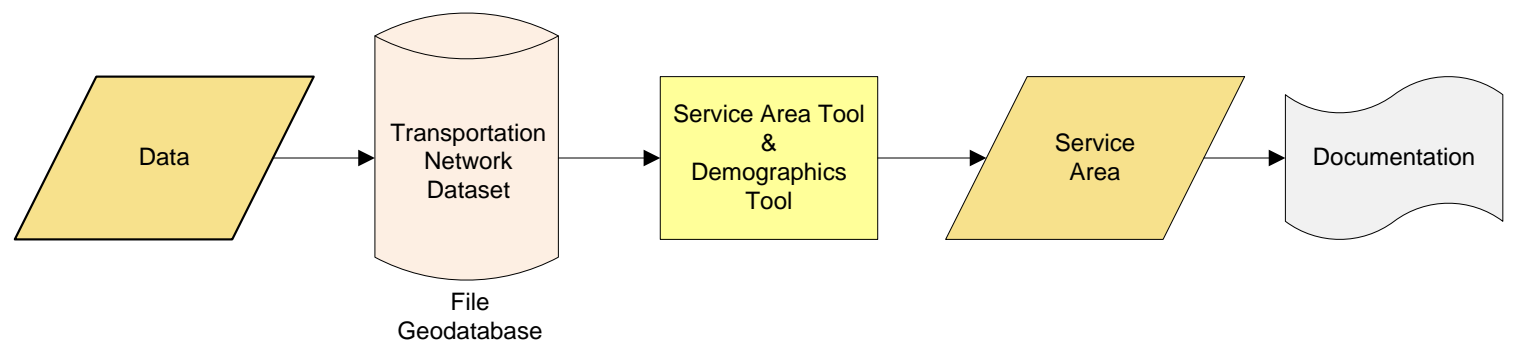

Figure 3-1 System Architecture

\subsection{Project Plan}

The project lifespan consisted of seven major phases. These phases occurred consecutively with some overlap between phases. An outline (Figure 3-2) and description of the phases is provided below. 


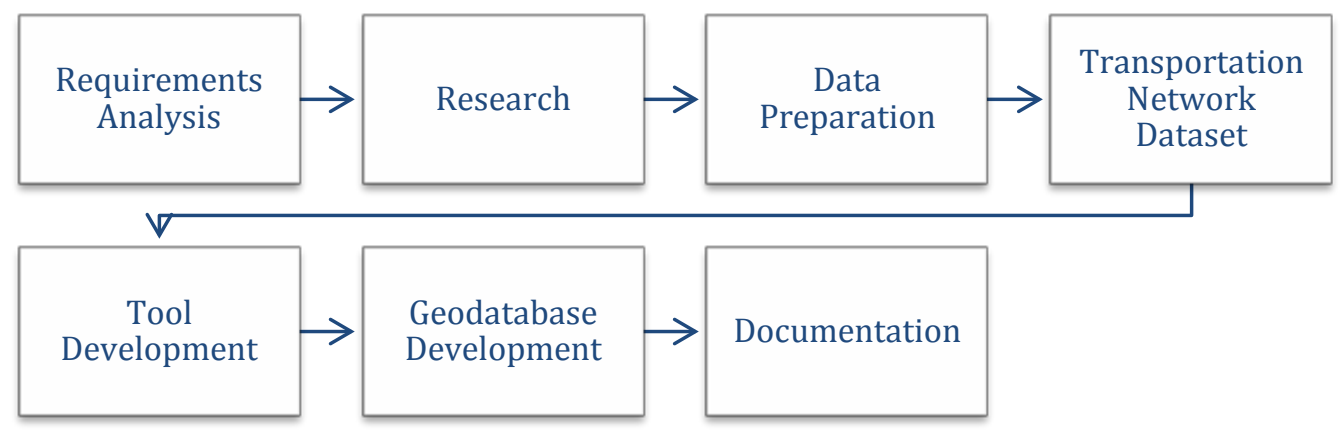

Figure 3-2 Project Plan Phases

\subsubsection{Requirements Analysis}

The first phase of the project was to establish the system requirements. This process involved discussions with the client, Mr. David Drescher, to determine what functionality the system would have to achieve the desired goals. In addition, information was gathered about the client's available technology and the GIS expertise of the system's users. This information was necessary to ensure that the established system would be useable and would function within the client's computing environment.

\subsubsection{Research}

The second phase of the project was to research methods for analyzing accessibility, which were discussed in Chapter 2. Through this process, it was decided that the development of a transportation network dataset would best model the available transportation modes in the Portland metropolitan area and would enable the analysis capabilities desired by the client. Further research was conducted to determine the best practices for developing a multimodal transportation network dataset.

\subsubsection{Data Preparation}

The third project phase involved editing the transportation data for successful integration into a transportation network dataset. Examination of the data showed that the bus routes, bus stops, bike routes, and streets data were not geographically coincident and lacked attributes essential for measuring accessibility. As a result, the data were modified to ensure connectivity. In addition, attribute fields were created and computed for determining distances, travel times, one-way restrictions, road class, and road connectivity.

\subsubsection{Transportation Network Dataset}

The fourth phase in the project was building the transportation network dataset. This required establishing a number of network parameters. First, the data layers to be incorporated were selected, and then data layers were divided into connectivity groups. Turns and elevation fields were specified and cost and restriction attributes were defined 
for measuring travel distance and time and restricting movement along prohibited paths. Finally, the fields used for deriving directions were defined.

\subsubsection{Tool Development}

The fifth phase involved building the service area and demographics tools in ESRI's ModelBuilder. These tools ensured that the user only needed to specify provided parameters to get the desired results. In addition, tool help was provided for both general tool use and specific field requirements to guide the user in proper functionality. By creating the tools in ModelBuilder, the client may easily make future modifications as necessary.

\subsubsection{Geodatabase Development}

The sixth stage was to build a file geodatabase and feature dataset that incorporated the data, transportation network dataset, and tools in an organized format. All data included in a network dataset and the dataset itself must be located within a feature dataset.

Further, file geodatabases are the primary ESRI data format used by the client. Feature datasets were given a UTM NAD 83 Zone 10 projection, which is the standard projection used by the U.S. Fish and Wildlife Service for the Portland, Oregon area.

\subsubsection{Documentation}

The seventh stage in the project was documentation. Throughout the project's lifespan, all methodologies were documented to ensure that the development process could be replicated and to provide complete and detailed metadata. This would allow the client to make any updates as needed and ensure that all data was used correctly with recognized limitations. In addition, tool help and training aides were developed to ensure usability by staff members.

\subsection{Summary}

The client desired a system that would enable users to determine and characterize the area within a specified travel distance or travel time to the Tualatin River National Wildlife Refuge. The developed system included a transportation network dataset created with provided transportation data. The system also included a service area tool and a demographics tool built within ESRI's ModelBuilder. This system is compatible with the client's technical infrastructure and includes help documentation and training aides to ensure usability. As a result, the system can be fully integrated into the client's computing environment and will be ready for staff use once implemented. 



\section{Chapter 4 - Database Design}

With the design of the system determined, the next step was to prepare the transportation data for integration into the transportation network dataset. This required developing a conceptual data model detailing the attributes needed within the transportation data. A logical data model was then created describing the inclusion of the transportation data as feature classes in an ESRI feature dataset within a file geodatabase. Once the database design was established, the data were prepared for inclusion into the feature dataset. The transportation network dataset was then built within the feature dataset using the developed transportation data.

\subsection{Conceptual Data Model}

The conceptual data model describes the data and the attributes needed to ensure system functionality. As detailed in the functional requirements, the system needed to incorporate the client's transportation data, which included bus routes, bus stops, streets, and bike routes. Two additional datasets (boarding and exiting bus stop paths) were created to provide connectivity between matching bus stops located on the streets and on the bus routes.

Since the data would be used for deriving travel costs, restrictions, and directions, it was imperative to include the necessary descriptive and functional attributes (Figure 41). Required attributes for the bus routes features included the unique identifier (required by the database management software), bus route number, direction, unique route identifier, beginning and end stops of each line segment, amount of time to travel along a given segment (in minutes), a one way descriptor for restricted directionality, and segment mileage for distance measures. The bus stops features also required the unique identifier, route, direction, and route identifier attributes, as well as a unique stop identifier, location description, jurisdiction, and zip code. The bus stop paths needed to contain all of the same attributes as the bus stops, since its primary purpose was as a connector between identical stops on the streets and bus routes. In addition, the bus stop paths required an attribute to account for the average waiting time for boarding or exiting a bus. The streets data required attributes for a unique identifier (unique id), street name (street name), restricted directionality (one-way), street hierarchy (road class), travel time cost (speed), distance cost (miles), and connectivity (from and to elevations). Finally, the bike routes needed to contain a unique identifier (unique id) and attributes for the street name as well as the bike mode, which described biking conditions for deriving detailed directions. 


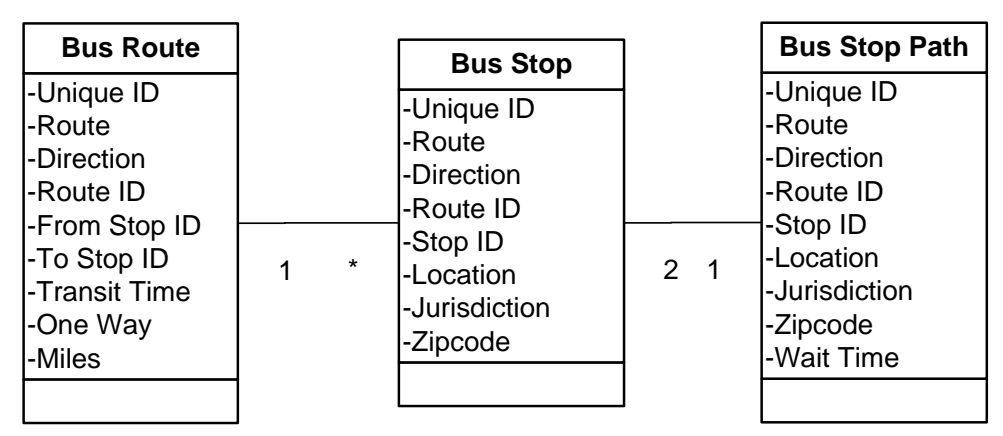

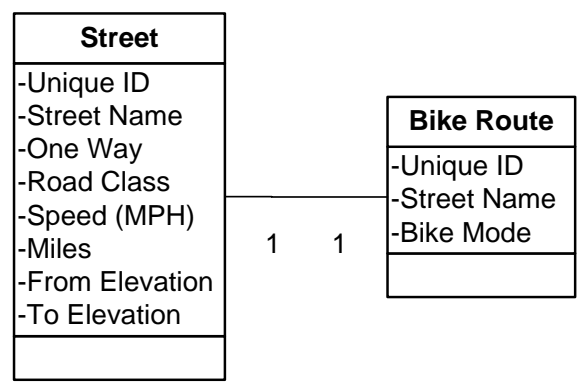

\section{Figure 4-1 Conceptual Data Model}

\subsection{Logical Data Model}

Once the conceptual data model was established, the logical data model was developed. The transportation data were provided in ESRI shapefile format with a projection of NAD_1983_HARN_StatePlane_Oregon_North_FIPS_3601. In order to develop a transportation network dataset that could be integrated into the client's computing environment, a geodatabase was developed with a feature dataset. The provided transportation shapefiles were imported into the feature dataset as feature classes, automatically creating an OBJECTID field as a unique identifier. Many of the attribute field names and data types were carried over from the original transportation data to ensure compatibility with the client's data, while other attributes were added to coincide with the required attributes described in the conceptual data model (Figure 4-2). 


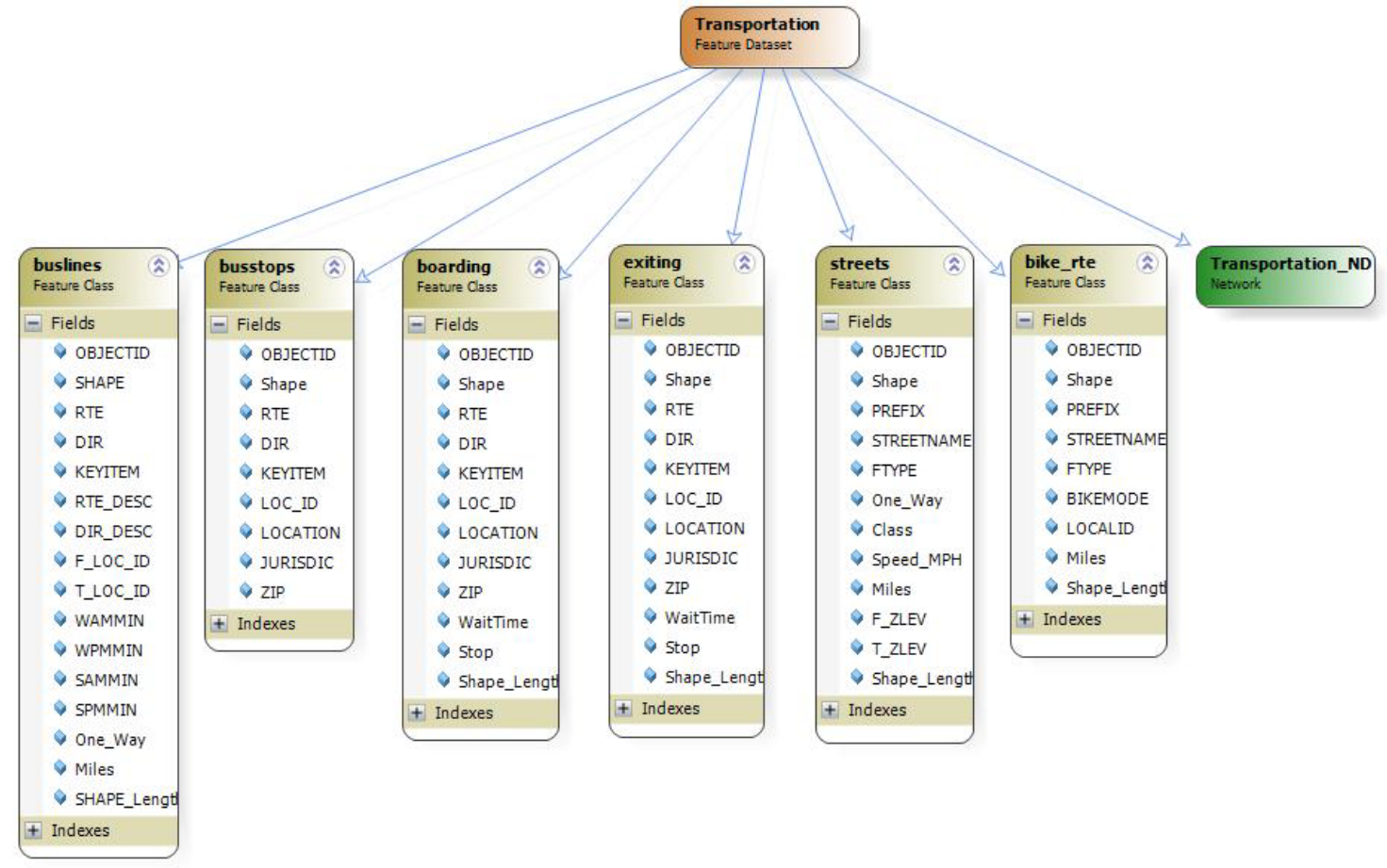

Figure 4-2 Logical Data Model

Within the bus routes feature class, RTE (route), DIR (direction), and KEYITEM (a unique route identifier and combination of RTE and DIR) attribute fields were provided. F_LOC_ID (from stop id) and T_LOC_ID (to stop id) were added to the bus routes features to contain the bounding bus stops for each route segment. These were based on the LOC_ID field provided in the bus stops features to uniquely describe each bus stop. In order to calculate travel times (in minutes) along bus route segments, four attributes were added: WAMMIN (weekday morning), WPMMIN (weekday afternoon), SAMMIN (weekend morning), and SPMMIN (weekend afternoon). The one-way attribute (One_Way) was added to account for directional restrictions to the bus routes features. A Miles field was also added to the bus routes features to provide a measure of travel distance along line segments.

In addition to the RTE (route), DIR (direction), KEYITEM (route id), and LOC_ID (unique stop id) fields, the bus stops features also included attributes to describe the location (LOCATION), jurisdiction (JURISDIC), and zip code (ZIP). Because the bus stop paths were used as connectors between bus stop pairs and as a descriptor for deriving directions, it contained all of the same features as the bus stops. However, the path features also had an additional attribute (WaitTime) to account for the wait time that a person might experience when boarding or exiting the bus.

The streets data came with a number of attributes to describe the street names. Although none of these fields were removed to ensure data integrity, the primary name fields used in this project were PREFIX (e.g. N, NW), STREETNAME, and FTYPE (e.g. Ave, St). The one-way attribute (One_Way) was added to describe roads with restricted directionality. The road class field (Class) provided a measure of hierarchy. The Class 
field allows a user to establish an order of preferred road types used for travel calculations (highways then primary roads, etc.). To calculate travel time along streets, the Speed_MPH attribute was added, which provides an average speed for each road segment based on the type of road. The Miles field was added for calculating distance along streets. Finally, from (F_ZLEV) and to (T_ZLEV) elevation attributes were added for connectivity.

Like the streets data, the bike routes feature class included attribute fields for direction descriptions including PREFIX, STREETNAME, and FTYPE. A BIKEMODE field was also included for describing biking conditions along streets. A Miles field was added to measure distance cost.

\subsection{Data Sources}

All transportation data were provided by the client and was produced by Metro Data Resource Center in Portland, Oregon. These data were provided as shapefiles in the NAD_1983_HARN_StatePlane_Oregon_North_FIPS_3601 projection. Complete metadata was provided describing data production.

\subsection{Data Preparation}

Prior to incorporation into the transportation network dataset, the transportation data were modified to ensure connectivity and to calculate values for the created attribute fields. Modifications to the bus routes, bus stops, bus stop paths, and streets data are described below. No changes were made to the bike routes data.

\subsubsection{Bus Routes Feature Class}

The bus lines data provided by the client included 87 bus routes in two directions, for a total of 174 features. The bus routes and bus stops features both contained a KEYITEM field, which was composed of the bus route (RTE) and bus direction (DIR) attribute fields and was used to identify each route and direction combination. Due to time limitations, eight bus lines (16 for both directions) were selected for inclusion in the transportation network dataset. These routes were chosen by examining the most frequent service lines (according to the TriMet website), the spatial distribution of bus routes (to provide the greatest coverage), and the bus routes within 3 miles of the Tualatin River National Wildlife Refuge entrance. The eight selected bus lines were 4, 8, 12, 33, 54, 57, 94, and 96 (Figure 4-3). 


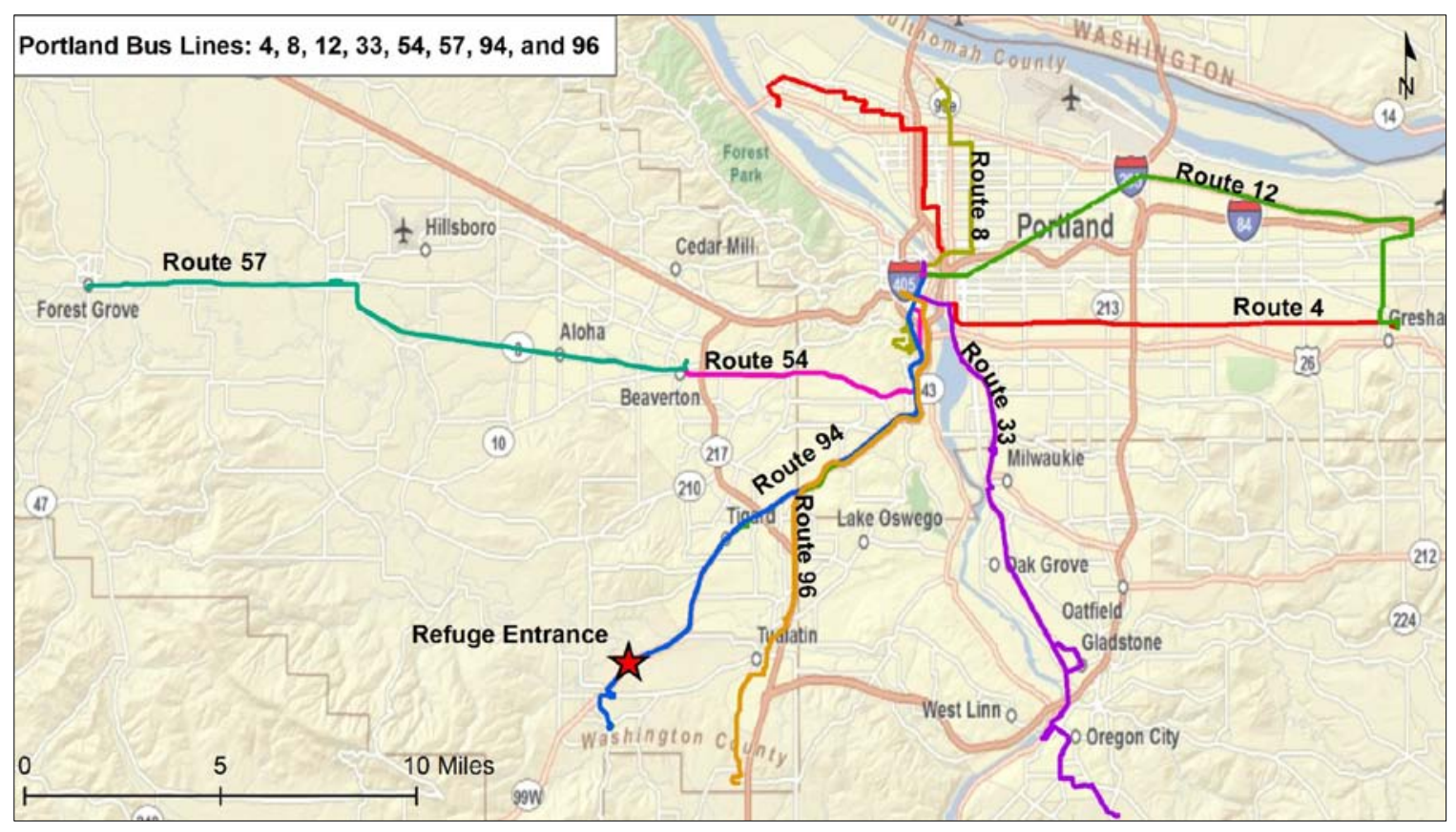

Figure 4-3 Eight Included Bus Lines

Each of the 16 bus routes was exported as a separate feature class. For each bus route and direction, the corresponding bus stops were snapped to the bus route using the Snap and Split ArcScript (Figure 4-4). This ArcScript shifts features in a selected point layer to the nearest feature of a second selected layer within a defined search radius. This was necessary since the bus stops were not located on the bus lines, most likely because they were created from GPS points at the actual location of the bus stops on the sidewalks. Connectivity between transportation data layers was essential for effective integration into a transportation network. 


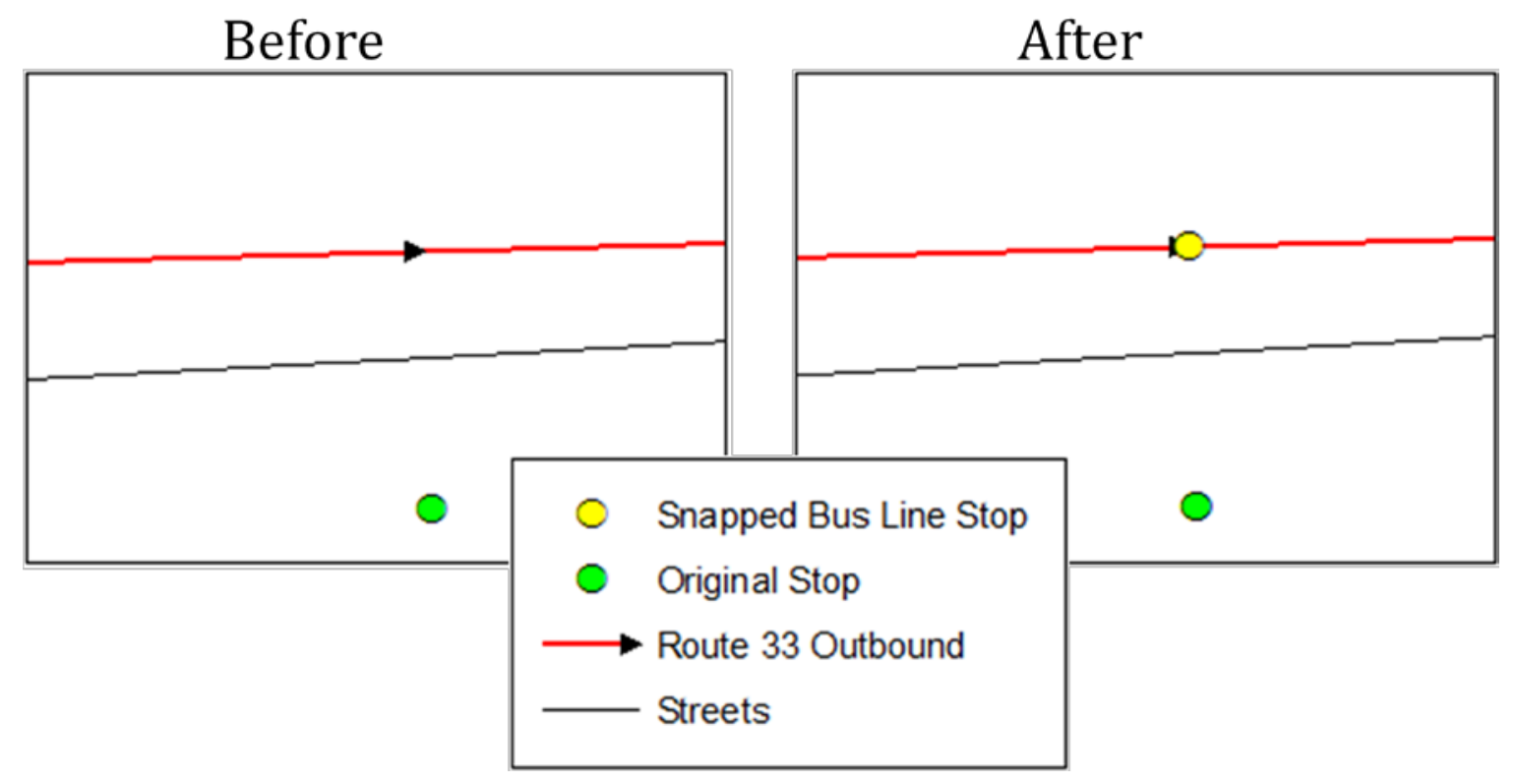

Figure 4-4 Bus Stops Before and After Snapped to Bus Lines

The Split Lines at Points ArcScript was then used to split the route into line segments at each bus stop. In the figure above, each bus line segment was represented as a red line with an arrow at the end. One segment ends at the snapped bus stop while another begins. Thus, each segment represented travel from one stop to the next. Segments were modified to ensure they were digitized in the direction of the route. In addition, attribute fields were created to contain travel times on a weekday morning (WAMMIN), weekday afternoon (WPMMIN), weekend morning (SAMMIN), and weekend afternoon (SPMMIN). In addition, a one-way attribute was created to account for directionality along bus routes, while another attribute was added and calculated to measure the distance in miles.

\subsubsection{Bus Stops Feature Class}

In order to determine travel time along bus routes, the bus stops schedule was downloaded from the TriMet Developer Resources website. This stop_times.txt file contained arrival and departure times for every stop on a weekday, Saturday, and Sunday (Figure 4-5). 


\begin{tabular}{|l|r|r|r|r|r|}
\hline trip_id & arrival_time & departure_time & stop_id & stop_sequence & stop_headsign \\
\hline 40W1140 & $7: 35: 00$ & $7: 35: 00$ & 4818 & 1 Gresham TC via Portland City Ctr \\
\hline $40 W 1140$ & $7: 36: 32$ & $7: 36: 32$ & 4817 & 2 Gresham TC via Portland City Ctr \\
\hline $40 W 1140$ & $7: 37: 13$ & $7: 37: 13$ & 8653 & 3 Gresham TC via Portland City Ctr \\
\hline $40 W 1140$ & $7: 37: 30$ & $7: 37: 30$ & 3509 & 4 Gresham TC via Portland City Ctr \\
\hline $40 W 1140$ & $7: 37: 57$ & $7: 37: 57$ & 3467 & 5 Gresham TC via Portland City Ctr \\
\hline $40 W 1140$ & $7: 38: 28$ & $7: 38: 28$ & 8480 & 6 Gresham TC via Portland City Ctr \\
\hline $40 W 1140$ & $7: 38: 57$ & $7: 38: 57$ & 3525 & 7 Gresham TC via Portland City Ctr \\
\hline 40W1140 & $7: 39: 41$ & $7: 39: 41$ & 11936 & 8 Gresham TC via Portland City Ctr \\
\hline 40W1140 & $7: 40: 23$ & $7: 40: 23$ & 5376 & 9 Gresham TC via Portland City Ctr \\
\hline $40 W 1140$ & $7: 40: 52$ & $7: 40: 52$ & 5373 & 10 Gresham TC via Portland City Ctr \\
\hline
\end{tabular}

\section{Figure 4-5 Sample Downloaded Stop Times Table}

A new Excel table was created with arrival times for each stop on the 16 included routes during a trip on a weekday morning, weekday afternoon, weekend morning, and weekend afternoon. A trip that began at or right after 7:30 a.m. was used to estimate travel time during mornings and a trip that began at or right after 4:30 p.m. was used to estimate travel time during afternoons. Weekday trips were selected from weekday stop times, while weekend trips were selected from the Saturday stop times. The arrival times (provided in HH:MM:SS format) were split into separate fields for hours, minutes, and seconds. The difference in arrival times between one stop and the next were than calculated and stored in decimal minutes format for a weekday morning (WAMMIN), weekday afternoon (WPMMIN), weekend morning (SAMMIN), and weekend afternoon (SPMMIN) (Figure 4-6). The travel time from one stop to the next was attributed in the latter stop field. Thus, travel from stop 4818 to 4817 in the figure below took approximately one and a half minutes on a weekday morning, and was included as an attribute for the 4817 stop.

\begin{tabular}{|c|c|c|c|c|c|c|c|c|c|c|c|}
\hline KEYITEM & RTE & DIR & LOCID & STOP & & ARRDEP & HOUR & & & SECOND & WAMMIN \\
\hline 0040 & 004 & 0 & 4818 & & 1 & 7:35:00 & & 7 & 35 & 0 & 0.00 \\
\hline 0040 & 004 & 0 & 4817 & & 2 & $7: 36: 32$ & & 7 & 36 & 32 & 1.53 \\
\hline 0040 & 004 & '0 & 8653 & & 3 & $7: 37: 13$ & & 7 & 37 & 13 & 0.68 \\
\hline 0040 & 004 & "0 & 3509 & & 4 & $7: 37: 30$ & & 7 & 37 & 30 & 0.28 \\
\hline 0040 & 004 & '0 & 3467 & & 5 & 7:37:57 & & 7 & 37 & 57 & 0.45 \\
\hline 0040 & 004 & $\bar{V}_{0}$ & 8480 & & 6 & $7: 38: 28$ & & 7 & 38 & 28 & 0.52 \\
\hline 0040 & 004 & '0 & 3525 & & 7 & $7: 38: 57$ & & 7 & 38 & 57 & 0.48 \\
\hline 0040 & 004 & 0 & 11936 & & 8 & $7: 39: 41$ & & 7 & 39 & 41 & 0.73 \\
\hline 0040 & 004 & 0 & 5376 & & 9 & $7: 40: 23$ & & 7 & 40 & 23 & 0.70 \\
\hline 0040 & 004 & 0 & 5373 & & 10 & $7: 40: 52$ & & 7 & 40 & 52 & 0.48 \\
\hline
\end{tabular}

Figure 4-6 Sample Calculated Travel Times Table

As discussed previously, sixteen bus routes were selected for use in the transportation network dataset. These included bus lines 4, 8, 12, 33, 54, 57, 94, and 96 in two directions, 0 and 1 . As a result, only the bus stops for these routes were used. These 
bus stop features were exported separately and each feature was joined to the Excel table by the unique stop id field to calculate values in the created WAMMIN, WPMMIN, SAMMIN, and SPMMIN fields within the bus stops attribute table (Figure 4-7).

\begin{tabular}{|c|c|c|c|c|c|c|c|c|c|c|}
\hline RTE & DIR & KEYITEM & LOC_ID & LOCATION & JURISDIC & ZIP & WAMMIN & WPMMIN & SAMMIN & SPMMIN \\
\hline 004 & 0 & 0040 & 4818 & N Richmond \& Syracuse & Portland & 97203 & 0 & 0 & 0 & 0 \\
\hline 004 & 0 & 0040 & 4817 & N Richmond \& Syracuse & Portland & 97203 & 1.533333 & 1.683333 & 1.266667 & 1.4 \\
\hline 004 & 0 & 0040 & 8653 & N Charleston \& Lombard & Portland & 97203 & 0.683333 & 0.733333 & 0.55 & 0.616667 \\
\hline 004 & 0 & 0040 & 3509 & N Lombard \& John & Portland & 97203 & 0.283333 & 0.316667 & 0.233333 & 0.266667 \\
\hline 004 & 0 & 0040 & 3467 & N Lombard \& Burlington & Portland & 97203 & 0.45 & 0.483333 & 0.366667 & 0.4 \\
\hline 004 & 0 & 0040 & 8480 & N Lombard \& Baltimore & Portland & 97203 & 0.516667 & 0.566667 & 0.416667 & 0.466667 \\
\hline 004 & 0 & 0040 & 3525 & N Lombard \& New York & Portland & 97203 & 0.483333 & 0.516667 & 0.4 & 0.433333 \\
\hline 004 & 0 & 0040 & 11936 & N St Louis \& Leonard & Portland & 97203 & 0.733333 & 0.816667 & 0.6 & 0.683333 \\
\hline 004 & 0 & 0040 & 5376 & N St Louis \& Smith & Portland & 97203 & 0.7 & 0.75 & 0.566667 & 0.633333 \\
\hline 004 & 0 & 0040 & 5373 & N St Louis \& New York & Portland & 97203 & 0.483333 & 0.533333 & 0.4 & 0.433333 \\
\hline
\end{tabular}

\section{Figure 4-7 Sample Bus Stops Attribute Table}

\subsubsection{Bus Route Travel Times}

The bus route and bus stops feature classes were converted into ESRI coverage format and then converted back into feature classes. The coverage format is an early ESRI data format that automatically calculates arc and node identifiers. This was used to associate each route segment with the nearest bus stops. This allowed the route segment to be attributed with the time taken to travel between the corresponding bus stops. For each route segment, the bounding bus stops were provided as the from node (FNODE) and to node (TNODE) attributes. The values in these fields corresponded to the OBJECTID field within the bus stops features.

The bus stop features contained the unique stop identifier field (LOC_ID) along with the four travel times (WAMMIN, WPMMIN, SAMMIN, SPMMIN). These fields were used to compute the bus route attributes (F_LOC_ID, T_LOC_ID, WAMMIN, WPMMIN, SAMMIN, and SPMMIN). The attribute fields were calculated by joining the FNODE field (to calculate the F_LOC_ID field) and then the TNODE field (to calculate T_LOC_ID, WAMMIN, WPMMIN, SAMMIN, and SPMMIN) in the bus routes feature class with the OBJECTID field in the bus stops feature class. Figure 4-8 below shows the association between a bus line segment (OBJECTID 126) with the corresponding bus stops (OBJECTID 125 and 123). 


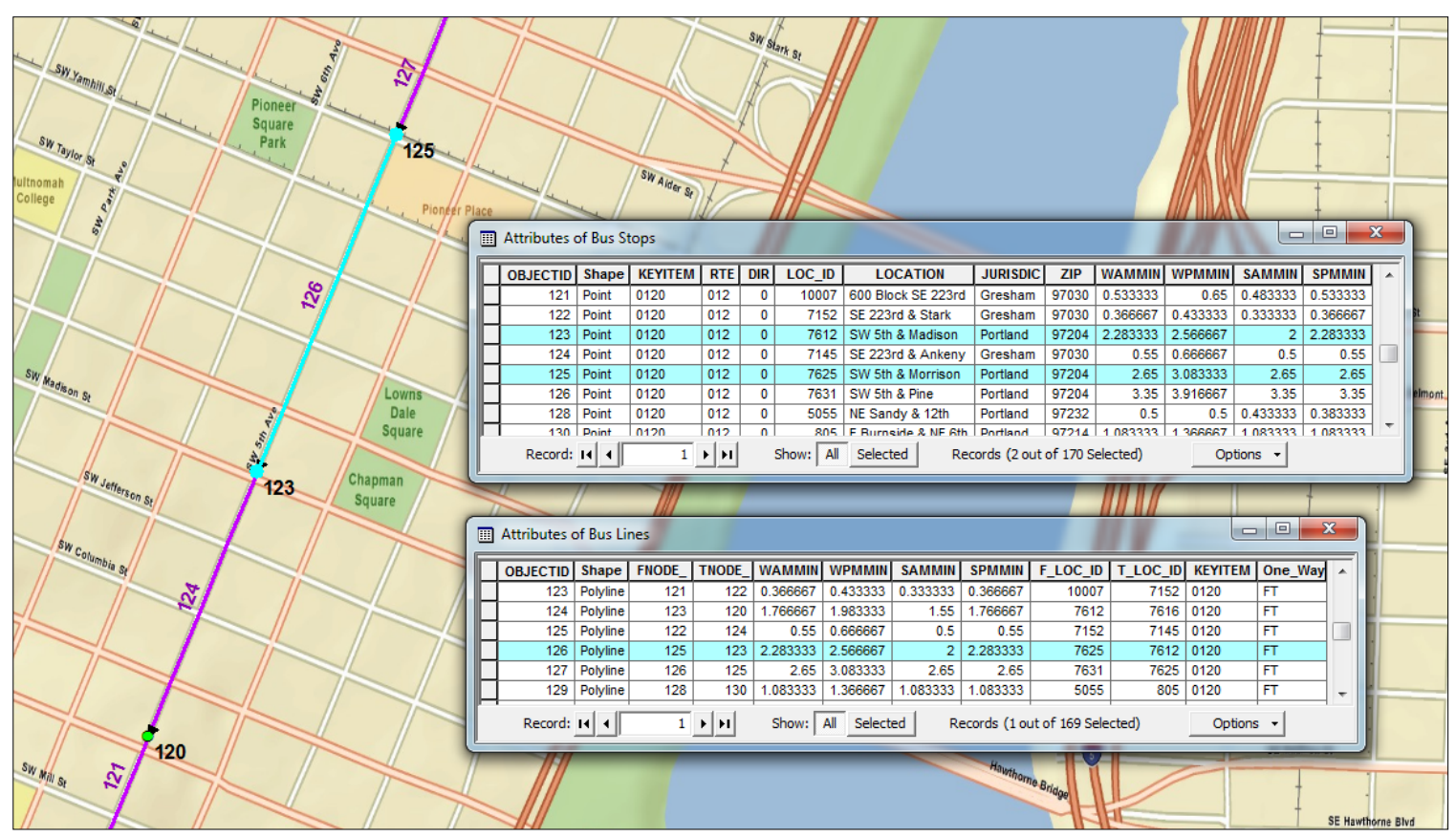

Figure 4-8 Relationship between bus routes and bus stops

\subsubsection{Bus Stop Connectivity}

Upon close examination of the bus lines and streets data, it was apparent that there were gaps between the two data layers. These ranged from less than an inch to a few feet and were likely the result of digitizing error. However, these gaps were significant enough to prevent connectivity along the network. As a result, a copy of the original bus stops data was snapped to the streets. These street stops were then loaded into the previously created bus stops features, which contained the bus stops snapped to the bus lines. Thus for every original bus stop, a pair of stops was created with one snapped to the bus lines and one snapped to the streets (Figure 4-9). Paired stops contained the same attribute values, which were equivalent to those provided in the original bus stop features (Figure 4-10).

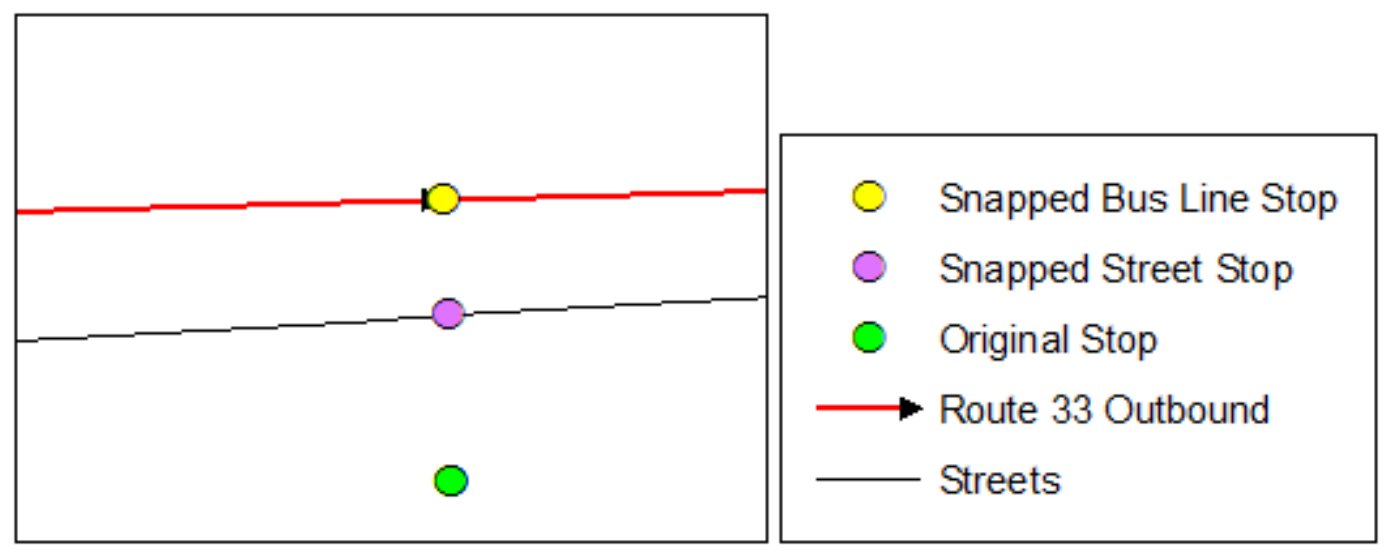

Figure 4-9 Original Stop, Stop Snapped to Bus Lines, and Stop Snapped to Streets 


\begin{tabular}{|c|c|c|c|c|c|c|c|c|c|}
\hline \multicolumn{7}{|c|}{ 囲 Attributes of Bus Stops } & \multicolumn{3}{|c|}{\begin{tabular}{|l|l|l|}
$口$ & 回 & $\mathbf{X}$ \\
\end{tabular}} \\
\hline OBJECTID* & Shape ${ }^{*}$ & RTE & DIR & KEYITEM & LOC_ID & LOCATION & JURISDIC & ZIP & $\Delta$ \\
\hline 1535 & Point & 033 & 0 & 0330 & 10 & Abernethy \& Barclay & Gladstone & 97027 & 1 \\
\hline 1622 & Point & 033 & 0 & 0330 & 10 & Abernethy \& Barclay & Gladstone & 97027 & \\
\hline 1533 & Point & 033 & 0 & 0330 & 11 & Abernethy \& Beatrice & Gladstone & 97027 & \\
\hline 1620 & Point & 033 & 0 & 0330 & 11 & Abernethy \& Beatrice & Gladstone & 97027 & 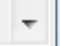 \\
\hline Record: 14 & 4 & $8 \cdot$ & & Show: All & Selected & Records ( 0 out o & Selected) & Optio & 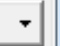 \\
\hline
\end{tabular}

\section{Figure 4-10 Attributes for Paired Bus Stops on Streets and Bus Lines}

To provide connectivity between the bus stops located on the streets and bus stops located on the bus routes, boarding and exiting paths were created. (Figure 4-11). Boarding paths provided connectivity from the streets to the bus routes, while exiting paths provided connectivity from the bus routes to the streets. These paths were created using the Create Attributed Lines from Points ArcScript. This ArcScript created a new shapefile of connector lines between stops based on the unique stop id field (LOC_ID). However, while the ArcScript successfully created connecting lines, the LOC_ID field was not attributed correctly. As a result, the bus stops and connector lines were exported into a coverage and then exported into a new line and point feature class. The KEYITEM and LOC_ID fields were added to the line features and calculated by joining the FNODE field in the lines feature class with the OBJECTID field in the point feature class. This line feature was then used to create the boarding and exiting feature classes with the same attribute fields as the bus stops (RTE, DIR, KEYITEM, LOC_ID, LOCATION, JURISDIC, and ZIP). Thus for every pair of bus stops, there was a boarding and exiting path with the same attributes.

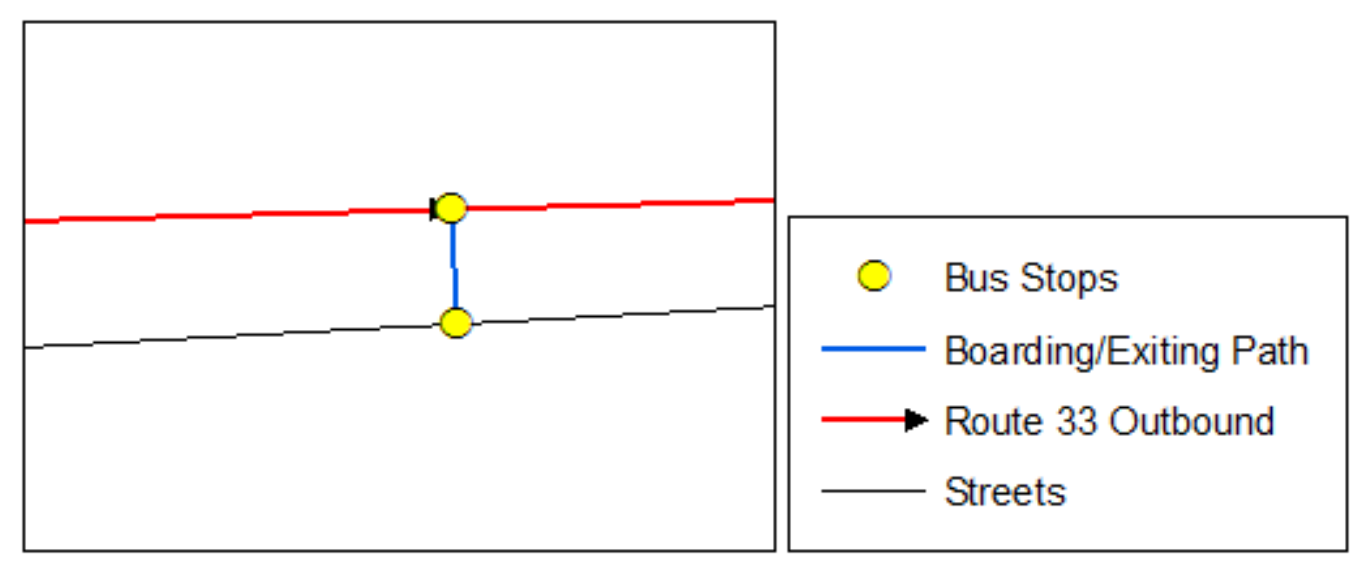

\section{Figure 4-11 Boarding/Exiting Paths between Bus Stops}

The boarding and exiting path features also contained two additional fields. A WaitTime field was created for estimating the time a person might spend waiting to board or exit a bus. This could provide a more accurate representation of the total amount of time spent travelling by bus. All boarding features were given a value of 5 to represent a wait time of five minutes. This was an estimate since boarding wait times vary depending 
on a number of factors including the time of arrival at a stop, bus line frequency, and whether travelling on a weekday or weekend. Six of the eight included bus lines were frequent service lines with an estimated run time of 15 minutes or less on weekdays. The WaitTime field for exiting features was calculated as 0 to represent zero minutes of wait time for getting off a bus. Both boarding and exiting WaitTime values can be modified to fit user needs. A Stop field was also added for describing the connected stops when producing directions for a created route.

Finally, all boarding and exiting paths were modified so that they were in the same direction. This was used to restrict movement so that travel from the streets to the bus lines would use the boarding paths, while travel from the bus lines to the streets would use the exiting paths.

\subsubsection{Streets Feature Class}

While the provided streets data came with a number of attributes to describe the street names, a number of additional attributes were necessary for connectivity and determining travel time by walking and driving. The added fields included One_Way, Class, Speed_MPH, Miles, F_ZLEV, and T_ZLEV.

The One_Way attribute was used to determine directionality for streets that have one-way driving restrictions. This is essential to prevent routing along prohibited streets. The one-way attribute was determined by symbolizing the streets with arrows at the end. This symbology shows the direction in which the streets were created. Streets with oneway restrictions were identified from a combination of comparing the streets to ESRI training data, as well as Google and Ask.com maps of the area. One-way streets created in the same direction as the actual direction of travel were assigned a value of "FT" (from-to), while one-way streets created in the opposite direction were assigned a value of "TF."

The Class attribute was used for creating a hierarchy within the streets. This will allow a user to create a route with a preference for using freeways, then highways, then primary roads, etc. Six classes were assigned: 1 (freeways), 2 (ramps), 3 (highways), 4 (primary roads), 5 (secondary roads), and 6 (local roads). These were determined based on the street type attribute provided and examining the ESRI data.

The Speed_MPH attribute described the speed (in miles per hour) for every line segment. These speeds were determined according to client specifications and by examining CFCC codes, and were calculated using the Class attribute. Freeways were assigned a speed of 55, ramps were assigned 20, highways assigned 45, primary roads assigned 35, and secondary and local roads were assigned 25. Miles were calculated using the calculate geometry tool.

The final two attributes added were F_ZLEV and T_ZLEV. These fields corresponded with the endpoints of each feature, and were used to ensure accurate connectivity between road segments. Thus, if there were connectivity between road segments, the elevation values would be the same for the shared endpoints. However, if there were no connectivity between road segments, such as in the case of overpasses, elevation values for the common endpoint would be different. The F_ZLEV and T_ZLEV values were determined by examining the data and comparing equivalent fields in the ESRI data and TeleAtlas 2009 data. 


\subsection{Transportation Network Dataset}

After preparing the individual transportation data layers within the feature dataset, the data layers were integrated using the Integrate tool to ensure connectivity between data layers. To build the transportation network dataset, the network properties were defined.

The first step in building a transportation network dataset was to define the transportation data layers that would be incorporated. These included the bus lines, bus stops, boarding, exiting, streets, and bike routes. The next step was to define connectivity. Since this was a multimodal transportation network dataset, more than one connectivity group was needed (Figure 4-12). Two connectivity groups were used. One group contained the bike routes, streets, and boarding lines. Because the bike routes occur along the streets and the data layers are coincident, it is logical for the two to be in the same connectivity group. The boarding paths provided connectivity from the streets/bike routes to the bus routes. The second connectivity group contained the bus lines and exiting paths. The bus stops were used to link the two connectivity groups. This, for example, would allow a person to travel on bike or on foot to a bus stop, get onto a bus via the boarding path, ride the bus, get off at a bus stop via the exiting path, and continue walking or biking to their destination.

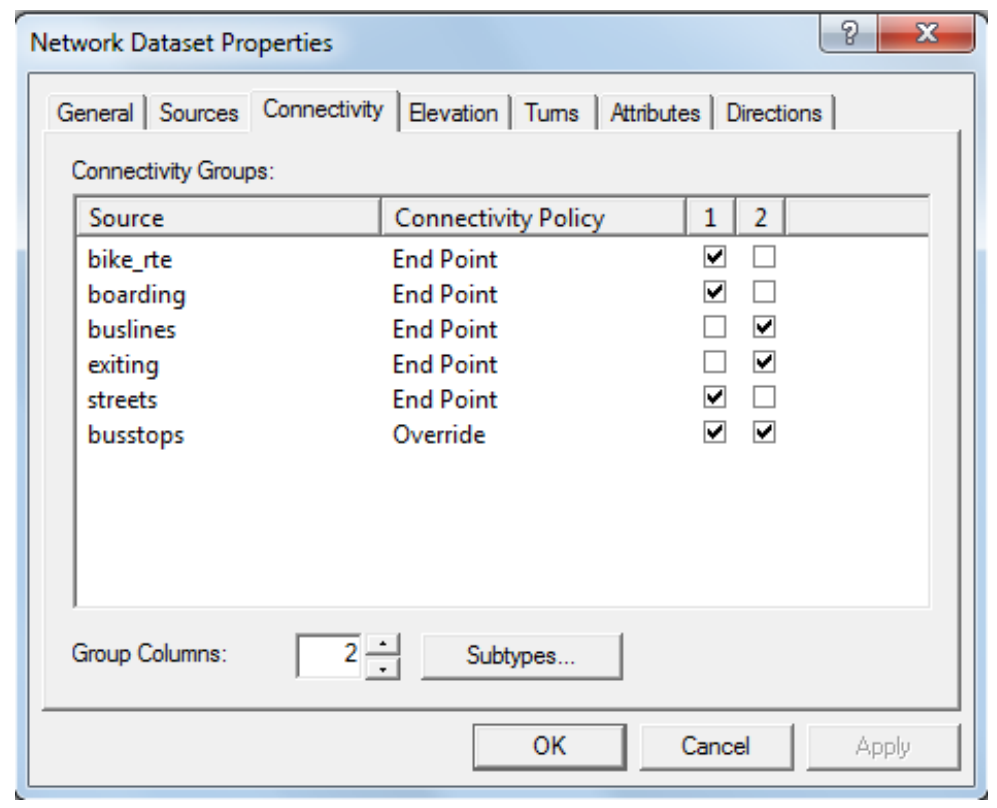

Figure 4-12 Transportation Network Dataset Connectivity Properties

The third step was to establish elevation properties. As described previously, the streets data included F_ZLEV and T_ZLEV attributes to ensure accurate representation of road connectivity. The F_ZLEV field was selected for the streets From End and T_ZLEV was selected for the To End (Figure 4-13). 


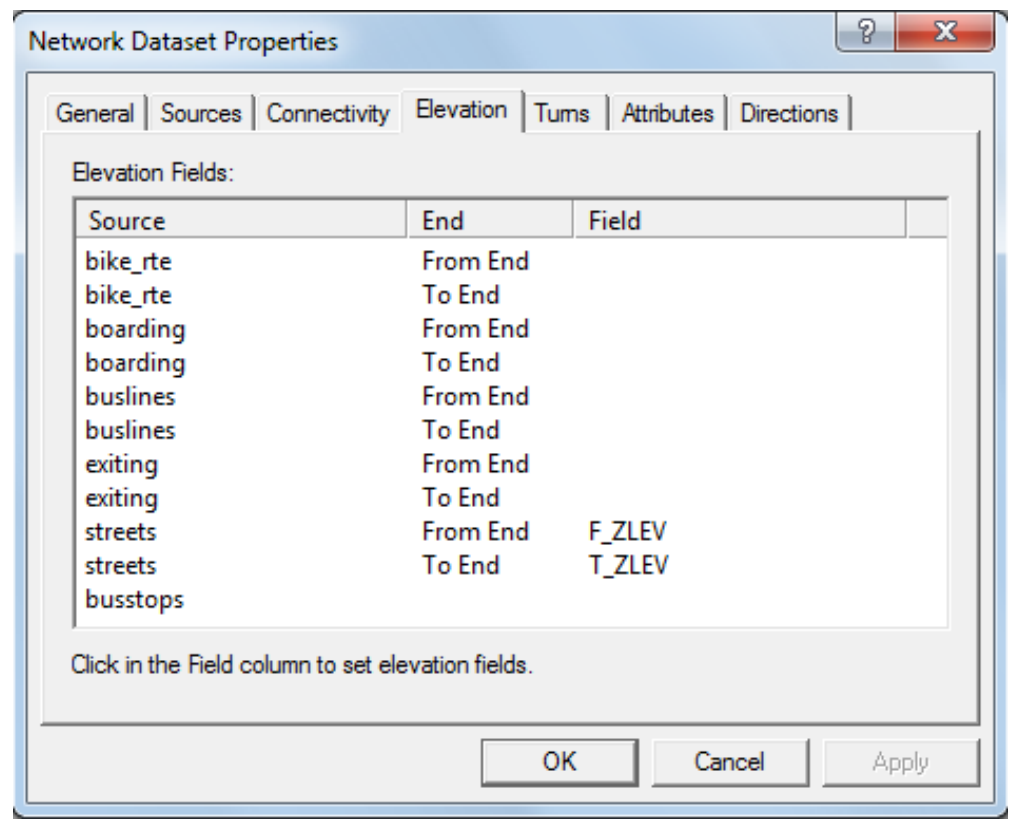

\section{Figure 4-13 Transportation Network Dataset Elevation Properties}

The fourth step was to determine the network turning properties. There were no turns added to the provided global turns, since there were no restricted turns besides those prevented by one-way streets. Global turn properties can be set up in the attributes tab to account for delays such as when making left turns while driving.

The fifth step was to establish network attributes including travel costs and restrictions. The costs were used to determine how travel distance and time would be measured in calculating accessibility. The travel distance cost was provided in terms of miles. The travel time costs were measured using the four primary means of transportation (bike riding, bus riding, walking and driving), which were also combined to create additional measures. All costs using bus transportation were provided for four different times: weekday morning (AM), weekday afternoon (PM), weekend morning $(\mathrm{AM})$, and weekend afternoon (PM). As a result, there were thirteen options for measuring travel along the network (Table 4-1). When a travel cost includes more than one type of travel, such as riding a bus and bike, Network Analyst selects the type of transportation at each point that would result in the quickest total travel time. Thus, a route from point A to point B would likely involve travelling on a bike from point A to the nearest bus stop, getting on a bus and riding on it, exiting at a stop close to point $\mathrm{B}$, and continue riding a bike to point $\mathrm{B}$. All Portland busses allow passengers to load their bike into one of two slots on the bike rack located on the front of a bus. 


\section{Table 4-1 Network Travel Costs}

\begin{tabular}{|l|l|}
\hline Cost & Units \\
\hline Bus and Bike Weekday AM & Minutes \\
\hline Bus and Bike Weekday PM & Minutes \\
\hline Bus and Bike Weekend AM & Minutes \\
\hline Bus and Bike Weekend PM & Minutes \\
\hline Bus and Walk Weekday AM & Minutes \\
\hline Bus and Walk Weekday PM & Minutes \\
\hline Bus and Walk Weekend AM & Minutes \\
\hline Bus and Walk Weekend PM & Minutes \\
\hline Bike and Walk & Minutes \\
\hline Bike Only & Minutes \\
\hline Walk Only & Minutes \\
\hline Drive Only & Minutes \\
\hline Miles & Miles \\
\hline
\end{tabular}

For each cost, evaluators were set up to establish how the cost would be measured with the included feature classes. Features that were not included in a particular travel cost were assigned a value of -1 , which effectively prohibits movement along those transportation modes. Thus, for the drive cost, all but the streets feature class was given a value of -1, since driving can only occur along streets (Figure 4-14). To calculate travel time along streets, a field-based expression was created that used the Miles and Speed_MPH attribute fields in the streets feature class (Figure 4-15). 


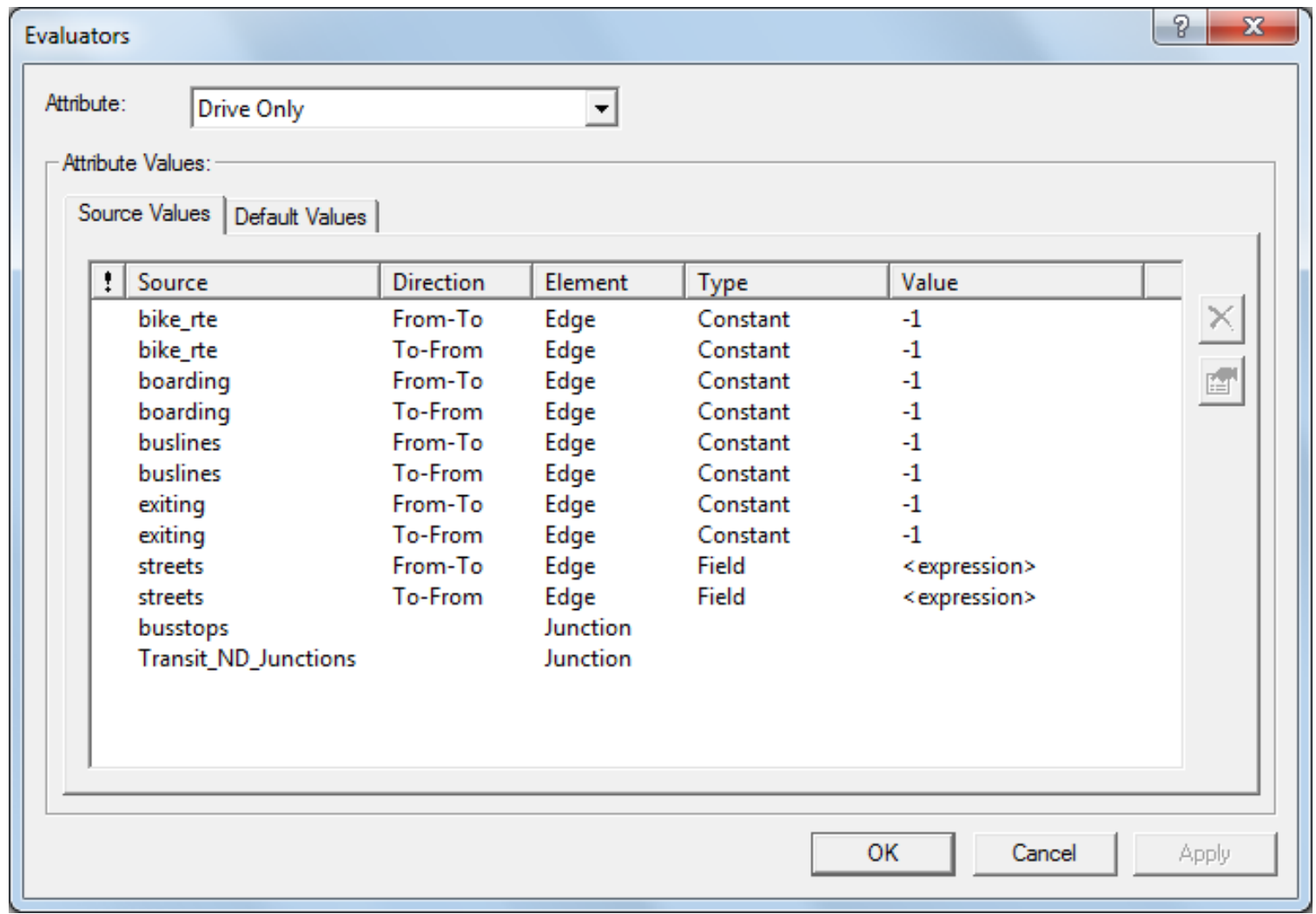

\section{Figure 4-14 Drive Time Evaluators}

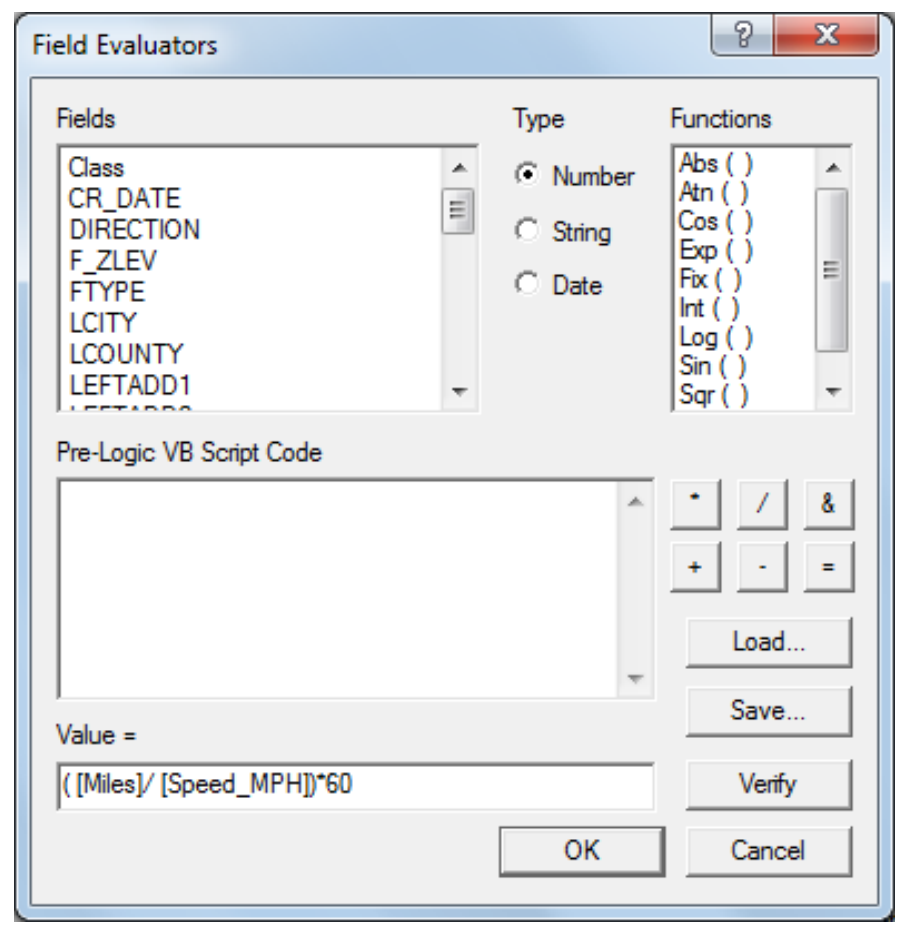

Figure 4-15 Drive Time Street Expression 
The expressions used to calculate biking and walking times were similar to the driving expression (([Miles]/ [Speed_MPH])*60), except the speed_mph field was replaced by a constant travel speed. Biking travel times were based on a travel speed of 10 miles per hour and were used in the expression for bike routes and in the expression for streets when not walking. Walking travel times were based on a travel speed of 3 miles per hour and were used in the streets expression. The user could alter these expressions to increase or decrease the assumed travel speed.

To calculate travel times along the bus routes, attributes from the bus lines, boarding, and exiting feature classes were selected on the evaluator page (Figure 4-16). The WaitTime field in the boarding and exiting feature classes was used to account for the wait time that a person might experience getting on or off the bus. These were computed as 5 for boarding and 0 for exiting within the attribute table. These values could be re-calculated and the network rebuilt if changes were desired. Each day/time of travel was assigned a different attribute field in the bus lines features. Thus, weekday AM travel was assigned the WAMMIN field (weekday AM minutes), weekday PM was assigned the WPMMIN field, weekend AM travel was assigned the SAMMIN field (Saturday/Sunday AM minutes), and weekend PM travel was assigned the SPMMIN field.

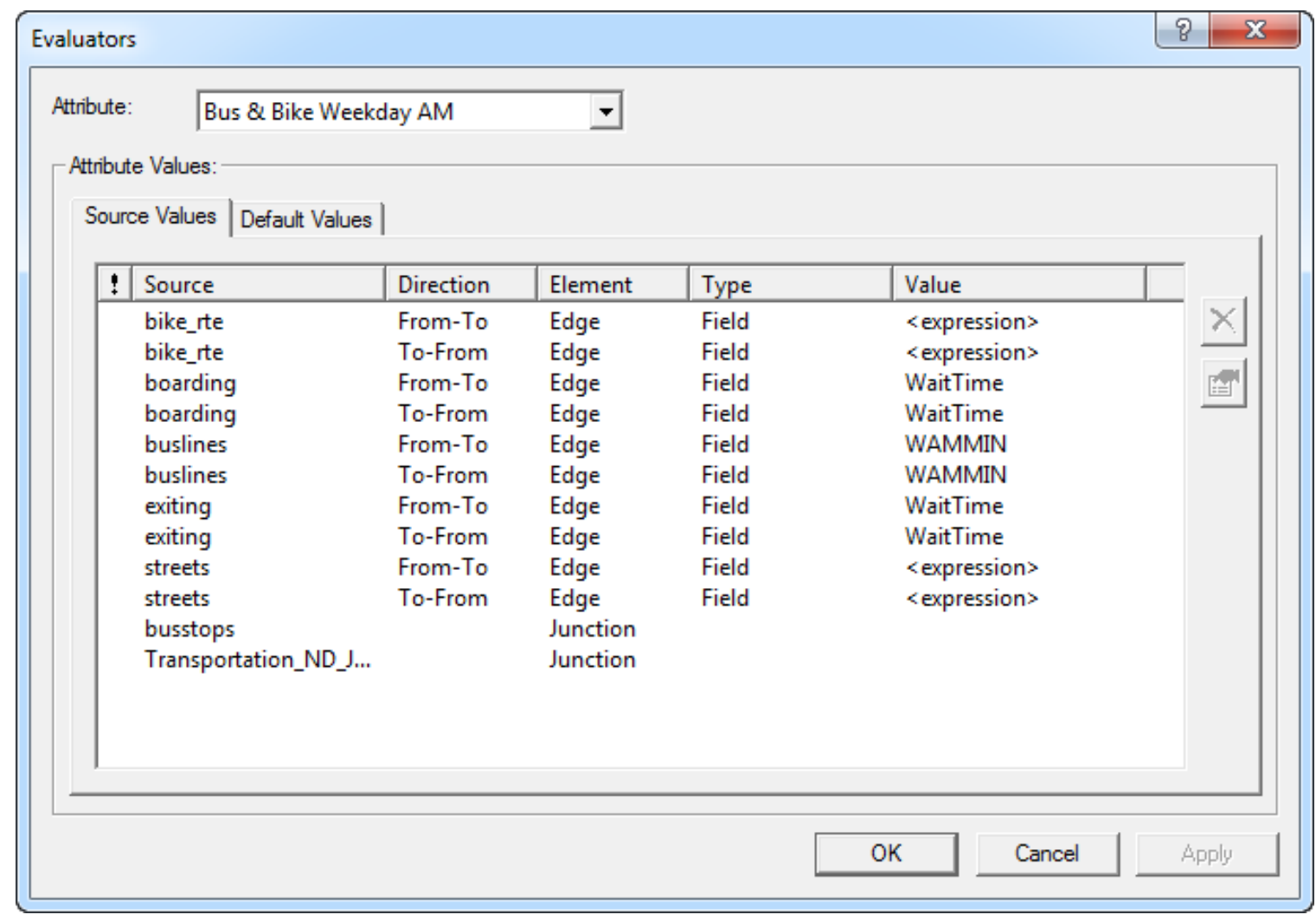

Figure 4-16 Bus, Bike, and Walk Weekday Morning Evaluators

In addition to establishing cost attributes used to measure travel times and distances, the attributes tab was also used to establish restriction attributes (Figure 4-17). 
These attributes were used to prevent travel when routes/times were unavailable. This includes preventing routing in the wrong direction of one-way streets and routing along unavailable bus lines.

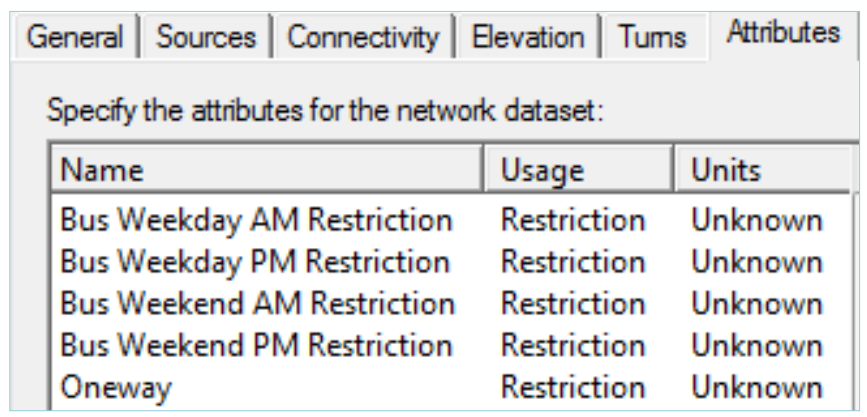

\section{Figure 4-17 Transportation Network Dataset Restriction Attributes}

One-way restrictions were established for the boarding paths, exiting paths, bus lines, and streets (Figure 4-18). Because boarding paths were developed going from the bus lines to the streets, boarding paths were restricted in the From-To direction. Thus, boarding paths only allowed movement from the streets to the bus lines. Since exiting paths were developed in the same direction as boarding paths, movement was prohibited in the To-From direction, ensuring exiting travel from the bus lines to the streets. Bus lines and streets in the From-To direction were restricted if the One_Way attribute field was populated with "TF" (Figure 4-19), while bus lines and streets in the To-From direction were restricted if the attribute field was populated with "FT." 


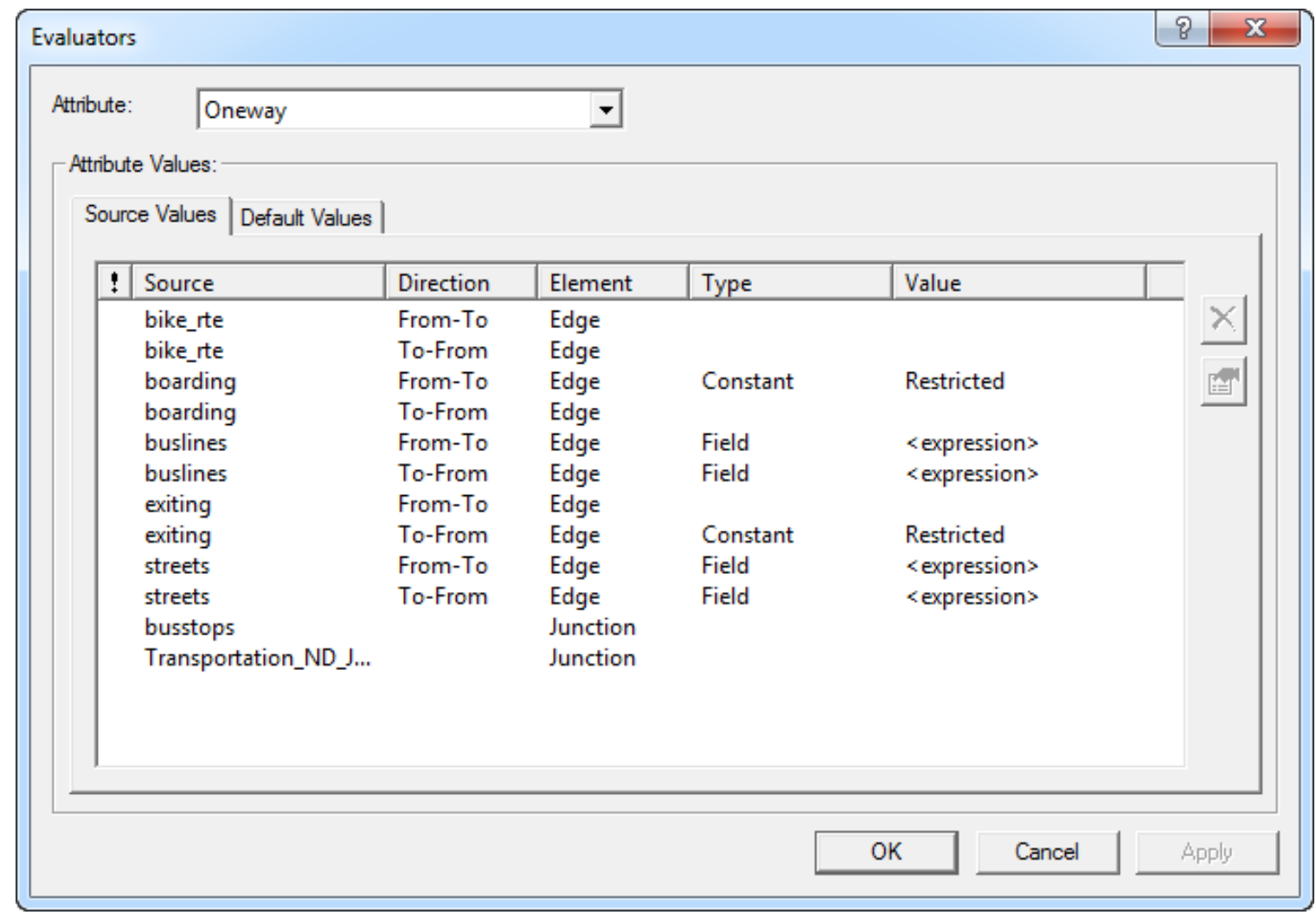

Figure 4-18 One Way Restriction Evaluators

\begin{tabular}{|c|c|}
\hline \multicolumn{2}{|l|}{ Pre-Logic VB Script Code } \\
\hline $\begin{array}{l}\text { restricted = False } \\
\text { Select Case UCase([One_way]) } \\
\text { Case "N", "TF". "T": restricted = True } \\
\text { End Select }\end{array}$ & 4 \\
\hline Value $=$ & \\
\hline
\end{tabular}

Figure 4-19 Expression Used to Handle One-Way Restrictions in From-To Direction

Unavailable bus routes were those that had no service at selected times during the week or weekend. Thus, bus routes that were not available on a weekday morning had the WAMMIN attribute field set to equal zero. A VBA expression was developed for each bus restriction to prohibit movement when the respective travel time attribute equaled zero (Figure 4-20). 


\begin{tabular}{|l|} 
Pre-Logic VB Script Code \\
\begin{tabular}{|l} 
restriction $=$ false \\
If $[$ WAMMIN] $=0$ then \\
restriction $=$ true \\
End if
\end{tabular} \\
\hline Value $=$ \\
\hline restriction \\
\hline
\end{tabular}

Figure 4-20 Expression Used to Handle Weekday AM Bus Route Restriction

In addition to establishing costs and restrictions, a descriptor attribute was created for describing bus lines. This BusRoute descriptor characterized bus routes by the KEYITEM attribute field and was used to reduce transferences between bus lines. Since all bus line features were included in one connectivity group and there was overlapping between bus lines, there was a tendency for Network Analyst to switch between bus lines in order to produce routes with the shortest travel time. As a result, a turn cost was created that would add 2 minutes every time a route switched from one bus line to another as distinguished in the BusRoute descriptor (Figure 4-21). This was implemented as a default turn value for all bus-related costs. The turn cost effectively reduced the number of transferences when routing along bus routes.

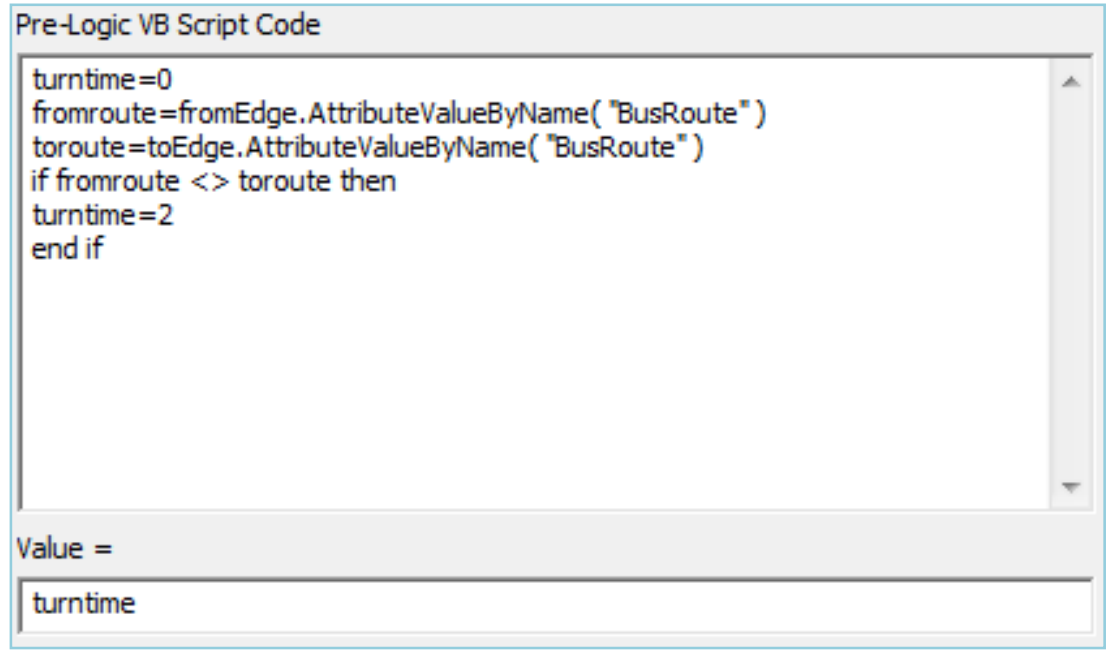

\section{Figure 4-21 Bus Route Turn Cost}

The final step in preparing the transportation network dataset was establishing the fields that would be used in the directions window. This would allow a user to calculate a route and provide travel directions between two or more points along the network. Streets were described using the PREFIX, STREETNAME, and FTYPE fields. Bike routes were also described using these fields, as well as an additional field to describe the BIKEMODE (Figure 4-22). Bus lines were described with the RTE, RTE_DESC, and 
DIR_DESC fields, while the boarding and exiting paths were described with the LOCATION and STOP fields. Once all of the network properties were established, the transportation network dataset was built.

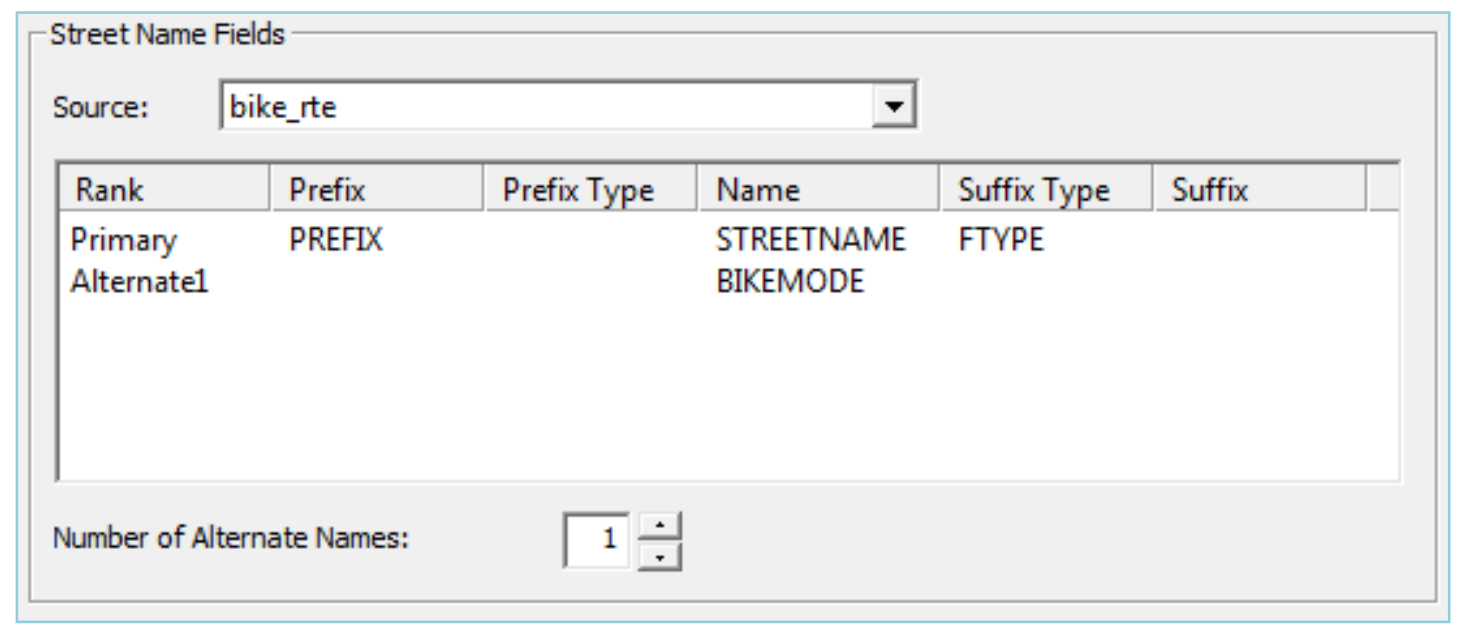

Figure 4-22 Bike Route Direction Properties

\subsection{Summary}

A transportation network dataset was built using transportation data provided by the client. Specifically, the network used the bus lines, bus stops, streets, and bike routes datasets. Modifications to the data's geography and attributes were made to ensure connectivity and the determination of travel costs and restrictions. Additional datasets (boarding and exiting paths) were created to provide connectivity between bus stops located on the streets and bus routes. The developed transportation network allowed for the determination of travel distance (in miles) and travel times (in minutes) along one or a combination of transportation means. These were essential for determining the area that was accessible to the Tualatin River National Wildlife Refuge. The data and transportation network dataset were developed within a feature dataset in a file geodatabase. The feature dataset had a UTM NAD 83 Zone $10 \mathrm{~N}$ projection, which is the standard projection used by the U.S. Fish and Wildlife Service for the Portland, Oregon area. 


\section{Chapter 5 - Implementation}

With the transportation network dataset complete, the next step was to build custom tools for analyzing accessibility. As detailed in the functional requirements, the system needed to allow users to determine the area that was accessible to the Tualatin River National Wildlife Refuge by car, bus, bike, and/or pedestrian travel. The system also needed to enable users to derive a population breakdown of the accessible area using available census data. As a result, three tools were created to calculate the service area (or area of accessibility) and provide a demographic summary of the area.

\subsection{Service Area Tool}

The purpose of the service area tool was to allow the user to calculate the service area for a given location using a specified transportation measure and length of travel time or distance. The tool consisted of seven fields (Figure 5-1).

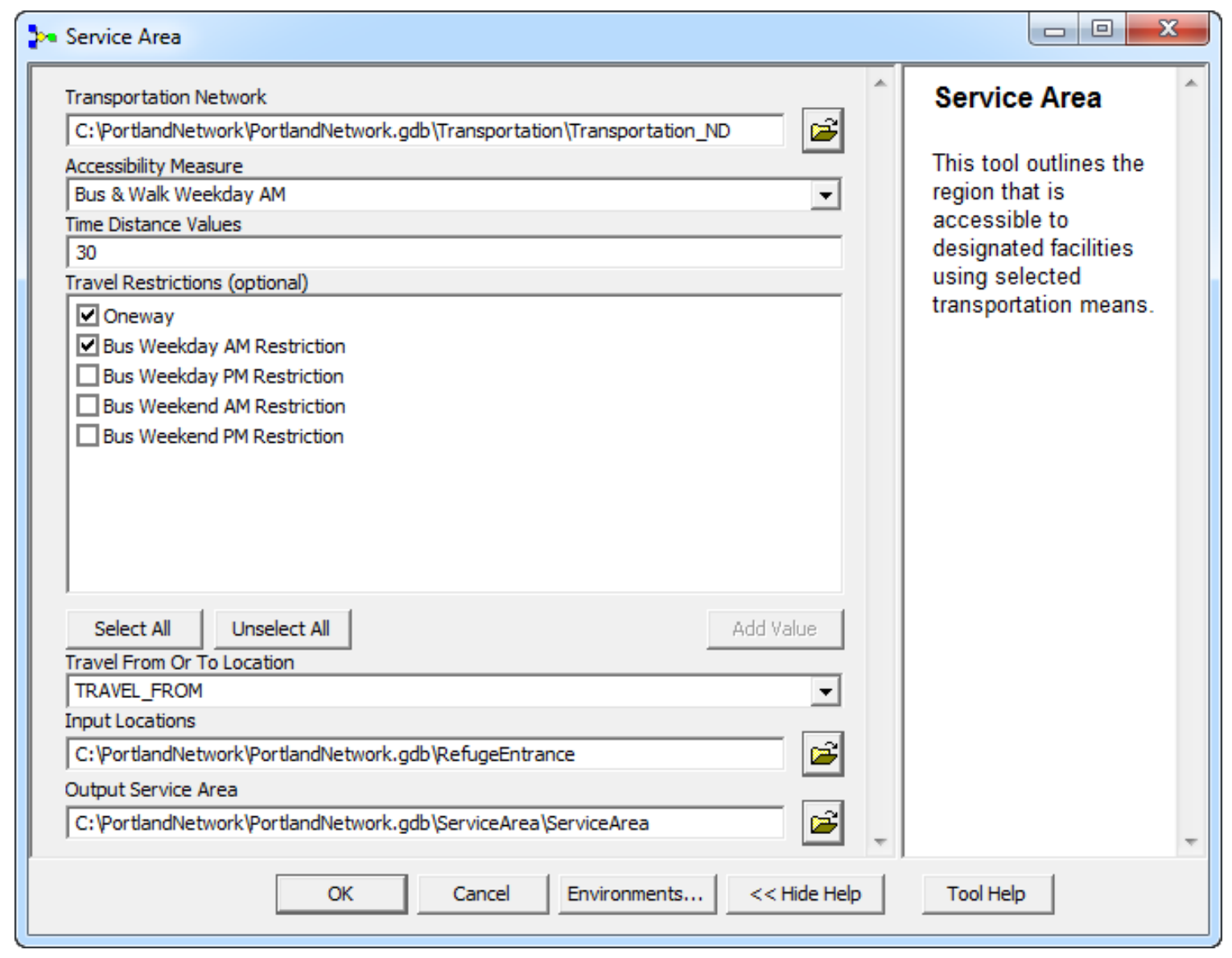

Figure 5-1 Service Area Tool

The first field required the user to input the transportation network dataset. While the default network dataset was developed for the Portland metropolitan area, this tool 
could be used with any transportation network. The second field required the user to select the desired measure of accessibility. These were defined as costs in the transportation network dataset and for the Portland network dataset included: bike and walk; bike only; bus and bike weekday AM; bus and bike weekday PM; bus and bike weekend AM; bus and bike weekend PM; bus and walk weekday AM; bus and walk weekday PM; bus and walk weekend AM; bus and walk weekend PM; driving; walking; and miles. The Time/Distance Value field required the user to input a number to represent the length of time or distance traveled. If a time accessibility measure was selected, the number represented travel time in minutes. If a length accessibility measure was selected, the number represented travel time in miles.

The Travel Restrictions field required the user to check the appropriate restrictions to prevent routing along unavailable transportation modes. The one-way restriction was checked if transportation needed to abide by one-way road restrictions. As a result, this restriction was checked for all accessibility measures except walking and miles. The four bus restrictions were used to prevent routing along bus routes that were unavailable during a weekday morning (Bus Weekday AM Restriction), weekday afternoon (Bus Weekday PM Restriction), weekend morning (Bus Weekend AM Restriction), or weekend afternoon (Bus Weekend PM Restriction). As a result, these restrictions were checked to match the bus accessibility measures with the same time of week/day.

The fifth field allowed the user to choose whether accessibility would be measured travelling from or to the input locations. While the default value for the Input Locations field was the entrance to the Tualatin River National Wildlife Refuge, any location feature in proximity to the transportation network (in this case the Portland metropolitan area) could be selected for accessibility analysis. The final field specified the output location and name for the service area.

\subsubsection{Service Area Model}

The model used to create the tool consisted of five steps (Figure 5-2). Three steps were necessary in producing a service area. The first step was to make the service area layer, which established the network properties that would be used in the analysis. This included selection of the transportation network dataset, accessibility measure, time/distance value, whether travelling from or to the input location, and travel restrictions. All five were made parameters, allowing the user to choose the desired fields and values within the tool dialog. Additional network properties that were set within the model included the type of polygon created (simple), how to treat multiple service area polygons (no overlap), how to treat nested polygons (rings), and whether lines were generated (no lines). The second step was to add locations, which would allow the user to select the starting point from which accessibility would be measured. Settings within the add locations tool included establishing the location field for deriving the service area name and setting a search tolerance of 5000 meters for positioning the input locations. The third step in producing a service area was to execute the analysis with the solve tool. The final steps in the model were to export the produced service area polygons into a specified feature class within a file geodatabase. 


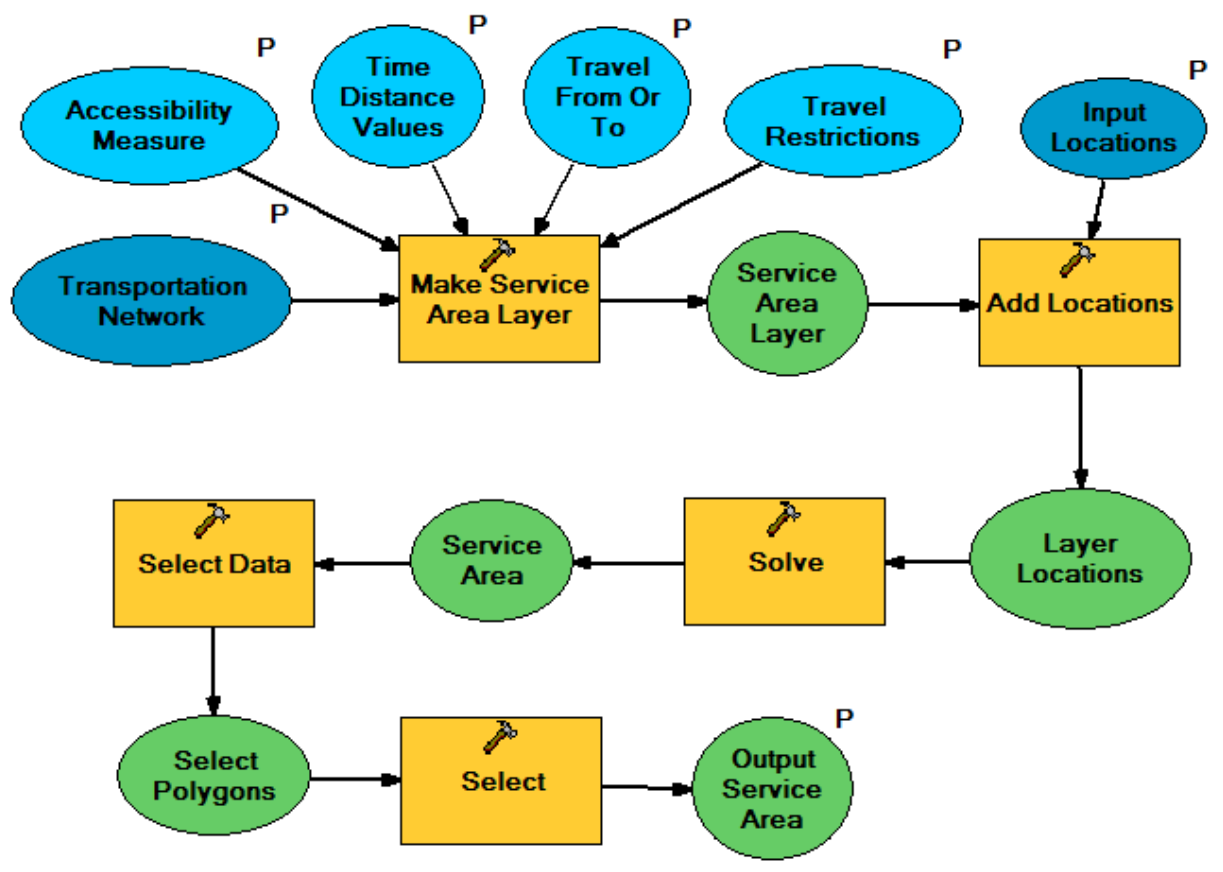

Figure 5-2 Service Area Model

\subsection{Demographics Tool}

The purpose of the demographics tool was to allow the user to produce a service area with summarized population characteristics (Figure 5-3). This tool consisted of four fields. The first field required the user to input the service area to be summarized. Outputs from the service area tool could be used as inputs to this field. The second field was used to select the census file for summarizing demographics. The provided census block data contained information on population, age, race, and household size. Using the Statistics Field drop-down, the fields containing the desired population characteristics were selected. Statistics measures were used to summarize the characteristics. The last field specified the output location and name for the service area. 


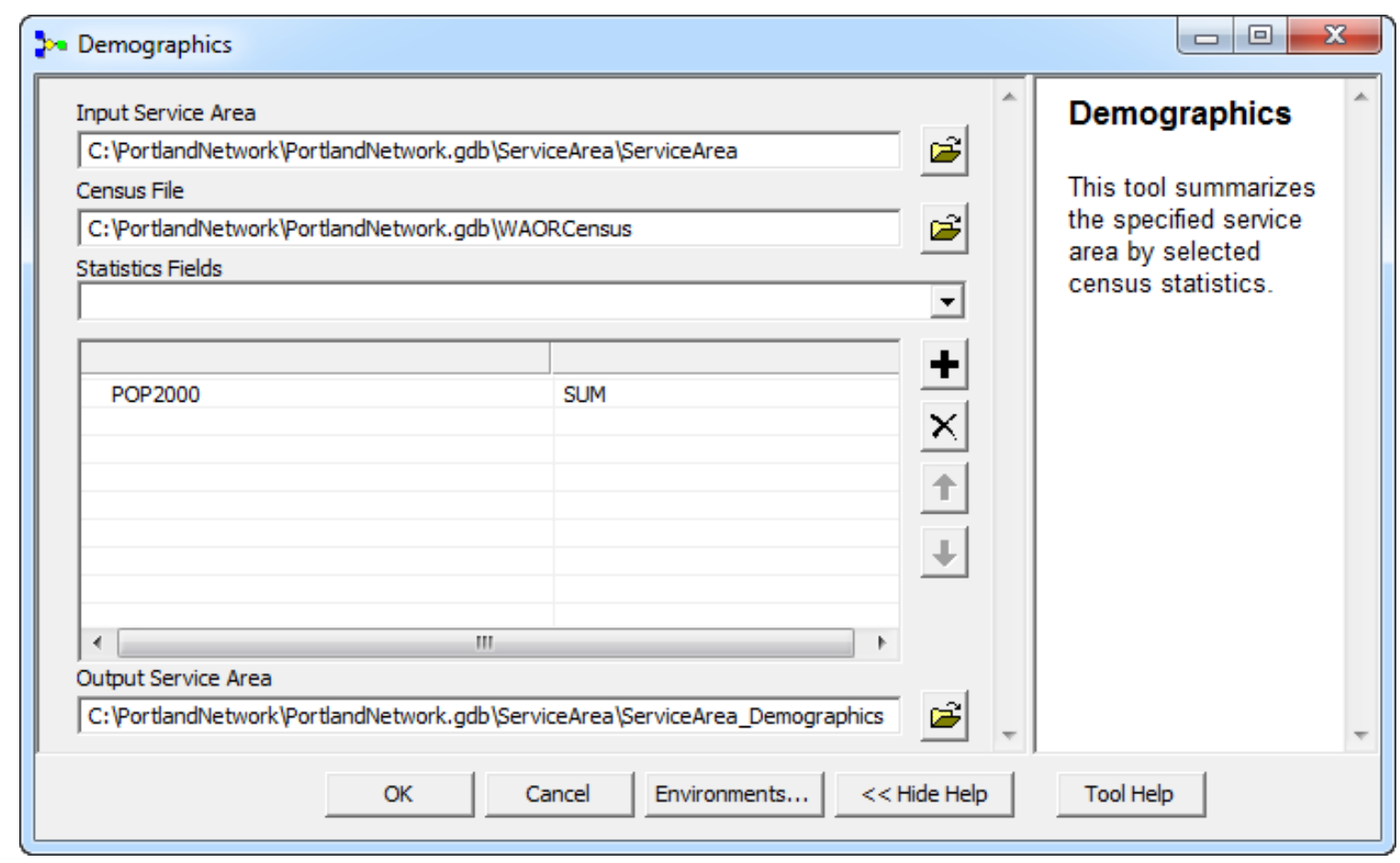

\section{Figure 5-3 Demographics Tool}

\subsubsection{Demographics Model}

Four steps were included in the demographics model (Figure 5-4). The first step was to convert the census file into a feature layer. The second step established how features within the census feature layer would be selected. The default setting was to select features that were completely within the service area. This ensured that the demographic statistics were not drastically overestimated. The third step was to union the selected census features with the service area to maintain the service area shape in the output feature. Finally, the census features were dissolved (using the name field) and a parameter was created to allow users to select fields and statistic measures for demographic summarization. The final output was a service area with the same geography as the input, along with additional attributes summarizing the selected demographic variables. 


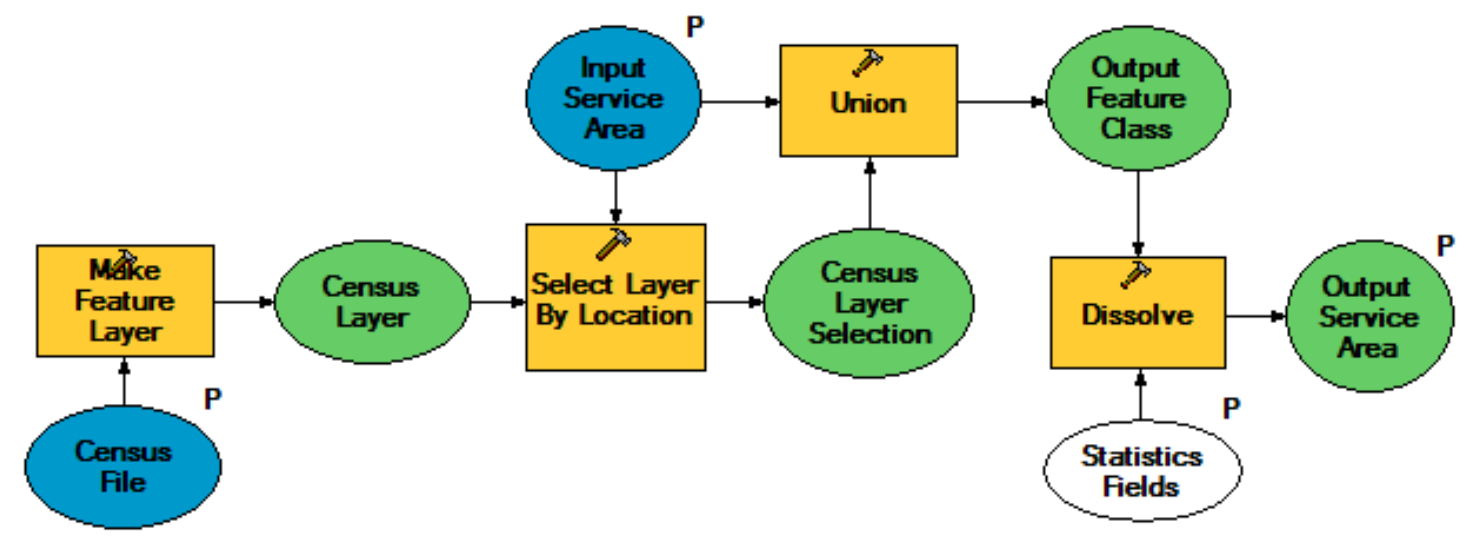

Figure 5-4 Demographics Model

\subsection{Service Area Demographics Tool}

The final tool combined the service area and demographics tools to allow the user to create the service area and summarize the demographics in one dialog (Figure 5-5). As a result, the tool and model consisted of the nine combined steps (Figure 5-6). 


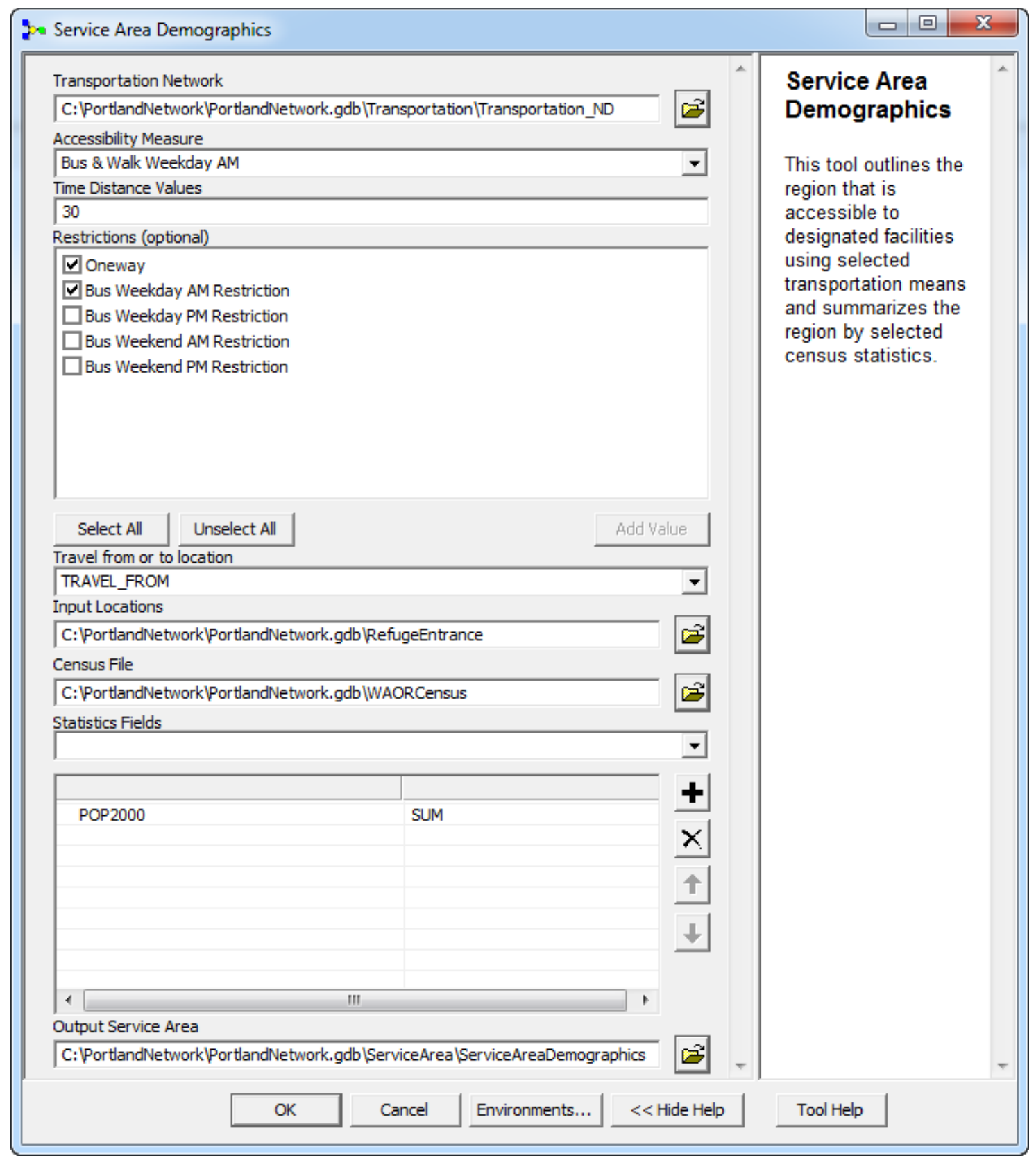

Figure 5-5 Service Area Demographics Tool 


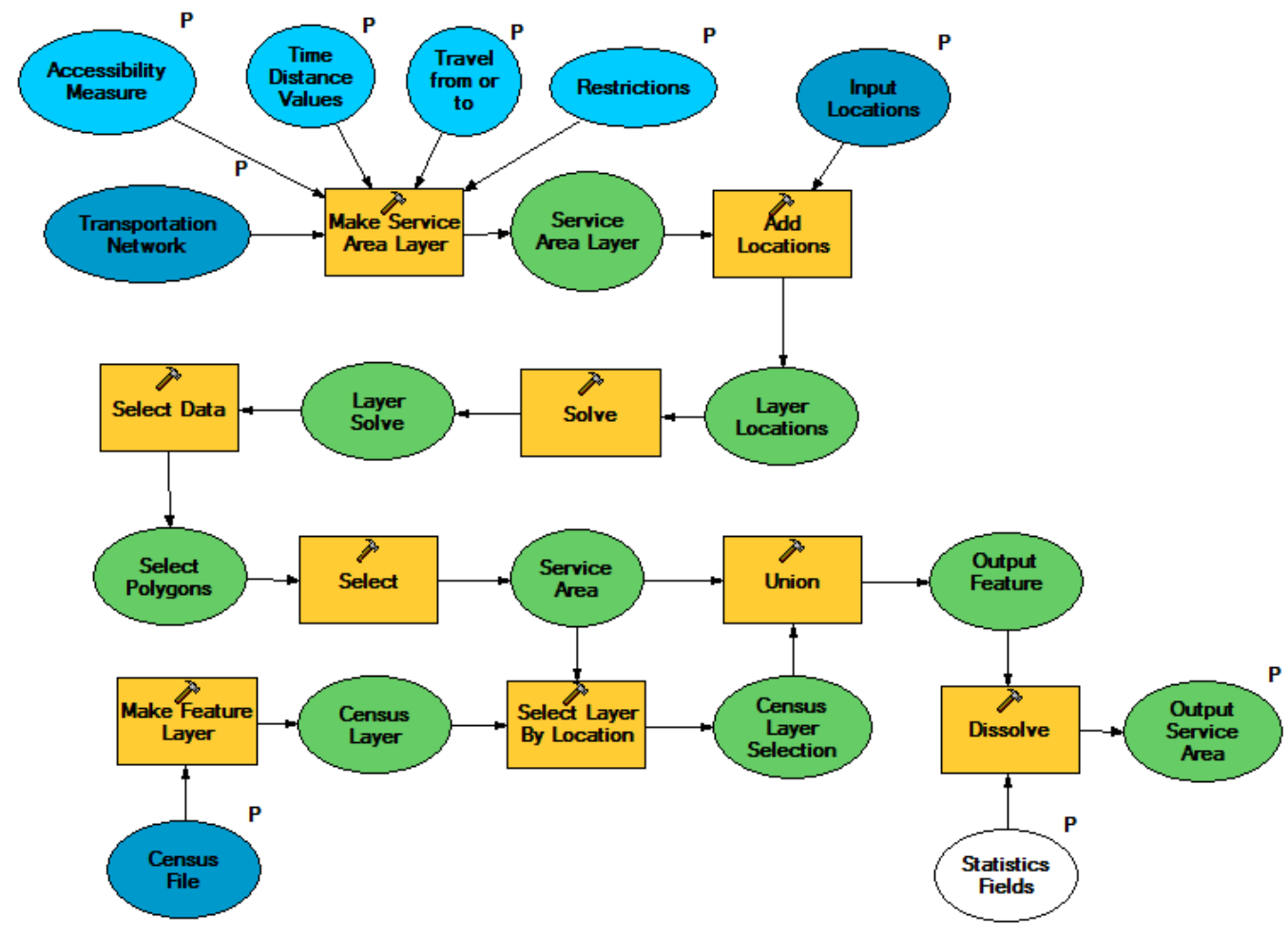

Figure 5-6 Service Area Demographics Model

\subsection{Geodatabase Development}

The transportation network dataset and all included feature classes were developed within a feature dataset in a file geodatabase. This feature dataset was given a projection of NAD_1983_UTM_Zone_10N, which is the standard projection used by the U.S. Fish and Wildlife Service for the Portland, Oregon area. A second feature dataset was created with the same projection to contain the results of the service area and demographics tools. The toolbox containing the toolset with the three created tools was placed within the file geodatabase. In addition, a feature class containing a point near the entrance of the Tualatin River National Wildlife Refuge and a feature class containing sample census data were included within the file geodatabase and used as defaults within the created tools.

\subsection{Summary}

Three tools were created in ESRI ModelBuilder to determine the area of accessibility to the Tualatin River National Wildlife Refuge and characterize it according to selected demographic variables. Creating tools in ModelBuilder produced a dialog box in a format familiar to users of ESRI ArcToolbox. ModelBuilder also provided an opportunity to create customized tool help to guide users in filling out the tool dialog to get the desired results. Further, this environment allows for future modifications. The toolbox containing 
all three tools was included within a file geodatabase. The file geodatabase also included a feature dataset with the transportation network dataset and transportation data. A second feature dataset was created within the geodatabase to contain the outputs of the service area and demographics tools. Both feature datasets had a projection of NAD_1983_UTM_Zone_10N. 


\section{Chapter 6 - Results and Analysis}

The transportation network dataset, service area tool, and demographics tool were developed to allow members of the U.S. Fish and Wildlife Service staff to examine accessibility to the Tualatin River National Wildlife Refuge (NWR). This would improve visitor services planning by providing information on the area and people that have access to the Refuge. This information could be used to promote the Refuge to potential visitors.

\subsection{Service Area}

Service areas examine accessibility to a location using available transportation means. The service area tool allowed users to analyze accessibility to a given location using a transportation network and selected transportation requirements. Thus, if a staff member wants to know the area within a 45-minute bus ride to the Tualatin River NWR on a weekend morning, the user would insert the values into the service area tool as shown below (Figure 6-1). 


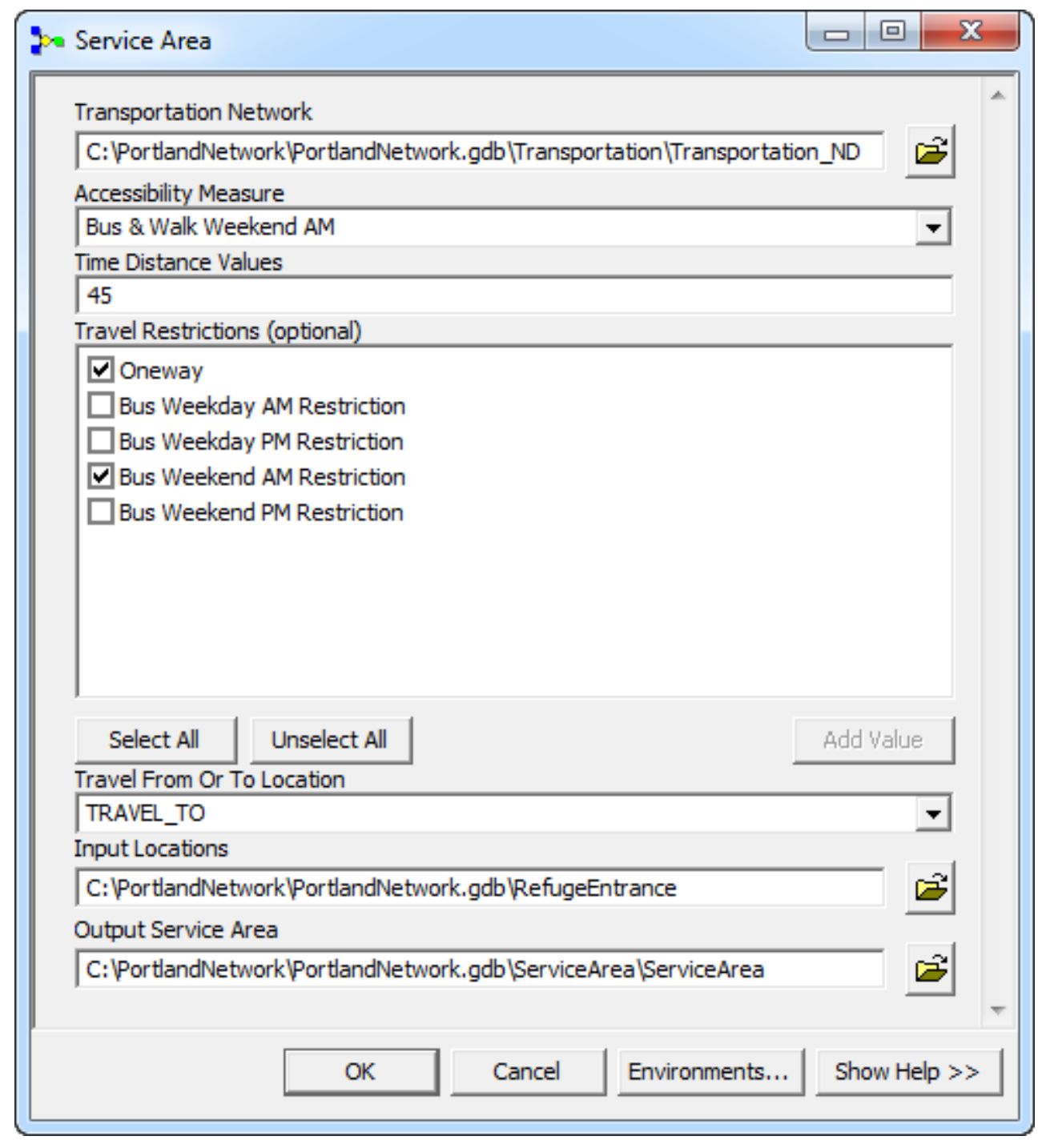

\section{Figure 6-1 Service Area Tool Example Inputs}

This tool produced a feature class of the service area, which when laid over a background image could be used to examine the extent of the service area (Figure 6-2). 


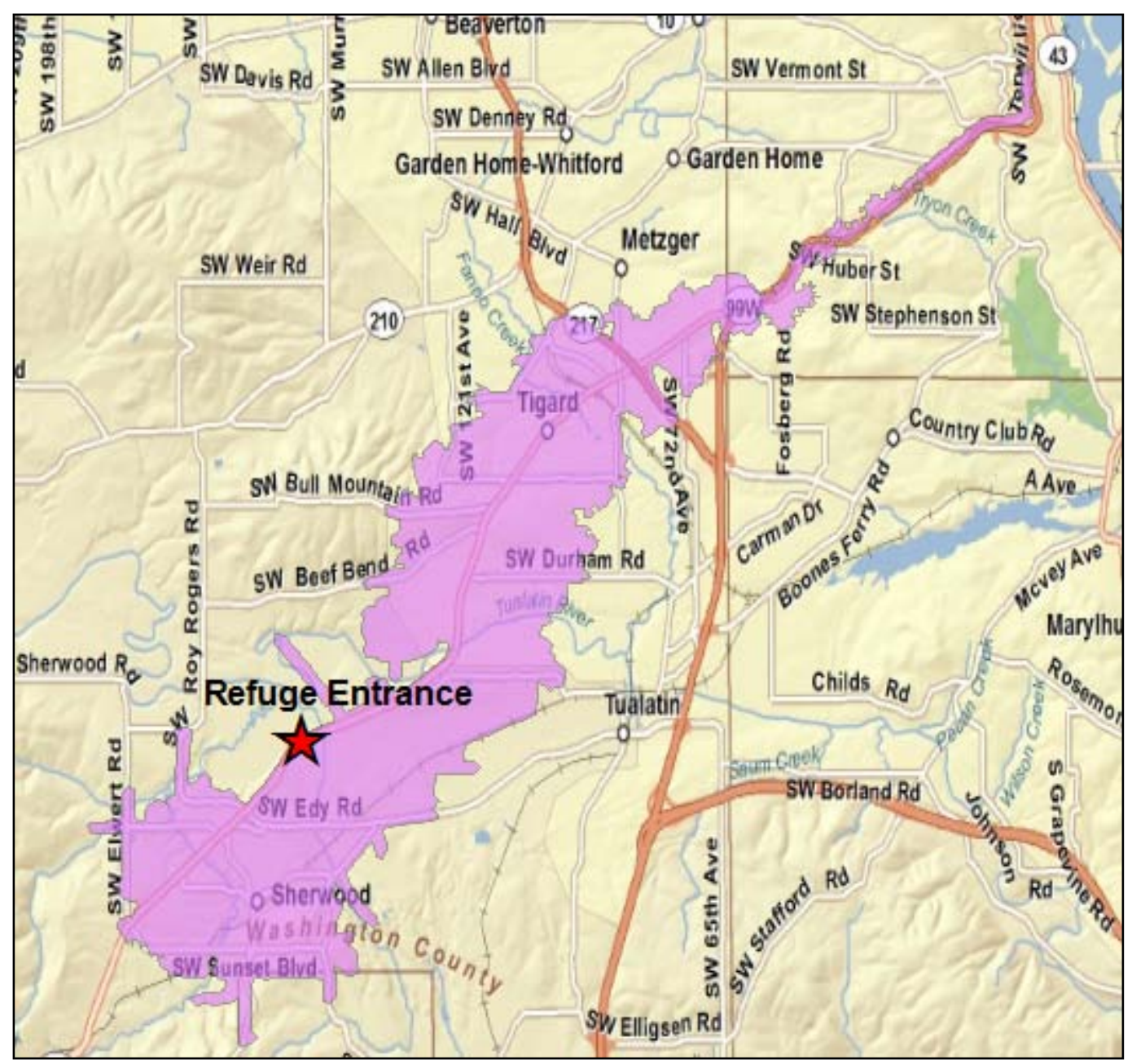

Figure 6-2 45-Minute Bus Ride Service Area to the Tualatin River NWR

The attribute table for the created service area included four fields in addition to the default feature class fields (Figure 6-3). The FacilityID field provided a unique identifier for each service area. Thus, if three locations were used, there would be three service area features with FacilityID values of 1, 2, and 3. The Name field provided a descriptor of the service area including the location name and time/distance range. Thus, a 45-minute service area for the Tualatin River NWR had a Name value of "Tualatin River National Wildlife Refuge: 0-45.” The FromBreak and ToBreak fields represented the start and end values of the time/distance range. In this case, the FromBreak and ToBreak values were 0 and 45, respectively. The Shape_Area field indicated that approximately 39.2 million square meters (3,920 hectares) were within a 45-minute bus ride to the Refuge. 


\begin{tabular}{|c|c|c|c|c|c|c|c|c|c|c|}
\hline \multicolumn{10}{|c|}{ 囲 Attributes of ServiceArea } & \multirow{2}{*}{\begin{tabular}{|l|l|l|}
$\square$ & 回 & $\mathrm{X}$ \\
\multicolumn{2}{|c|}{ Shape_Area } \\
\end{tabular}} \\
\hline & OBJECTID * & Shape * & \multicolumn{2}{|r|}{ FacilityID } & \multicolumn{2}{|r|}{ Name } & FromBreak & ToBreak & Shape_Length & \\
\hline$D$ & 1 & Polygon & & 1 & \multicolumn{2}{|c|}{ Tualatin River National Wildlife Refuge : 0 - 45} & 0 & 45 & 95368.105645 & 39202071.474744 \\
\hline & Record: 11 & 4 & • & $\$ 1$ & low: All & \multicolumn{2}{|c|}{ Records ( 0 out of 1 Selected) } & \multicolumn{2}{|c|}{ Options - } & \\
\hline
\end{tabular}

Figure 6-3 Service Area Attributes Table

\subsection{Demographics}

Demographics describe the characteristics of the people that live within a designated area. The demographics tool allowed users to examine the population characteristics of a service area. Thus, if a Refuge staff member wanted a description of the population that lived within a 45-minute bus ride to the Tualatin River NWR, the user would insert the values into the demographics tool as shown below (Figure 6-4).

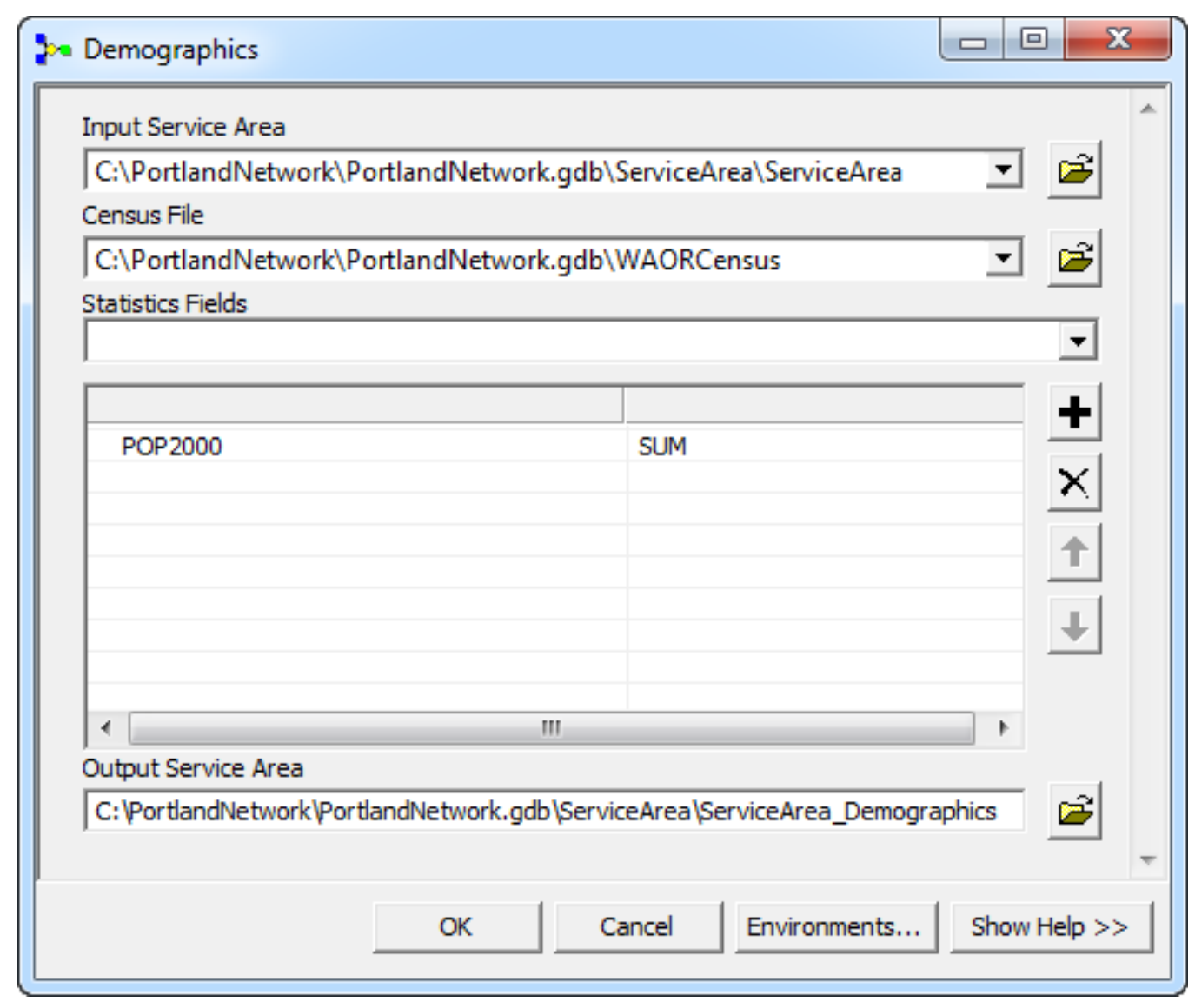

\section{Figure 6-4 Demographics Tool Example Inputs}

The demographics tool produced a service area identical to the input, but with additional attribute fields containing the selected demographic fields. Demographic information was derived from available census data. As a result, the fields available for 
examination were dependent on the census file used. The client provided data at the census block level. The demographic output for the 45-minute service area contained a SUM_POP2000 field, which represented the total population of the area (Figure 6-5).

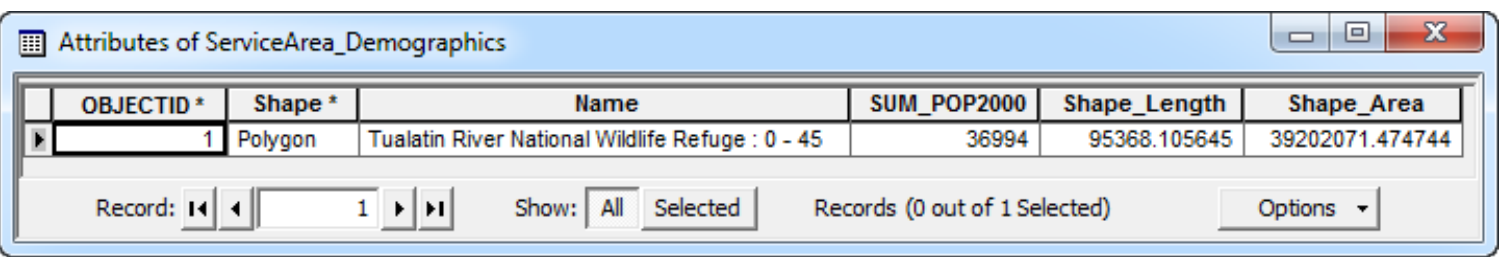

\section{Figure 6-5 Service Area Demographics Attribute Table}

Comparing the area and population characteristics of service areas provided an understanding of the people that lived within travel distance to the Tualatin River National Wildlife Refuge as well as an understanding of how differences in transportation means can influence who has access (Figure 6-6). From this comparison, it is evident that only a few people were within walking distance, more people were accessible by bike than by bus, even more were accessible by a combination of bus and bike travel, and the largest number of people was accessible by driving (Table 6-1).

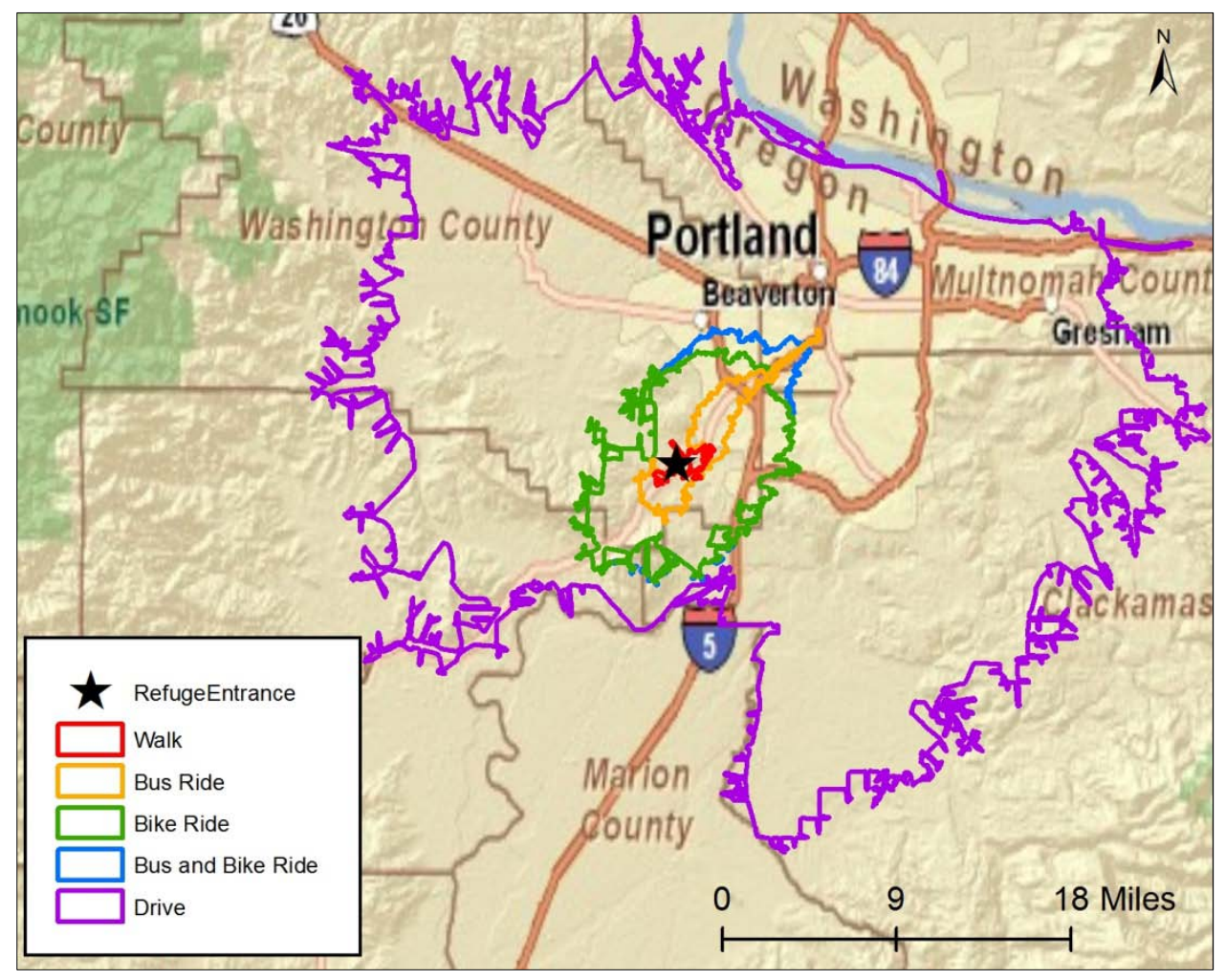

Figure 6-6 45-Minute Service Areas to the Tualatin River NWR 
Table 6-1 Demographics for 45-Minute Service Areas to the Tualatin River NWR

\begin{tabular}{|l|r|r|r|r|}
\hline Travel Mode & $\begin{array}{l}\text { Total } \\
\text { Population }\end{array}$ & $\begin{array}{l}\text { Total } \\
\text { Population } \\
\text { Age 5-17 }\end{array}$ & $\begin{array}{l}\text { Total } \\
\text { Population Age } \\
\text { 65 and Up }\end{array}$ & Hectares \\
\hline Walk & 234 & 41 & 4 & 436.61 \\
\hline Bus Ride & 36,994 & 6,057 & 5,834 & $3,920.20$ \\
\hline Bike Ride & 134,032 & 25,443 & 12,548 & $20,144.01$ \\
\hline Bus and Bike Ride & 172,472 & 31,750 & 16,215 & $23,189.85$ \\
\hline Drive & $1,399,879$ & 246,947 & 146,250 & $258,753.09$ \\
\hline
\end{tabular}

Examining the demographics of the service areas can provide an understanding of population characteristics such as the total number of people aged 5 to 17 and the total number of people aged 65 and older living within the accessible area. Using this information, staff at the Tualatin River National Wildlife Refuge can develop programs for kids or seniors with an understanding of how many people could potentially visit by different transportation means.

\subsection{Additional Network Analyses}

While the transportation network dataset was primarily intended for use in analyzing service areas, the network was developed to allow for additional analysis functionality. Thus, for example, the network could be used to find the best route between specified locations using different transportation means and calculate directions.

When comparing the route between two locations on a bus line using the network dataset and TriMet website, the two methods provided similar results. Both routes estimated time spent riding the bus from stop 6008 to stop 1495 at approximately 21 minutes. However, unlike the TriMet website, which accounts for all available bus routes, the transportation network only included 16 routes and thus frequently produced routes with different bus lines. Another difference was that the TriMet website did not take into account the amount of time spent waiting for a bus to arrive. Thus, if a person actually arrived at the first stop at 8:30, they would have a 5 minute wait, bringing the total travel time to 26 minutes (Figure 6-7). This wait time is included within the Network Analyst calculation. In addition, the Network Analyst calculation includes 2 minutes for transferring from bus lines to streets (Figure 6-8). This is a result of the 2-minute turn cost created to prevent multiple transferences between routes. 


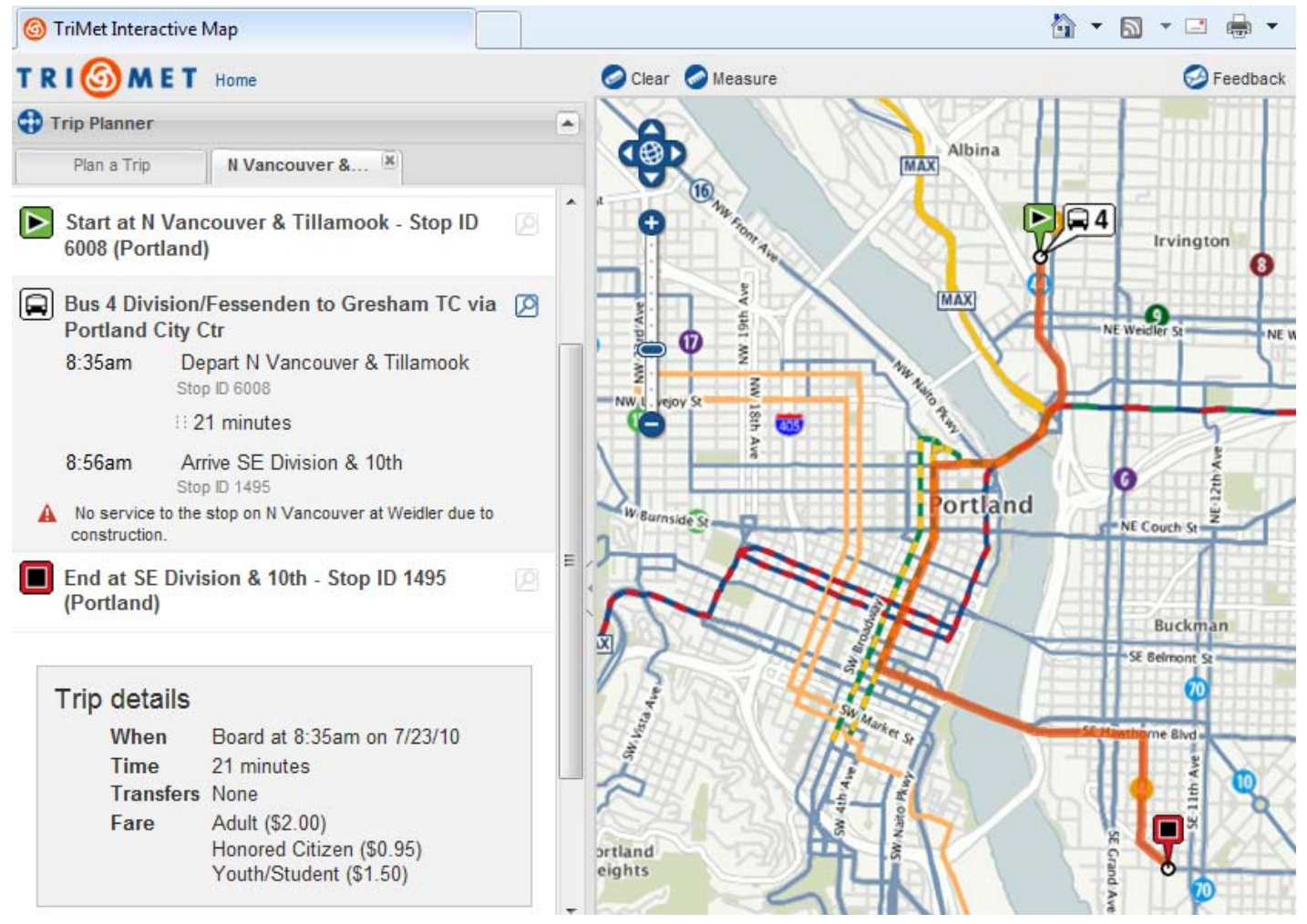

Figure 6-7 TriMet Website Suggested Bus Route

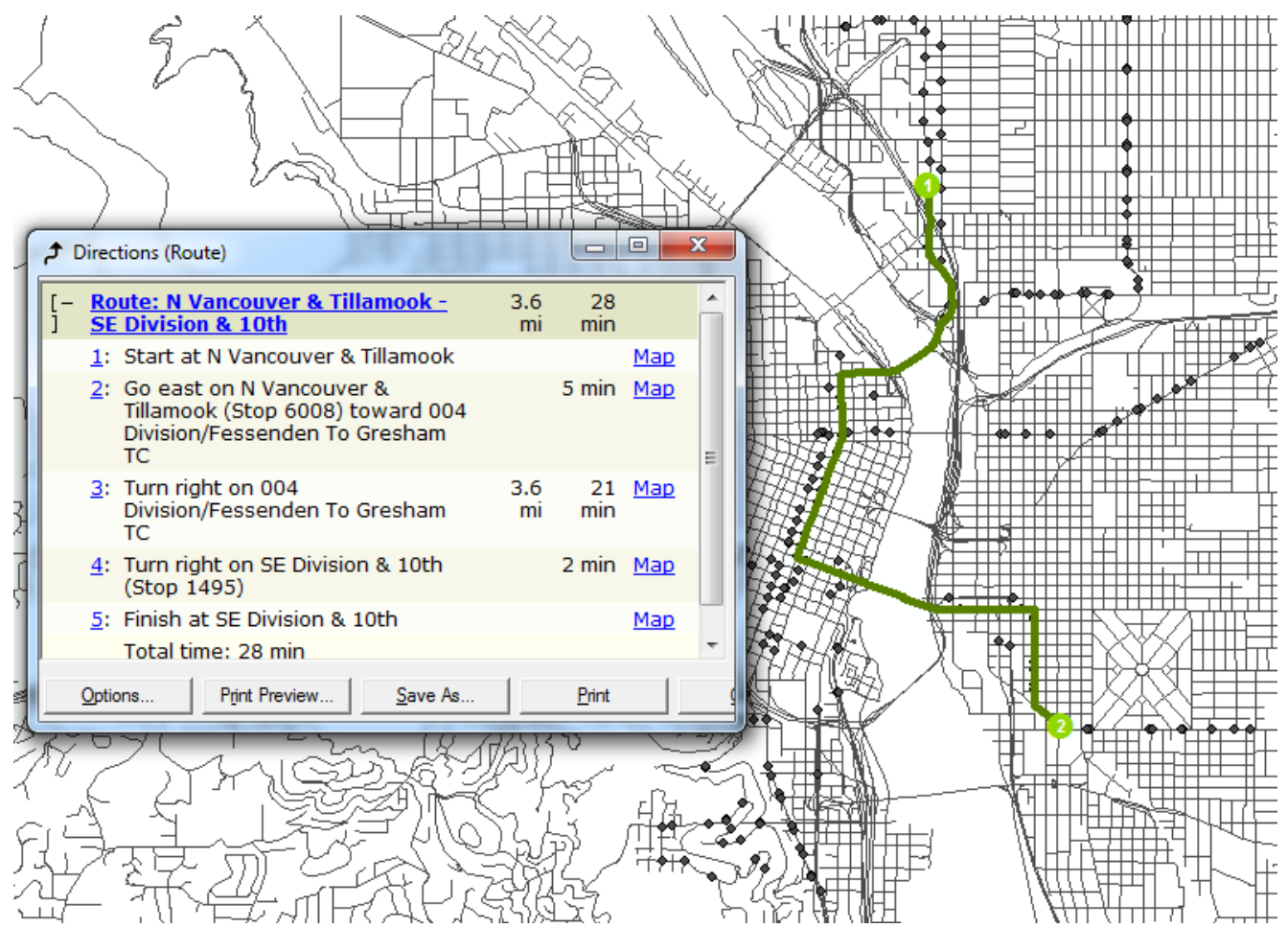

\section{Figure 6-8 Network Analyst Suggested Bus Route}


The transportation network dataset can also be used similar to Google Maps in order to produce driving routes and estimate travel times and distances (Figure 6-9). However, there were significant differences when comparing routes from Google Maps and Network Analyst. Because Google Maps more accurately represented travel speeds, there was a tendency to produce different routes and driving times. Nonetheless, Network Analyst was able to produce directions that were identical to Google Maps (Figure 6-10). Further, Network Analyst was able to successfully create routes that obeyed one-way restrictions.

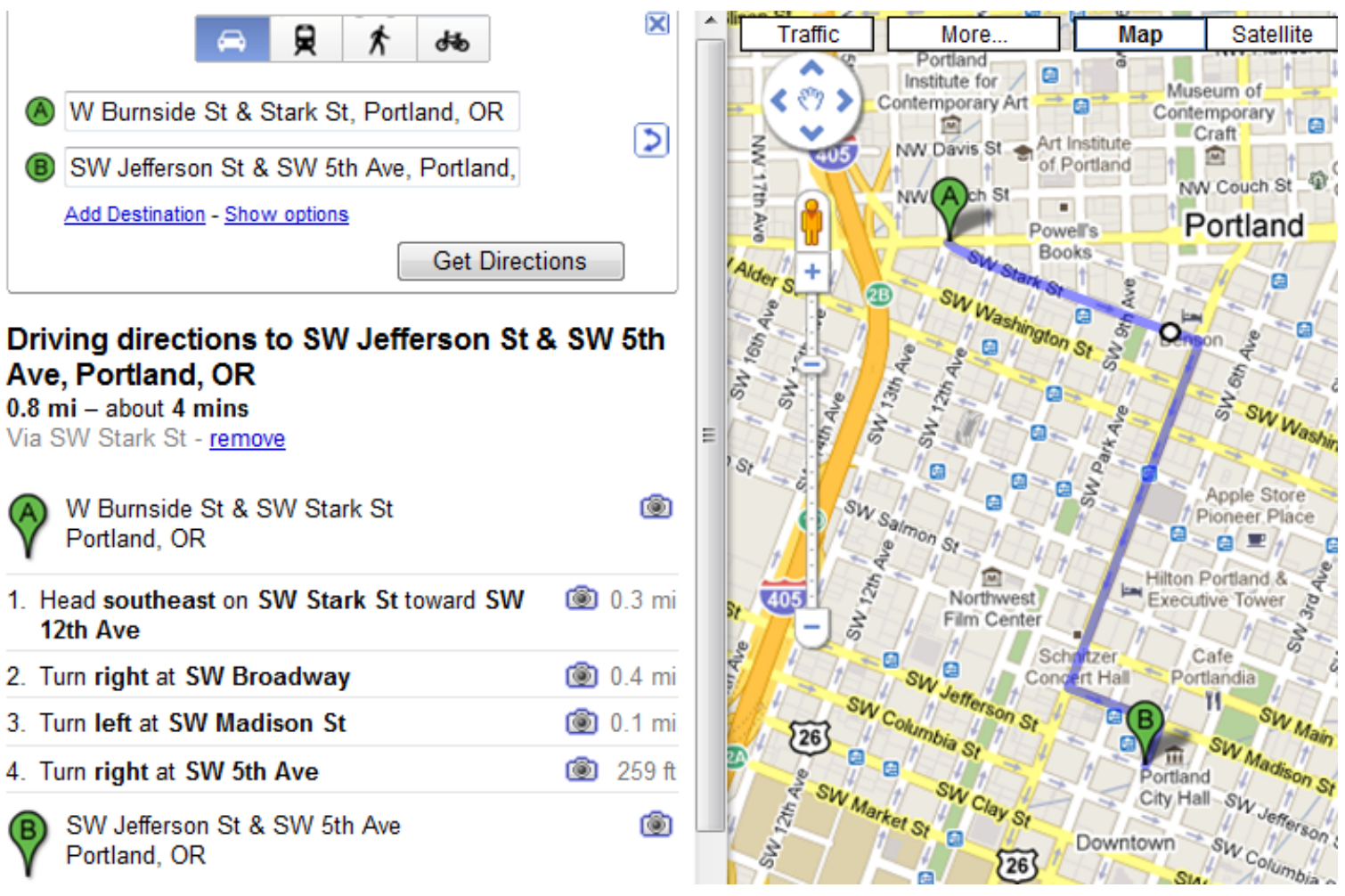

Figure 6-9 Google Maps Suggested Driving Route 


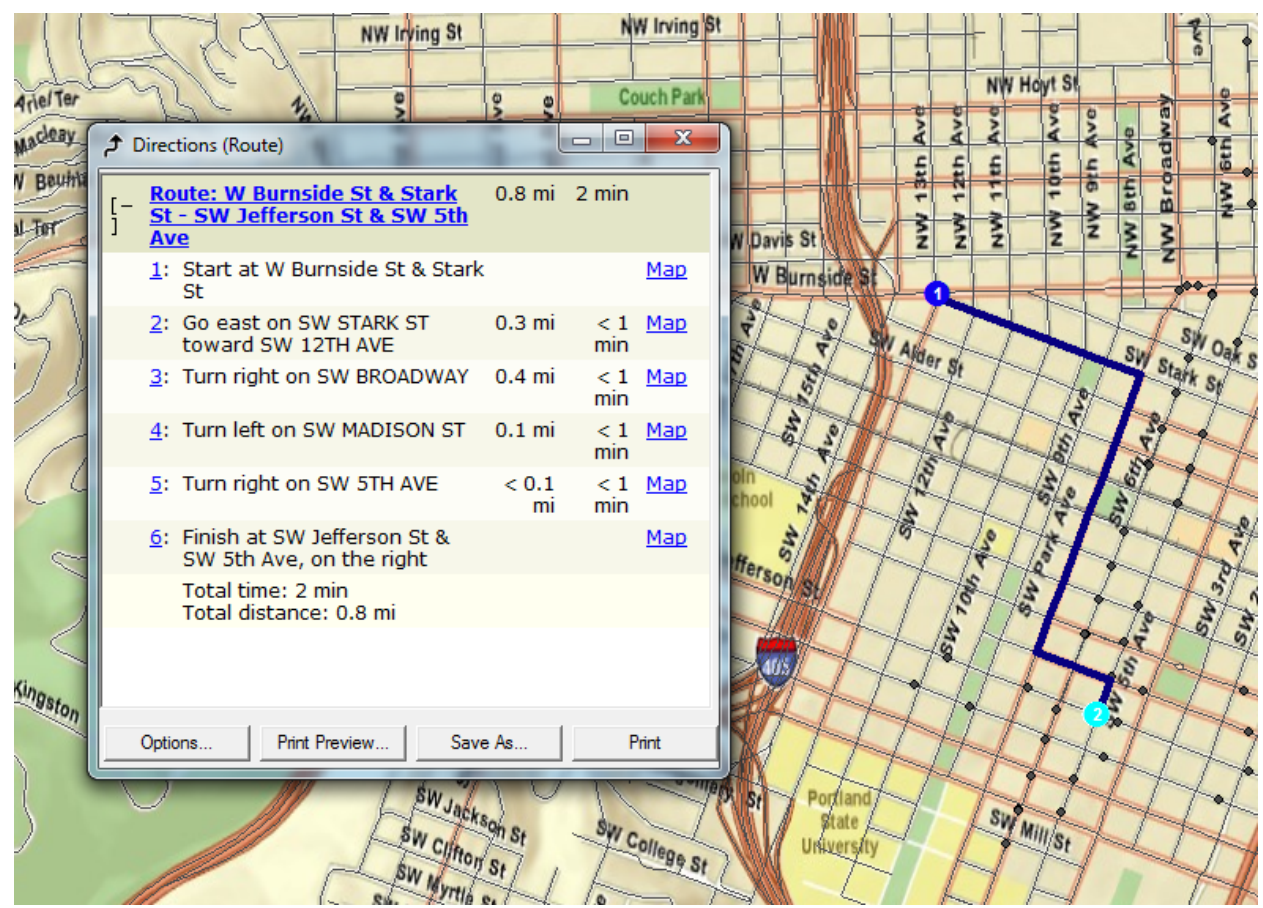

Figure 6-10 Network Analyst Suggested Driving Route

\subsection{Limitations}

While the transportation network does allow for other types of analyses, there were limitations to its use. First, since the bus lines only included 16 of the over 150 routes, there was not an accurate representation of public transportation in the Portland area. Thus, any bus-related calculations using locations far from the included bus routes would not provide accurate values.

Further, only four bus trips were used to estimate travel time for riding a bus on a weekday morning, weekday afternoon, weekend morning, and weekend afternoon. Thus, it is likely that depending on the time of day a person was travelling, travel times may be significantly different. In addition, changes to the bus routes from construction and other causes were not taken into account, which may significantly alter the routes actually available for travel. Thus, use of the TriMet website for more accurate routing is recommended. However, Network Analyst allows for inclusion of different types and combinations of transportation such as riding a bike and riding a bus, which is not available with the TriMet website.

While the transportation network can be used for creating driving routes, it does not produce the most accurate results. This in part due to the fact that travel times for driving were based on an established estimate of speed in miles per hour. Thus, unlike Google Maps, routing by automobile does not take into account changes in speed due to rush hour, construction, or other causes. Further, while Network Analyst uses roads that provide the fastest travel times, Google Maps may use a more complex algorithm taking into account more factors, resulting in different routes.

Another limitation that is important to note is that there are only two slots for bikes on a bus's bike rack. Thus, accessibility measures that include both riding a bike 
and riding a bus assume a best-case scenario where a person is able to take their bike with them on the bus. Worst-case, a passenger would end up waiting longer to get on a bus that had bike space or would leave their bike in one of the available bike racks. Many of the Portland transit centers have bike racks available for passengers to leave their bike before getting on a bus. However, this would prevent a person from using their bike to get to their final destination once getting off a bus.

A final limitation was that the population values calculated with the demographics tools were highly dependent on the census features selected. This can present a problem, because the included census features may not accurately represent the area. For example, a 30-minute walk to the Tualatin River NWR (Figure 6-11) had a total population of 25.

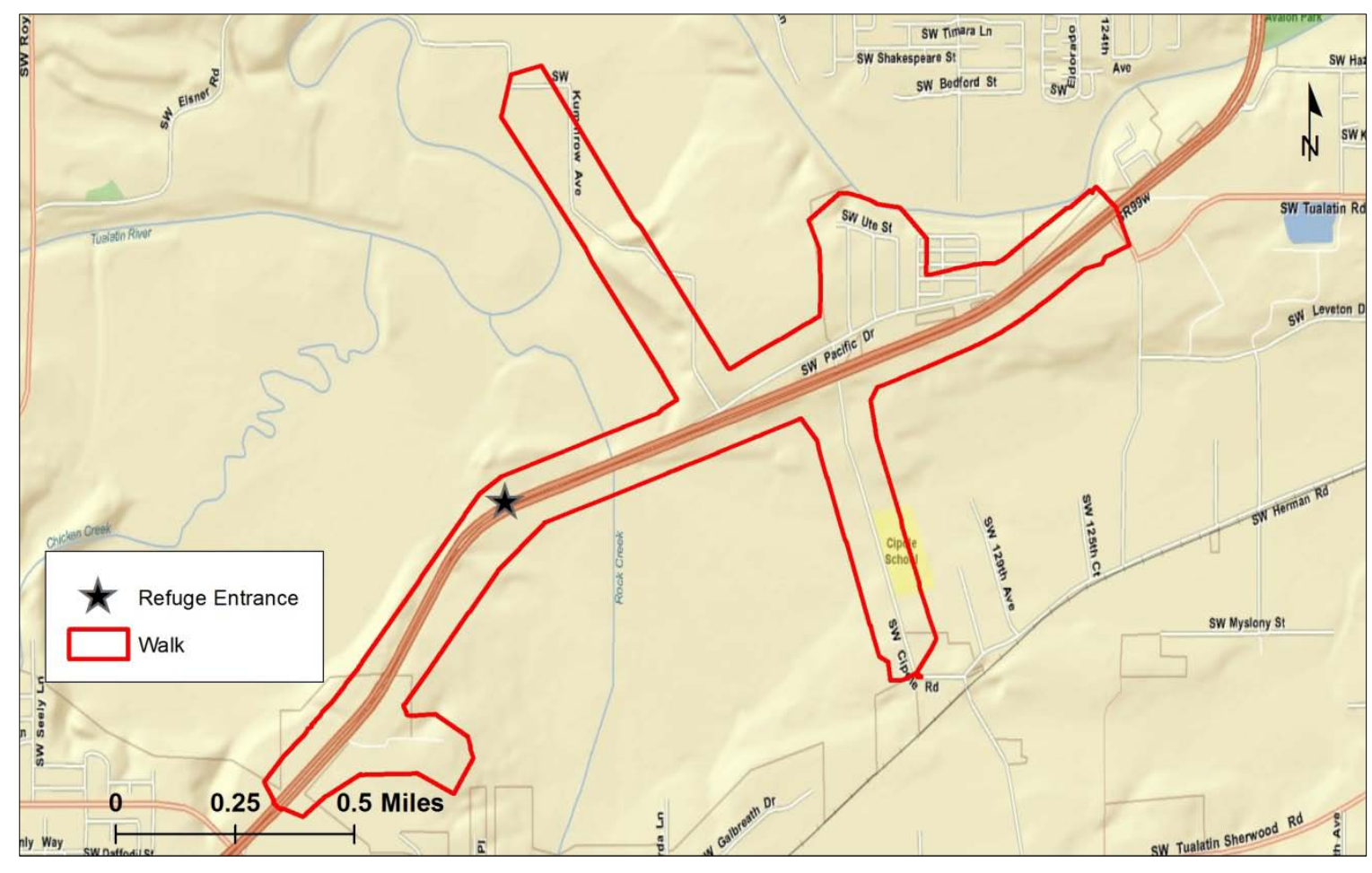

\section{Figure 6-11 30-Minute Walk Service Area to the Tualatin River NWR}

The primary cause of this unlikely population value was a result of only including census features that were completely within the service area. The client requested including only these features in order to reduce overestimation of population values. As a result, a census block that included over 600 people was not included and might have provided a more reasonable total population value (Figure 6-12). Upon further examination, it appeared that the area outlined in blue, which was included in the demographic calculations, contained 17 people according to the census data. The housing area within the blue census blocks was largely developed in the late 1990s and may not have been fully occupied during the 2000 census (Figure 6-13). The development seen on the right, on the other hand, had been around for decades by the time of the 2000 census, and thus may have made up a significant portion of the 600 people recorded. More recent census block data would provide a better estimate of current population numbers. 


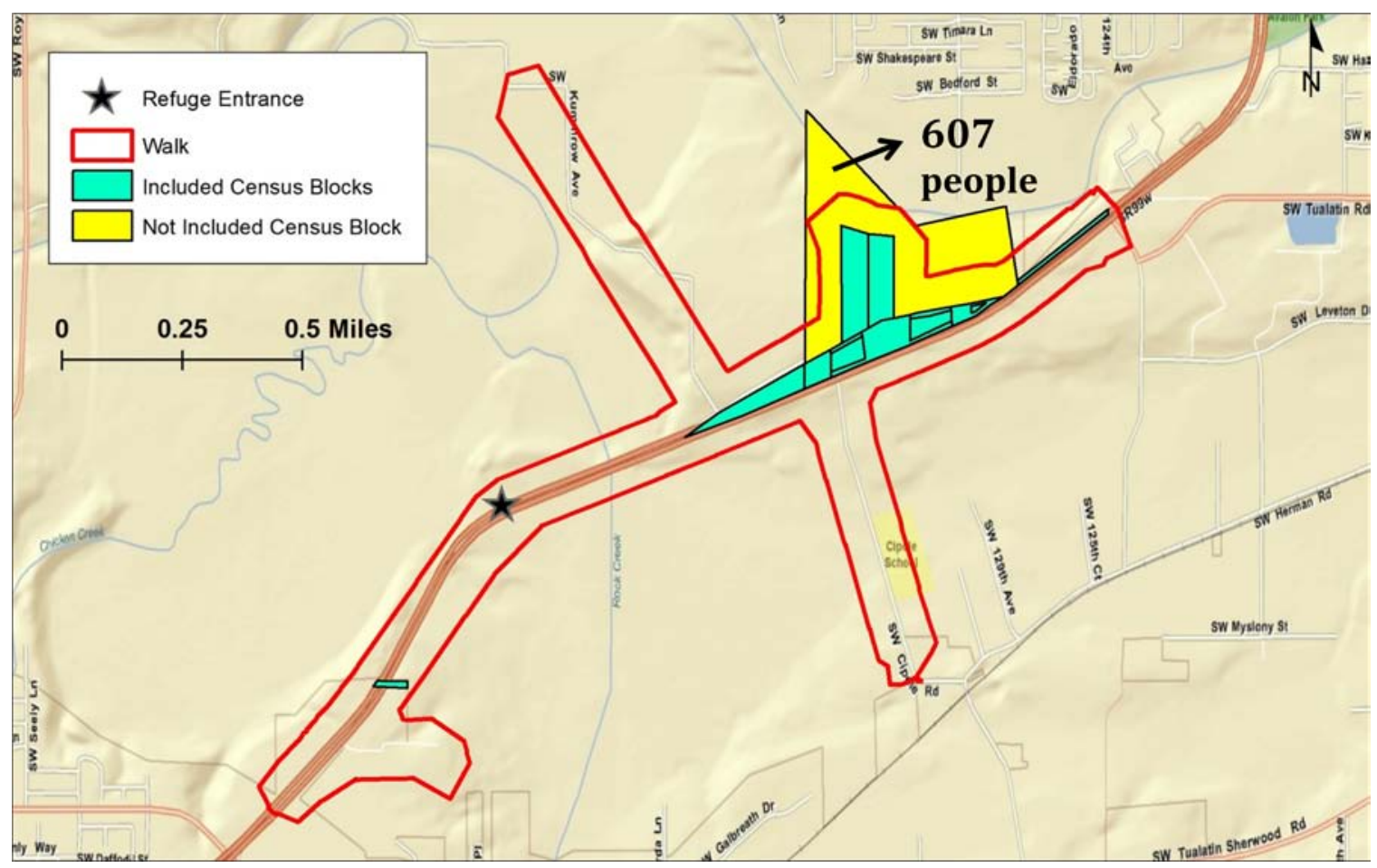

Figure 6-12 Census Features Within a 30-minute Walk to the Tualatin River NWR

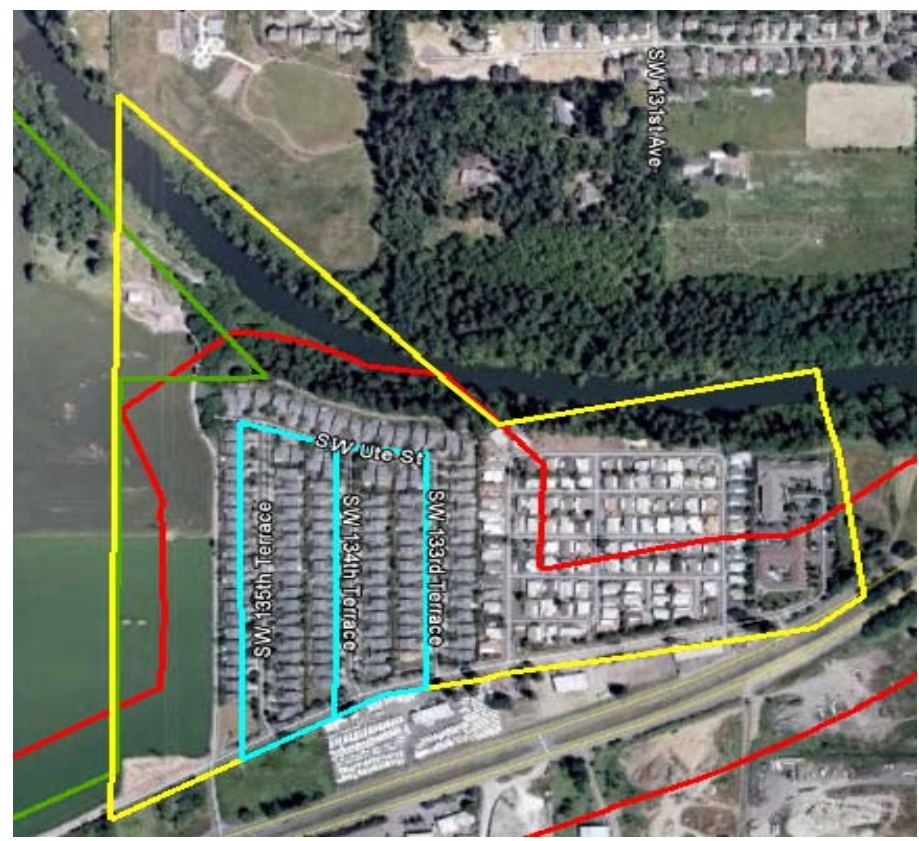

Figure 6-13 Imagery of the Included/Excluded Census Blocks

\subsection{Summary}

The service area and demographics tools were developed to enable U.S. Fish and Wildlife Service staff members to examine the area and people that have access to the 
Tualatin River National Wildlife Refuge by different transportation means. These tools allow users to better understand who does or does not have access to the Tualatin River NWR and develop steps to improve visitor numbers and enhance visitor experiences. These service area and demographics tools allowed for a range of analyses depending on the user's needs. This included analyzing different means of transportation, different travel times or distances, different starting locations, and different demographic characteristics. As a result, these tools have the potential for a long lifespan and a variety of uses.

Further, the transportation network dataset was created to be fully functional for all network analysis including service area calculations. As a result, users can create routes by different transportation means that are comparable to standard routing sources including the TriMet website for bus routes and Google Maps for driving routes.

While the transportation network dataset allows for a variety of analyses, there were some significant limitations to its use. This included the fact that only 16 bus routes out of over 150 routes were included in the network, and thus was not an accurate representation of available transportation. Further, all bus and automobile travel times were based on averaged values and thus did not take into account potential changes or variations in route, travel speeds, etc. In addition, because buses only have room for two bikes on their bike racks, there is a potential for passengers travelling with the bike to not be able to take their bike with them. Thus, the bus and bike accessibility measures assume a best-case scenario where a passenger is able to load their bike on the bus's bike rack. A final limitation was that service area demographic values were based on census features that were completely within the service area. This often resulted in values that did not represent true population characteristics. 


\section{Chapter 7 - Conclusions and Future Work}

This chapter discusses how the client's needs were met as determined in Chapter 3. In addition, recommendations for potential applications and future work are provided.

\subsection{Conclusions}

The purpose of this project was to enable U.S. Fish and Wildlife Service staff to identify and characterize the area that was accessible to the Tualatin River National Wildlife Refuge by car, bus, bike, and/or walking using provided transportation and census data. This was accomplished through the creation of a transportation network dataset and service area and demographics tools.

The transportation network dataset was composed of bus, bike, and streets data for the metropolitan area of Portland, Oregon. Data were provided by the Metro Data Resources Center located in Portland, Oregon. Modifications to the data ensured network connectivity and the ability to measure travel distance and time. The network provided 13 means of measuring travel: miles; bike and walk; bike only; bus and bike weekday AM; bus and bike weekday PM; bus and bike weekend AM; bus and bike weekend PM; bus and walk weekday AM; bus and walk weekday PM; bus and walk weekend AM; bus and walk weekend PM; driving; and walking.

The service area tool could be used to determine the area that is accessible to the Tualatin River National Wildlife Refuge. This tool allows a user to input the transportation network, select the desired means of measuring travel, enter a travel distance/time value, check the appropriate travel restrictions, choose whether accessibility is measured to or from the input locations, select the input locations, and produce a feature class of the resulting service area.

The demographics tool could be used to characterize the accessible area by selected demographic characteristics. This tool allows a user to input the service area, choose a census file, select the desired census fields and statistic measures, and produce a service area with the summarized demographic information. The service area demographics tool combined the service area and demographics tools to allow the user to create a service area with summarized demographic information in one dialog. All three tools were created in ESRI ModelBuilder, which could be modified for future needs. Provided tool help included a description of how the tool could be used and guidance for filling out the required fields.

\subsection{Future Applications}

Besides use in the service area tools, the transportation network dataset was developed for use in a wide range of network analyses. One such application would be to provide custom routing directions for locations within the Portland metropolitan area. Thus, a user could select two or more locations and the desired means of travel to determine the best route and produce a set of directions. Another possible application would be to use different locations in the Portland area for service area analysis. 


\subsection{Future Work}

The transportation network dataset created for this project used eight bus lines (in two directions) for 16 total routes. As a result, 158 routes in the provided data were not included. A more accurate representation of transportation in the metropolitan Portland area would involve a network that included all of the bus routes and associated bus stops. Other transportation data layers including light rail lines could also be included for a more representative network. These additional transportation data layers could be easily integrated into the network by following the modification process outlined for bus line and bus stops and loading the modified layers into the current bus lines and bus stops feature classes.

Future work could also include developing a web service with the transportation network and service area tools. This web service could then be implemented on the TriMet website. The TriMet website provides bus information for the metropolitan Portland area. The site allows users to find the best route between two locations, determine the travel distance, and calculate the travel time. By implementing the web service, users could determine the area of accessibility for any location within the metropolitan Portland area.

Finally, the use of census data features larger than census blocks requires modification of the demographics tool. Currently, the demographics tool selects only census features that are completely within the service area. Using data such as census block groups or tracts select few if any features and does not give an accurate statistical summary. The demographics model could be modified to select features by those that have their centroid in the service area, or, better yet, it could be modified to apposition the population of any census feature, divided by the service area boundaries.

Future work with the transportation network dataset, service area, and demographics tools could improve representation and understanding of available transportation means within the Portland, Oregon metropolitan region. Making this network and tools available for public use could enhance transportation-related planning and allow people to improve their understanding of the area and opportunities available to them by different modes of transportation. 


\section{Works Cited}

Aloisio, K., Cruz, R., Marcus, L., \& Whitlow, H. (2002). Assessing Multi-Modal Transportation Accessibility Using ArcView Network Analyst. Paper session presented at the Twenty-Second Annual ESRI User Conference, San Diego, CA.

City of Portland Office of Transportation. (2004). Facts About Portland. Retrieved January 1, 2010 from http://www.portlandonline.com/shared/cfm/image.cfm?id=65158

Clark, J. L. (2003). Wildlife Refuges: Lands of Promise. Portland, Oregon: Carpe Diem Books and Graphic Arts Center Publishing.

Hansen, J. \& Munoz, A. (2008). Developing a Multimodal Spatial Network Prototype Using ArcGIS 9.2. Retrieved January 3, 2010 from http://csci8715.googlepages.com/CSCI8715_P9_Final_Project.pdf

Judson, D.H., Reynolds-Scanlon, S., \& Popoff, C.L. (1999). Migrants to Oregon in the 1990's: working age, near-retirees, and retirees make different destination choices. Rural Development Perspectives. 14(2): 24-31.

Kreisa, E. A. (2007). Equity in Access to Greenways: Measurement and Application to the Capital Area Greenway in Raleigh, NC. Paper session presented at the $87^{\text {th }}$ Annual Meeting of the Transportation Research Board, Washington, D.C.

Landex, A. \& Hansen, S. (2006). Examining the potential travelers in catchment areas for public transport. Paper session presented at the Twenty-Sixth Annual ESRI User Conference, San Diego, CA.

National Wildlife Refuge System Improvement Act of 1997, Pub. L. No. 105-57, 111 Stat. 1252 (1997). Retrieved October 23, 2009, from http://www.fws.gov/Northeast/planning/downloads/NWRSimprovementact.pdf

Nicholls, S. (2001). Measuring the Accessibility and Equity of Parks: a Case Study Using GIS. Managing Leisure, 6, 201-219.

Oh, K. \& Jeong, S. (2007). Assessing the spatial distribution of urban parks using GIS. Landscape and Urban Planning. Retrieved December 10, 2009 from http://geoinformatics.sut.ac.th/sut/student/GISpresent/20071/distributionParks.pdf

Oregon Parks and Recreation Department. (2003). 2003-2007 Oregon Statewide Comprehensive Outdoor Recreation Plan. Retrieved December 16, 2009, from http://egov.oregon.gov/OPRD/PLANS/scorp_review.shtml 
Racca, D. (2004). Transportation Network Models to Accurately Estimate Transit Level of Service. Paper session presented at the Twenty-Fourth Annual ESRI User Conference, San Diego, CA.

Starcher, J. (2007). Drive-Time Analysis of West Virginia Hospitals Using Network Analyst. Paper session presented at the Twenty-Seventh Annual ESRI User Conference, San Diego, CA.

Tribby, C. (2009). Construction of a Household-level Public Transportation Accessibility Model. Paper session presented at URISA's $47^{\text {th }}$ Annual Conference and Exposition, Anaheim, CA.

Tualatin River National Wildlife Refuge. (2008). [Trail map]. Retrieved December 16, 2009, from http://www.fws.gov/tualatinriver/recreation/documents/TrailMap.pdf

Tualatin River National Wildlife Refuge. [Refuge map]. Retrieved March 27, 2010, from http://www.fws.gov/tualatinriver/pdf/TRNWR_Map.pdf

U.S. Fish and Wildlife Service. (2001). Land Protection Planning for the National Wildlife Refuge System. Retrieved November 15, 2009, from http://www.fws.gov/pacific/planning/Final_LPPQnA_text.pdf

U.S. Fish and Wildlife Service (2008). Visitor Service Planning: Spelling It Out. Internal Document received December 2, 2009 from David Drescher, Refuge Information Branch Chief.

U.S. Fish and Wildlife Service. (2009a). Retrieved September 25, 2009, from http://www.fws.gov/refuges

U.S. Fish and Wildlife Service. (2009b). Fact Sheet: Tualatin River National Wildlife Refuge. Retrieved October 25, 2009, from http://www.fws.gov/tualatinriver/documents/factsheet10-09.pdf 